

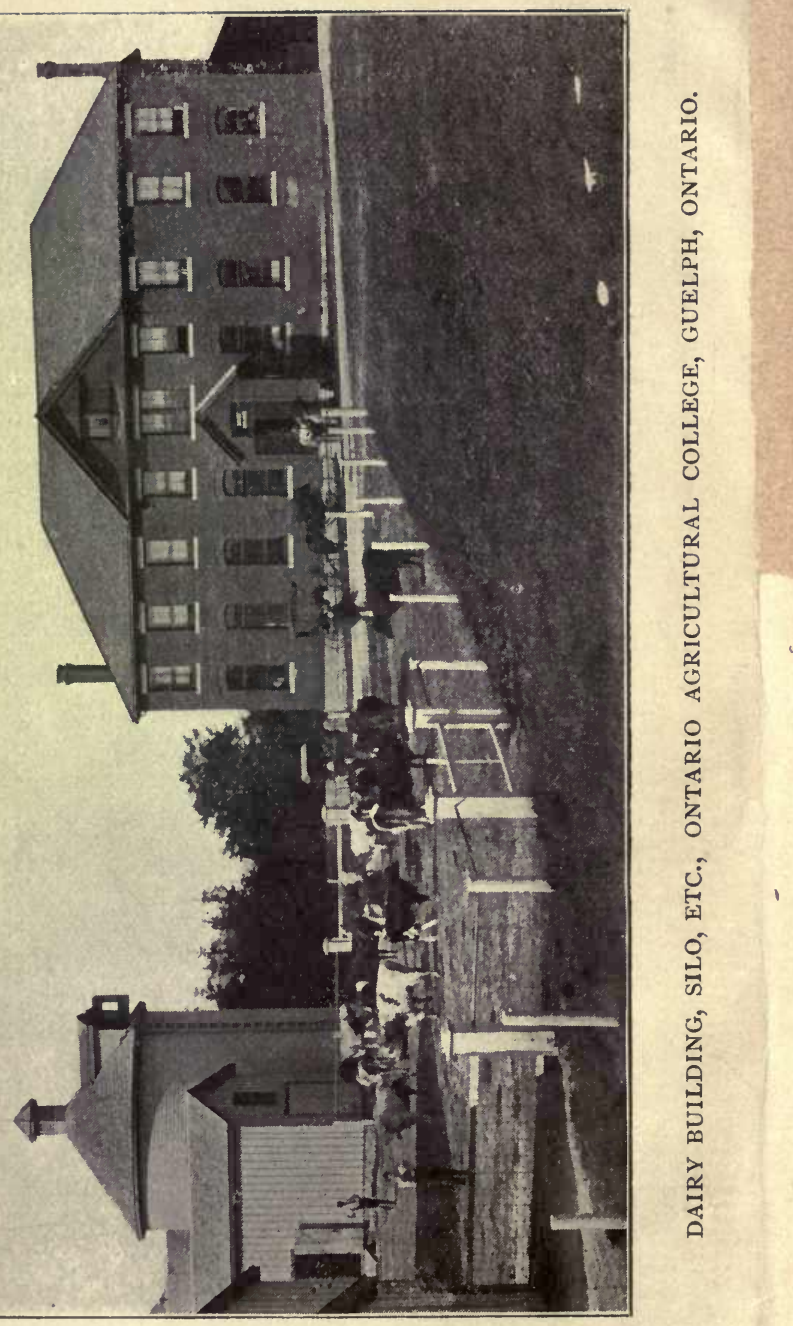


D

\section{CANADIAN DAIRYING}

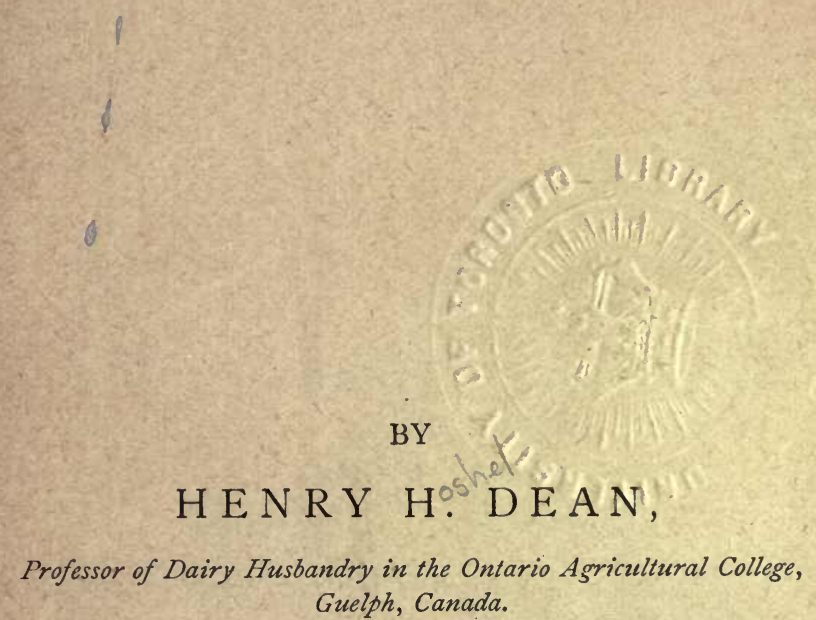

Vuitb Fllustrations.

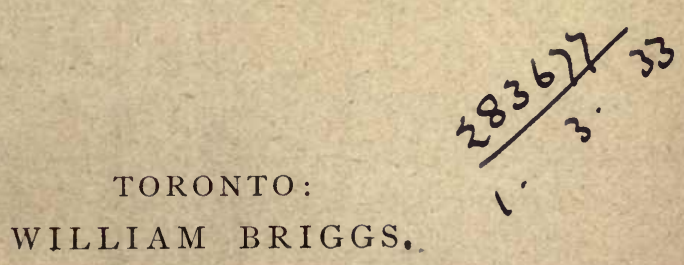

1903 


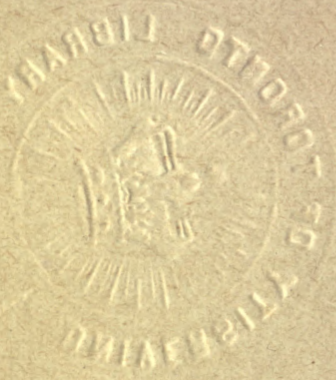

Entered according to Act of the Parliament of Canada, in the year one thousand nine hundred and three, by HENRY HOSHEL DEAN, at the Department of Agriculture. 


\section{PREFACE.}

THE wonderful growth of dairying in Canada during the past ten years made it seem advisable for the Author to prepare a simple work on dairying, which would be helpful in the class-room and also be beneficial to all classes of dairymen. The book contains chiefly the experience of the writer, gathered during the past twelve years as Professor of Dairy Husbandry in the Ontario Agricultural College. He has in addition to his own experience imbibed much dairy knowledge, which he has taken neither the time nor space to acknowledge. In many cases he could not do so, if he would, as the source of information has been crowded from his memory-the fact only remaining.

The Author wishes to acknowledge the kind assistance of the Ontario and Dominion Departments of Agriculture, The Farmers' Advacate, and Mr. T. B. Macaulay, Montreal, and to thank them for loan of electrotypes, blueprints, and photos to illustrate the 
work. He is indebted also to Prof. Woll, of Wisconsin; Prof. Stone, of Cornell University, N.Y., and Mr. J. H. Thompson, Laurel, Ont., for permission to use tables.

The Author trusts that the Agricultural Colleges and Dairy Schools will find in "Canadian Dairying" a reliable and suitable text-book for the use of students. He also hopes that the man on the farm, the maker in the factory, the manager of the factory, the cheese and the butter buyer, and all those interested in the welfare of dairying in Canada, will find in the work many useful and valuable lessons.

The writer has, since 189I, been slowly gathering the data here given. Many of the facts have been stated at various places and in various forms, but they are now collected in what he hopes will be a concise, simple and readable book on dairying.

To the dairymen of Canada, who have been so uniformly kind to the Author, and who have been so patient with his many weaknesses, this little work is affectionately dedicated.

H. H. DEAN.

GUELPH, 1903. 


\section{CONTENTS.}

PART I.-FARM DAIRYING.

CHAPTER

I. Dairy Farming _ - - - - - - - - 9

II. Dairy Stables - _ _ _ _ _ _ _ - - 16

III. Dairy Cows and Management of the Dairy Herd - 2 I

IV. Feeding Dairy Cows - - - _ - - - 33

V. Secretion of Milk-Milking Cows _ _ _ _ - 37

VI. Composition and Physical Properties of Milk - - 42

VII. Testing Milk - - - - - - - - - 48

VIII. Caring for Milk on the Farm _ _ _ _ 59

IX. The Farm Dairy _ - _ - _ - - - 62

X. Creaming Milk at the Farm _.. _ _ _ _ - 66

XI. Ripening and Churning Cream-Marketing Dairy

Butter - _ - _ - _ _ _ - - 84

XII. Skim-milk, Buttermilk, and Whey - _ _ - 93

XIII. Farm Dairy Cheese - _ - _ - _ - - 97

XIV. Town and City Milk and Cream Trade _ _ _ 102

PART II.-CO-OPERATIVE DAIRYING.

I. Origin and Advantages of Co-operative Dairying - IO7

II. Establishing and Managing Creameries and

Cheeseries - $-\ldots+\ldots+\ldots$ - $-\ldots 13$ 
1II. Buildings and Machinery for Co-operative

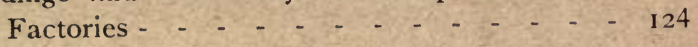
IV. Methods of Paying Patrons _ _ _ _... 140

V. Canadian Cheddar Cheesemaking _ _ _ . - - 151

VI. Special and Fancy Cheese _ _ _ _ _ - - 180 VII. Pasteurizers, and the Pasteurization of Milk and Cream for Buttermaking _ _ _ _ _ $\quad 185$ VIII. Buttermaking in the Creamery _ _ _ _ _ - 194

IX. Marketing Cheese and Butter _ _ _ - - $22 \mathrm{I}$

X. Condensed Milk - _ _ _ _ _ _ _ - 226

XI. Appendix, containing useful Tables of Reference for Dairyemn _ _ _ _ _ _ _ $\quad 229$ Index ${ }_{-}+{ }_{-}{ }_{-}+{ }_{-}-_{-}-255$ 


\section{ILLUSTRATIONS.}

PAGE

Dairy Bullding, Silo, Etc., Ontario Agricultural

College, Guelph, Ontario _ _ _ . Frontispiece

Breetos of Dairy Cattle-

AYRSHIRE $\quad-\quad-\quad-\quad-\quad-\quad-\quad-\quad-\quad-24$

CANAdian $\quad-\quad-\quad-\quad-\quad-\quad-\quad-25$

GuERNSEY - - - - - - - - 26

HOLSTEIN-FRIESIAN

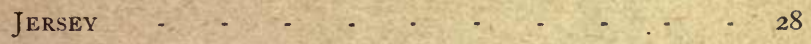

SHORT-HORN - - - - - $\quad-28$

Creamometer - - - - - - - - 449

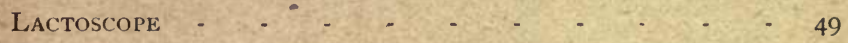

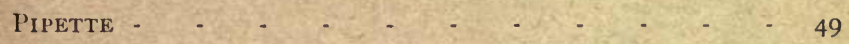

PIOSKOP - - - - - - - - - 50

BABCOCK TESTER - - - - - - + - - - 50

Ground Plan for Farm Dairy, Refrigerator aNd ICE-

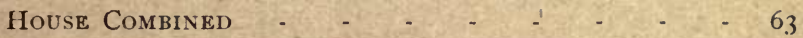

CAN FOR DEeP-SeTting OF Milk _ _ - _ - 70

CONE-Shaped Skimmer - - - - - - - - 7 I

National Cream Separator - - - - - $\quad$ - $\quad 74$

Bowl of National Separator - - - - - $\quad-75$

INSide Devices of National Separator - - $\quad 75$

Magnet Cream Separator - $\quad-\quad \cdot \quad \cdot \quad+\quad 76$

Plan for Tread-Power and Cream Separator - $\quad 79$

Brusil for Cleaning Dairy Utensils - - : - 8 I

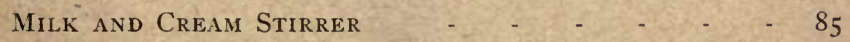




\section{viii}

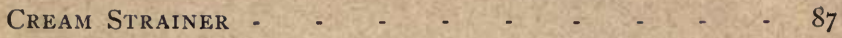

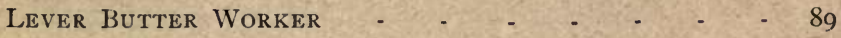

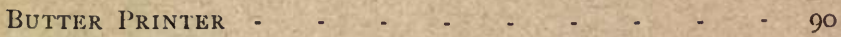

Removing the Butter from the Printer - - - 90

Butter Shipping Box Showing Trays and ICe Chamber - 91

Wire Handled Dippeir for StirRing Milk - - - 103

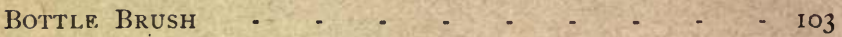

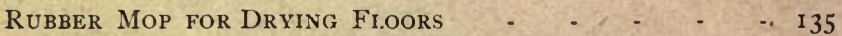

Sub-Earth Sewage Disposal - - - - - -

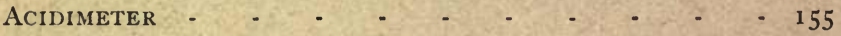

Plan for Cheesery - - - - - - - - 245

Cheese Factory with Cool Curing Room-Floor Plan 246

CheEse Factory With COOL CURING Room-SeCtion - 247

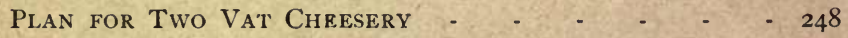

Plan for Whole Milk Creamery - - $\quad$ - $\quad$ - 249

Plan for Cream-Gathering Creamery - - - 250

Plan for CREamery -

Plan for Chegery and Creamery Combined - - $\quad 252$

Plan for Skimming Station - $\quad$ - $\quad$ - $\quad$ - 253 


\section{Part I.}

\section{FARM DAIRYING.}

\section{CHAPTER I.}

\section{DAIRY FARMING.}

SUCCESSFUL farming is the basis of successful dairying. To be successful, farming must be profitable. Dairy farming has been and will be profitable in Canada because it is a manufacturing business, because it is less subject to adverse conditions of season and weather, and because it changes waste or by-products into valuable ones.

The farmer who sells hay, straw, coarse grains, or roots from his farm, sells his raw materials, and hence loses some of his profits, as there is always more profit in selling a manufactured article than in selling raw material. The profits of the manufacturer may be reaped by the dairy farmer. Grass, hay, corn, coarse grain and roots are more certuin crops than wheat, fruit or other crops; hence the dairy farmer runs less risk of losing his crop in a bad season than 
the man who depends solely upon one crop, such as wheat. By feeding whey, skim-milk, or buttermilk to animals upon the farm, the dairy farmer converts these by-products into valuable ones, such as bacon, beef, dairy cows and poultry, thus obtaining an additional source of revenue from what was once considered a waste.

The farmer hopes to make profit by producing food which others require. The prime materials for the manufacture of food are soil, sunlight, air and water. Of these four, the soil is of chief importance to the farmer, as the others are obtained for the most part free. Hence, it is necessary that the dairy farmer should understand his soil, and know how to conserve the plant-food stored up in his farm.

As it is not possible for the farmer to directly change his prime materials into food, he makes use of two classes of agents-plants and animals. Plants cause the first change of prime materials into food, but a further and more valuable change is made as a result of using animals. Animal food as a rule is more valuable and more easily digested than food in the form of plants; hence consumers of food are willing to pay a higher price per pound for it. The farmer should aim to produce high-priced foods as far as possible, thus increasing his profits. To do this economically, he requires the best plants and the best animals which can be obtained for his purpose.

Dairy farms need not be large. A small farm growing a maximum amount of crops at a minimum expense, and which receives the personal attention 
of the owner, is more likely to be profitable than a large farm. The location of the dairy farm should be near a town or railway station, or in the vicinity of a creamery or cheesery, according to the character of the farming which it is intended shall be carried out. If private dairying, or selling milk, is the chief object, then it is necessary to be near a market or shipping point. If a creamery or cheesery be the enterprise, then the location should be in the vicinity of one or other of these manufacturing places.

As far as possible, the land should be well-drained and arable. An abundant supply of pure water is very necessary on a dairy farm. This can be got by digging or boring wells, and using a wind-mill to elevate the water to a tank located in a convenient and safe place. A never-failing spring may be safely piped to the barn or house, if there be sufficient fall to convey the water by gravitation. A water-ram may be used to elevate the water, in case the fall and volume are sufficient.

The buildings of the dairy farm should be neat, convenient, suitable and tasteful. A coat of paint on the outside of all farm buildings adds much to their appearance and durability. If constructed of wood, plenty of building paper and at least one still-air space should be used in the construction of the walls, so as to enable the owner to control the inside temperature both summer and winter. Cement or hollow brick walls are suitable for stable and other farm structures.

The aim of the dairy farmer should be to grow all 
the bulky food on his farm, and also as much as possible of the concentrates (meals). Very often, meals, such as oil-cake, gluten-meal, etc., may be purchased at reasonable prices, thus increasing the milk-flow and adding to the fertility of the soil.

The standard of production should be one cow for each acre of land.

\section{ADVANTAGES OF DAIRY FARMING,}

More Esiecially to Ontario and Eastern Canada.

I. Our soil and climate are well adapted for dairying. The soil, more especially in Ontario and some parts of Quebec, is well suited for growing all crops needed for the production of milk. The Maritime Provinces have excellent pastures and grow large crops of hay and plenty of coarse grains. Manitoba and the North-West can furnish the bran, which is such an excellent food for cows. In British Columbia, creameries, where established, thrive remarkably well. Ontario is almost surrounded by the great fresh water lakes, which temper the winter and moisten the atmosphere of the summer. The Maritime Provinces feel the stimulus of sea breezes, which have been helpful in developing the dairy countries of Europe.

Our population is inclined towards dairying, as we are descended from the famous dairymen and dairywomen of Europe-English, Scotch, Irish, French, Germans - the blood of these dairy races runs through the veins of Canadians, hence we are predisposed to favor dairying. 
2. Milk is a necessary article of food for which there will always be a demand. For a considerable length of time the young animal, man, lives almost exclusively upon milk. Milk and its products enter into the dietary of all civilized people at all ages, hence the dairy farmer knows that he is producing an article for which there will always be a market. Changes of fashion, or whims of fancy, will not rob him of a market for his produce.

3. Plenty of labor is required upon the dairy farm, and in all labor, if properly directed, there is profit.

4. The results are more uniform year after year. The price of dairy products does not vary so much as that of other farm produce.

5. Rough, waste land may be utilized for profitable dairy farming, where other modes of farming would be unprofitable.

6. It may be carried on all the year-winter as well as summer-thus giving profitable employment in winter.

7. Dairy farming enables the farmer to produce articles of high value according to weight and bulk. This is a material advantage where the chief market is distant. A ton of butter will sell for about $\$ 400$, a ton of cheese for about $\$ 200$, and a ton of wheat for less than $\$ 25$. The cost of transportation to market, per $\$ 100$ worth of these three products, is very much in favor of the butter and cheese.

8. The fertility of Canadian soils will not be robbed by selling dairy products, especially butter. Every load of grain, hay or straw, every live animal sold 
from the farm, carries away soil fertility. The sale of milk also robs the soil; but in order to produce the milk, food must be fed to the cows, and about eighty per cent. of the fertilizing material in the food is available for the soil. Where butter or cream only is sold very little soil fertility is carried from the farm, as butter and cream consist largely of those elements which the plant gathers from the air, hence cost the farmer nothing. Buttermaking is a most valuable means of restoring the fertility to worn-out soils.

\section{ICE-HOUSES FOR THE DAIRY FARM.}

Every dairy farmer should provide a supply of ice for cooling milk and other farm products. It is also very convenient for household purposes in hot weather.

A very simple and cheap house will serve for storing ice. The main requisites in an ice-house are to have drainage under the ice, ventilation above it, and protection from the direct rays of the sun and from the rain. A few rails covered with sawdust, placed in the bottom of the house, will provide drainage. Some posts placed in the ground in such a way as to provide support for a "shanty-roof," and support on the sides for rough lumber, and holding the sawdust in place, will produce the other requisites. The ice should be packed firmly and solidly, having about one foot of sawdust around the sides and on top of the ice. The air should circulate above the sawdust, which can be got in a shanty-roof building by leaving the gables on the sides not boarded. 
A permanent and neat building is preferable, but no dairy farmer should neglect a supply of ice because he has no suitable building.

Less sawdust is required on the ice if the walls of the building be packed with six or eight inches of sawdust ; but this plan tends to hold moisture in the walls, and causes the building to decay in a short time.

For a herd of twenty-five cows a dairyman should provide from fifty to seventy-five tons of ice. This would require about 2,000 cubic feet of space, or a room ten by ten and twenty feet high. 


\section{CHAPTER II,}

\section{DAIRY STABLES.}

$\because$ IN Canada cows have to be housed for nearly onehalf of each year, hence it is important that the house should be suitable for maintaining the health and vigor of the cows, and that the conditions shall be favorable for a large flow of milk. The whole question may be summed up in one word-comfort. Make the cow as comfortable and contented as possible while in her house, and if she be the right kind of a cow she will respond with a good flow of milk.

The main points are to have plenty of light, an even temperature throughout the year, tight floors, comfortable ties and stalls; have it convenient, and have from 500 to 800 cubic feet of air space for each animal. The ceiling should be from seven to ten feet high. If possible, have a yard on the south side, where the cattle may be turned out in fine weather.

Stables should be light, in order to ensure healthy, thrifty stock, as light is a great disinfectant. - There should be plenty of large windows on all sides.

An average temperature of fifty to sixty degrees should be aimed at, although at night a temperature so low as forty degrees will do no harm. Even 
temperature may be got in wooden buildings by using rough lumber on the studding, then building paper, and then matched lumber. The outside may also have rough lumber and paper on the studs, with a finish of planed lumber and battens put on perpendicularly. Cement, hollow and ordinary brick and stone may also be used for the walls of stables. Double windows on the north side are an advantage in winter.

The problem of ventilation involves the bringing of fresh air into the stable without causing a cold draught upon the cows, and the removal of the foul air from both the upper and lower parts of the stable. A sub-earth duct, which will be more fully described in connection with curing-rooms at cheeseries, gives an excellent means of bringing fresh air into a stable, as it cools the air in summer and warms it in winter. Where this is not practicable, the air in winter should enter near the ceiling, so as to be warm before it is distributed among the cattle. The foul air should be taken from the floor as well as from the ceiling. This may be done by having the ventilators extend to near the floor, with adjustable openings at the top and bottom.

For sanitary reasons, there should be no room for hay and straw above the cows. For economic reasons, the plan of having a storage above the stable is usually adopted.

Cement floors are most easily kept clean, and also most durable, but they are somewhat objectionable, as they tend to cripple the animals and cause dis- 
order of the udder unless a large supply of bedding is kept under the cows at all times. This difficulty is overcome by placing a wooden floor or platform, in sections, under the cows and on top of the cement.

Wooden floors should be tight, and have a filling of concrete or coal ashes to the level of the joist below the floor.

The tie which has given the writer the best satisfaction is a chain, the ring of which is placed on an upright pole or bar, or on an iron about three feet long fastened to the side of the stall. This is a safe and handy tie, and at the same time it gives the cow considerable freedom. Rigid stanchions should not be used in a dairy stable.

The writer prefers single stalls which are about three and one-half feet wide, and from five to five and one-half feet long from the manger to the drop behind the cows. A partition making each manger separate and extending about one-half the length of the stall is convenient for feeding, milking, and keeping the cows in their places. A partition between the stalls is not an absolute necessity.

The manger should be about twenty inches wide in the bottom, and not over one foot deep on the side next to the cow. The front of the manger should slope into the passage and be about two feet high, with a narrow strip projecting on the inside to prevent the cows throwing out the feed. The bottom of the manger should be made of cement; and, where practicable, the whole manger may be constructed of this material, which will be more easily cleaned. The 
most sanitary manger is one with no wood in connection with it, and no partitions to prevent easy cleaning. The objection to a manger without divisions is that it is more difficult to feed the cows according to their milk-flow.

For two rows of cows facing each other, the stable should be from 28 to 40 feet wide. The latter width gives plenty of room for feed and manure passages, but adds to the labor of keeping the passages clean.

A drop of about eight inches behind the cows tends to keep them clean. The gutter should be about eighteen inches wide, and the passage for taking out the manure should be from four to six feet wide, and two to four inches lower than the platform on which the cows stand. The gutter should be made tight, so that no liquids are wasted. Sufficient absorbents should be used to take up all the liquid manure. Land plaster and sawdust are both good absorbents, and tend to sweeten the stable. Where power is available, it pays to cut the straw used for bedding.

All stables should have at least one box-stall for sick cows. Calves are best kept in a separate stable if possible.

The inside of the stable should be whitewashed at least once a year. This may be done very rapidly with an ordinary spray-pump. The stable should be kept free from dust and cobwebs. A broom should be convenient for that purpose. The stable should be as clean as possible at all times.

It is not a good plan to clean out the stable at, or . just before milking time, as the odors may taint the milk. 
Dusty feed or bedding should not be handled in the stable near milking time.

Cows should have a supply of salt accessible at all times. If the salt be placed in the manger, the rock salt is more convenient, as it is not so likely to be thrown out with refuse feed, which latter should be cleaned from the manger daily.

A convenient and cheap water trough may be made of heavy galvanized iron placed about two feet above the manger, and in a convenient place for the cow to drink. This trough may be about seven inches wide on top, four to six inches deep, and about four inches wide in the bottom. It should slant towards one end, where a plug may be removed when cleaning the trough, which should be done daily. The trough is filled at the other end through pipes from a supply tank. Water is placed in the trough two or three times daily by opening a valve. 


\section{DAIRY COWS AND MANAGEMENT OF THE DAIRY HERD.}

\section{SELECTION.}

THERE-are good milkers amọng nearly all breeds, but they are rare in some and more common in others. The wise dairyman will select his cows from among those breeds which are characterized by dairy qualities, rather than from those noted for beefmaking. Whether a cow will change her food largely into milk or into beef will depend upon inherited characteristics and upon training. Both of these are potent factors in deciding wh ther a cow will be profitable or not. When selecting cows for breeding, as well as for milking purposes, it is important to have animals which belong to milking families or strains, as well as belonging to one of the dairy breeds. Cows of any breed may be developed into dairy animals by a process of selection and training; but this is too long a task for the average dairyman. A cow's milk-yield depends not so much upon breed as upon her own characteristics and her food and management.

As regards size, choose a small cow where the supply of food is somewhat limited, and larger ones where there is an abundance of feed. 
If butter-making be the chief object, select cows which give as large a flow as possible of rich milk, or milk containing a high percentage of fat. For cheesemaking and general dairying, quantity of flow is an important factor, as well as richness.

All dairy cows should have good constitutions or vitality, as indicated by plenty of room in the heart and lung region, oily hair, mellow skin, and easy, regular breathing. Cows hollow behind the elbows are predisposed to lung trouble.

Good digestion, or power to use food in large quantities, is shown by a large paunch or middle piece, plenty of space between the last rib and hipbone, large mouth, strong lips, good appetite and a general appearance of contentment.

Large milking capacity, the most important point in a dairy cow, is not easily determined by outward appearances. In fact, there is no certain indication of this subtle quality. The only way to ascertain this point for certain is to weigh and test the milk daily or at regular intervals throughout the lactation period. It should, if possible, be weighed and sampled daily. However, there are some points which serve as a guide where there is no opportunity to weigh and test the milk for fat. Nervous power for the transformation of food into blood, and for the elaboration of milk, is indicated by a high, broad, dishing forehead; tright, prominent eyes; and a prominent spinal column. A large, well-balanced udder which is not fleshy and shows elastic quality; udder and 
mammary veins prominent; large milk wells, and good-sized escutcheon, these indicate power to produce milk. "No udder, no cow," may serve as a maxim when selecting cows.

Lastly, beauty may be looked for when selecting cows. It is not well to sacrifice utility for beauty; but where both are combined, the cow is that much more valuable. Beauty in the dairy cow consists of fine, clean-cut head, fine horns, bright eyes, medium length of rather thin neck, fine shoulders, large barrel, broad loin and hips, long rump, well-developed udder, fine tail with good switch, and short limbs. No one part should be unduly prominent unless it be the udder. She should have a proper combination of colors and a stylish appearance, all of which please the eye. The emphasis should be placed upon perform, not on form.

In no case should a cow be retained in the herd if her yearly record falls below 6,000 pounds of milk or 250 pounds of butter, without some good reason.

\section{BREEDS OF DAIRY CATTLE.}

There are several breeds of cattle noted for their special dairy characteristics. Some breeds are largely beef-making in their tendencies, while some combine fair beefing qualities with fair dairy tendencies. A dairyman should select animals of a breed noted for dairy qualities rather than those in which beefing qualities predominate. 
The Ayrshire breed of cattle originated in the county of Ayr, Scotland. They are a very thrifty breed, especially adapted to a somewhat rough country, and for places where forage is scarce. They are of a rather high nervous temperament, requiring gentle handling, and are inclined to have short teats, which are difficult to milk. In size, they take a medium position, as the cows do not weigh much over 1,000 pounds live weight. They are very persistent milkers,

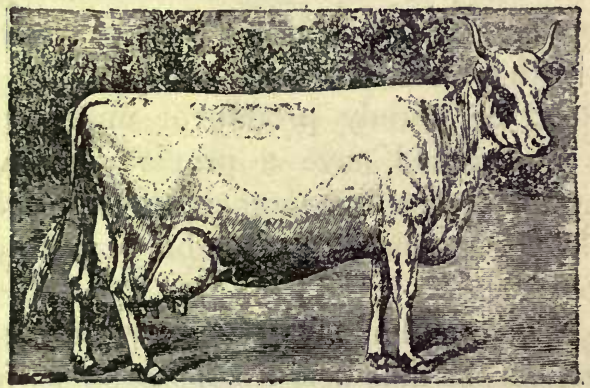

AYRSHIRE.

giving a moderate quantity of milk of average quality or percentage of fat. The fat globules are small in size, hence the milk from Ayrshire cows is not adapted for creaming by any gravity method, as there is too great a loss of fat (cream). Their milk is, however, specially well suited for cheesemaking, and in cheese factory sections this hardy breed is very popular. Henry Wade, Toronto, is Secretary of the Canadian Association and in charge of the herd books. 
Canadian. - This breed originated in the Province of Quebec, where they are now recognized as a distinct breed. They are descended from the cattle brought to Canada by the early French settlers. They are small in size, very hardy, and give large returns in butter for the feed consumed. They are darker in color (the favorite color being black with

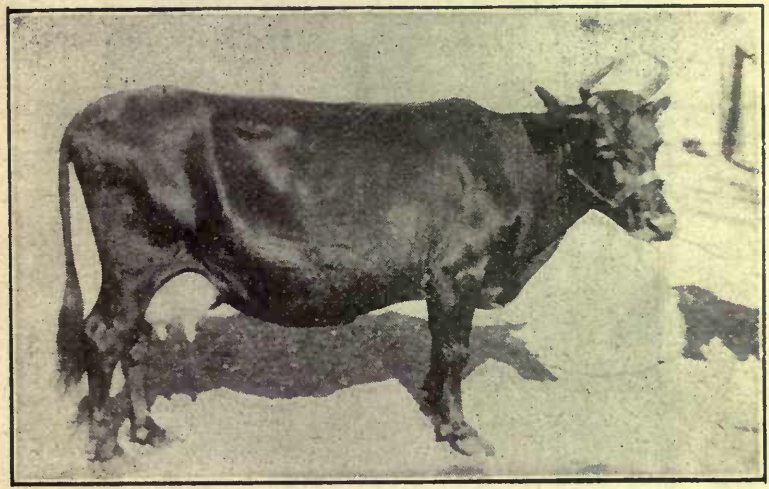

CANADIAN.

ROUEN (589)-One of the five cows chosen to represent the Canadian breed at the six-months' dairy contest at Buffalo in rgor. Record for the six montbs: Milk, 4896. I lbs.; per cent. of fat, 4.46 ; value of butter at 25c. per lb., $\$ 64.30$; cost of food, $\$ 23,68$; net profit from butter alone, $\$ 40.62$; weight of cow at entry, $794 \mathrm{lbs}$; gain in weight, 27 lbs. Breeder, Arsene Denis; present proprietor, T. B. Macaulay, Hudson Heights, P.Q.

an orange stripe on the backbone and a fawn-colored muzzle) and smaller in size than the Jersey, but have many of the characteristics of this well-known breed. They have been recognized as a distinct breed since 1886. J. A. Couture, V.S., Quebec, is Secretary of the Association and in charge of the herd books. 
Guernsey.-This is a Channel Island breed, larger in size than the Jersey. The lighter shades of color -fawn and white-predominate. Their milk is rich in fat, and of a golden color. As a breed, judging by their numbers, they have not been popular in Canada. In the Island of Guernsey and in the United States are to be found some excellent cows.

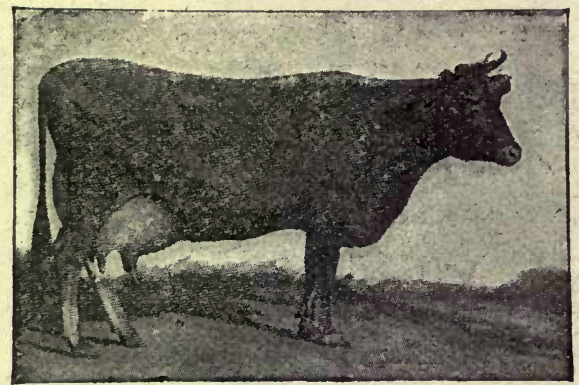

GUERNSEY.

Holstein-Friesian.-The home of this breed is in North Holland and the Province of Friesland. It is claimed that the breed has been kept pure for 2,000 years. This is the largest of the dairy breeds, and they have a very strong, somewhat bony frame. Their chief characteristic is a large flow of milk, having a somewhat low, or under average, per cent. of fat, though some cows give milk considerably above the average in fat. Strong efforts are being made by breeders to overcome this weakness of an otherwise 
excellent breed for dairying. Good cows are possibly more common among Holsteins than among animals of any other breed. G. W. Clemons, St. George, Ont., is Secretary of the Canadian Association and in charge of the herd books.

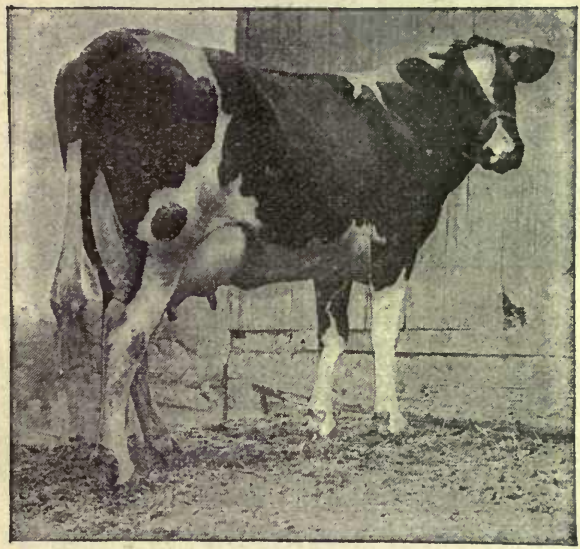

HOLSTEIN-FRIESIAN.

Jersey.-This is one of the best breeds for purely butter purposes. The home of the breed is in the Island of Jersey, one of the Channel Islands. The cows are rather small in size, weighing from 700 to 900 pounds, and do not, as a rule, give a large quantity of milk, although some individual cows are noted as heavy milkers. The milk is rich in fat, usually testing above 4.5 per cent., and the fat globules are large 
and firm, making it specially well adapted for creaming by gravity process, and for making firm butter in hot weather.

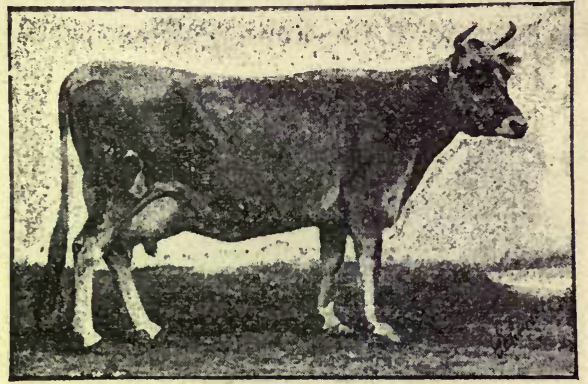

JERSEY.

Short-Horn.-Grade Short-horn (Durham) cows are possibly more common in the Province of Ontario than cows of any other breed. Many of these are

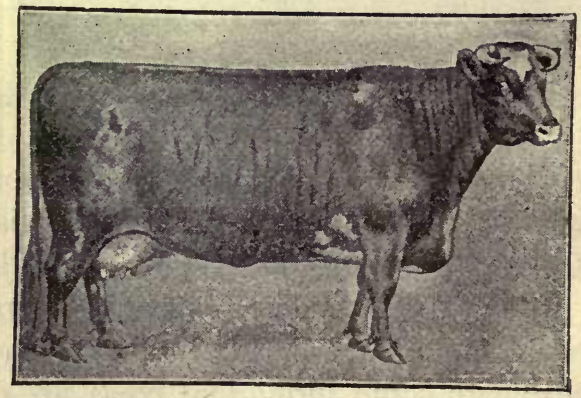

SHORT-HORN.

excellent milkers, but the beefing tendency predominates in most of the pure-bred stock ; hence it is very 
difficult to procure a sire that will produce dairy heifers. It is to be regretted that the dairy qualities of this excellent breed have been neglected by most breeders.

\section{ESTABLISHING AND MAINTAINING A DAIRY HERD.}

If the dairyman can do so, he may use pure-bred cows for his herd, although many grades are good milkers. The average dairyman should secure the best possible grade cows, and breed these to a purebred sire of a milking breed and strain. It is best to select the breed which he considers will most nearly fill his requirements, then stick to that breed, as much time and effort are lost by changing from one breed to another.

When selecting a dairy sire, get a good representative of the breed, and one from a milking family. He should have good constitution, a masculine character indicating prepotency and power to get heifer calves which will prove to be good milkers. His breeding, as indicated by pedigree and performance of dam and grand-dam, and the development and placing of the rudimentary tests, are the best indications of this latter quality.

As far as possible, the heifer calves from all the best animals should be reared. These calves should be given their dam's milk for the first three or four days, except in the case of very rich milk, when it should be diluted for the young calf. New, warm milk in small quantities should be given to the calf until it is three or four weeks old, at which time it 
may be changed to warm, sweet skim-milk. Add a little ground oats or ground flax-seed to the milk as soon as the calf can digest this food. Some nice clover hay, dry bran and oats, mixed in equal quantities by weight, and a few roots in winter should be given to the calf at an early age. The calf should be kept clean and dry, and should remain in the stable during the hot, cold, or stormy weather of the first summer. She should be kept thrifty, but not fat. When sixteen to twenty months old, she may be bred. The heifer should be in good condition when freshening, but the calf should not, as a rule, be raised for dairy purposes. She requires gentle and patient handling in order to develop a kind disposition and dairy qualities. The first lactation period should last for at least ten months, in order to establish the milking habit. Her second freshening should take place in from twelve to fifteen months after the first. If at the end of the second lactation period she does not attain to the standard of 6,000 pounds of milk, or 250 pounds of butter, she may be considered as not worthy a place in the herd. By weighing and testing the milk from each cow in the herd, at least once a month, and weeding out the unprofitable cows, a marked improvement in the dairy herds of Canada would soon be noticed. Breed, Feed, Weed-the triple servants of the dairyman.

\section{CARE AND MANAGEMENT OF THE DAIRY HERD.}

Dairy animals must be treated kindly. No one can hope to succeed in the dairy business who neglects 
this point. The owner or attendant must have the confidence of his animals, and rule them with lovenot with the lash.

Sick cows, and cows unduly excited, should be kept from the herd. Cows suffering from any contagious disease should be isolated until all danger of spreading the disease is past. Their stalls and mangers should be disinfected with a carbolic acid solution.

Cows should have access to salt and plenty of pure water at all times, if possible. They should never be allowed to drink dirty or stagnant water. Ashes or ground bone should be given to cows which chew bones or sticks, as it indicates a desire for mineral matter.

Heavy milkers 'should be placed on rather low, succulent diet before freshening. From one and a half to two pounds of Epsom salts should be given in the form of a drench, just before or directly after calving. The calf should be removed from the dam in about twenty-four hours, unless the udder be much inflamed, in which case the calf may be left with the dam for a longer time. In no case should the calf suck the dam for more than three or four days. Bathing the udder with warm water, or some form of liniment, will assist in reducing the inflammation.

Cows should have shade in hot weather, or be kept in a darkened stable during the day. A mixture of fish oil (one-half gallon), coal oil (one-half pint), and crude carbolic acid (four tablespoonfuls), mixed and applied to all parts of the cow except the 
udder, once a week, will keep the flies from about twenty-five cows. Lighter mixtures may be sprayed on once a day for this purpose.

Cows should not be exposed to cold or stormy weather, but on fine days during the winter they may be turned into a sunny yard for two or three hours with profit. They should also be out of doors as much as possible during the. fine weather of the summer, in order to preserve their health. Suitable shade ought to be provided in the pasture-field, or the cows may be kept in a cool, well-ventilated stable during very hot weather. 


\section{CHAPTER IV.}

\section{FEEDING DAIRY COWS.}

THE following principles should be observed in the economic feeding of dairy cows :

I. Feed liberally, especially of the cheap, bulky foods. Make these as palatable as possible.

2. Feed the concentrates (meals) according to the milk-flow. Test the cows occasionally with an increase of meal, and note whether or not they respond.

3. Study the capacity, likes and dislikes of each cow.

4. Keep the mangers clean.

The cheapest and most valuable bulky foods, after grass, for the dairyman are corn silage, clover hay and mangolds. The cut clover hay (eight to ten pounds for each cow) and the pulped mangolds (thirty to forty pounds per cow) should be mixed with the corn silage (thirty to forty pounds per cow), if possible, a few hours before feeding, in order to soften the hay and make the whole mass more palatable and more easily digested. When hay is not available cut straw may be used. The cows and the young stock may receive practically all they wish of this cheap, bulky food. Corn fodder or cornstalks 
may be used instead of corn silage, but it is not so satisfactory a food for milk production.

The meal may consist of wheat bran (four pounds), ground oats (two to three pounds), and ground peas, oil-cake, or gluten-meal (one to two pounds) per cow, per day. About eight pounds of meal for each thirty pounds (three gallons) of milk or for each pound of milk-fat (butter) is an economical basis to. work upon. The amount of meal should be increased so long as the cow responds, and so long as there is no danger of causing indigestion. The careful feeder will soon know the capacity of each cow for economic production.

The bulky feed may be put in the manger and the meal be placed on top, or the meal and bulky feed may be fed separately.

Feeding twice a day while the cows are in the stable is sufficient. A light feed of long hay or a few whole roots may be given at noon for a change. Study variety, and also economy consistent with a good milk flow, in order to be successful in the feeding of cows.

Green peas and oats mixed in the proportion of one bushel of peas to one and one-half bushels of oats per acre, and sown at two or three intervals in the spring, make excellent substitutes or supplements for short pasture. Corn silage, preserved in a small summer silo, is another good summer food, and more economical than soiling crops. Lucerne clover makes an excellent soiling or green crop for dairy cows. 
By cutting it for hay before it becomes too woody it makes a good winter food. Green corn, sorghum, millet and other crops may be grown for summer feed. All these crops should be fed in the stable, and not "over the fence" in a pasture-field. If possible, they should be run through a cutting-box, thus saving a waste of about twenty-five per cent. as compared with feeding them whole.

In the making of good corn silage the two main points are to have an air-tight silo, which may be made of cement or wood, and to have the corn crop well matured before cutting or shredding it into the silo. Select a variety of corn which will give a large crop of ears and stalks, and one which will mature in the locality before frost. Provide about four tons of silage for each mature animal in the herd. Twenty cows will require eighty tons of silage, which should grow on about five acres of land.

\section{FOOD-COST OF MILK, BUTTER AND CHEESE.}

The average food-cost of milk in the O. A. College Herd for three years (1896, I 897 and I 898) was 46 cents per 100 pounds. The average cost for the food to produce one pound of butter was $10 \mathrm{x} / 2$ cents, and the cost for one pound of cheese was 4.85 cents.

For six months (May to October), the average food cost of one pound of butter was 8.88 cents, and for one pound of cheese, it was 3.96 cents. For the six winter months (November to A pril), the average foodcost of one pound of butter was I 2.65 cents, and for 
IoO pounds of milk it was 58.3 cents. We found a marked difference in individual cows with reference to economy of production. Some cows produced milk more economically than did other cows which excelled in small cost for the food to produce a pound of butter.

(For composition of foods and dairy rations see tables in Appendix). 


\section{CHAPTER V.}

\section{THE SECRETION OF MILK-MILKING COWS.}

THE cow secretes milk in the mammal glands known as the udder, but incorrectly spoken of as "the bag." This udder consists of two glands running lengthwise of the body, which are separated by a fibrous partition dividing the udder into right and left. Each gland has two, sometimes three, outlets called teats. The udder is not divided into quarters, though each section is more or less independent of the section on the same side. This fact explains why a cow, having lost one teat, will give nearly as much milk from three as from four teats. The loss of two teats on the same side reduces her value nearly one half, and such a cow is not profitable. Sometimes a cow will have only two teats and about half the ordinary sized udder, showing a reversion to what was probably the original type of a cows's udder, viz., similar to that of the sheep.

The outer covering of the udder is the skin of the animal, and it is joined to the muscles of the abdomen by strong ligaments. This fact explains the "holding up" of milk, which is a bad habit contracted by some cows. Giving the cow something to eat while milking will often overcome this trouble. 
The glands consist of tissue, fat, nerves, arteries, and veins. The secretion takes place in the lobules, which are made up of from three to eight vesicles grouped together. These vesicles are lined with cells having a common outlet. These outlets, or tiny ducts, connect with other ducts, and finally empty into the sinus or milk-cistern placed in the upper part of each teat. From the milk-cistern the milk passes through a teat-canal to the opening at the bottom of the teat. This opening is closed with a muscle. When cows leak their milk it is due to the muscle being too weak. When cows are hard to milk this muscle is too tense, or there may be obstructions in the teat-canal. There is no remedy for the latter. A sharp three-edged knife may be used to release the tension of the muscle in bad cases.

The glands are not equally active at all periods of life with the cow. The call upon the dam to provide nourishment for her offspring is the first stimulant to milk secretion. Withdrawing the milk by the calf, or by the skilful hand, is the second cause of stimulation. The secretion of milk is usually most active during the third, fourth, fifth and sixth lactation periods, but may continue active up to the tenth or twelfth.

Various explanations have been given of the secretion of milk, none of which is satisfactory. The metamorphic theory assumes that milk is formed by the decomposition of the cells of the gland. An objection to this theory is that with cows giving a large quantity of milk the glands would have to be built up several times during the day, which is impossible. 
The transudation theory assumes that milk is filtered from the blood. The objections are that neither casein nor milk sugar, which are constituents of milk, are found in the blood; hence must be a result of cell activity. The fat in the milk is also in much greater proportions than found in the blood; while the ash constituents of milk and blood have their proportions of soda and potash reversed. If the udder were simply a filter, we should expect milk and blood to be similar in composition.

The secretion of milk is also ascribed to ferments acting upon the blood in the cow's udder, but this does not seem feasible.

A combination of the metamorphic, or change, and the transudation, or filter, theories, possibly offers the best explanation. The fat, casein, sugar, and some of the ash constituents of milk are probably the result of cell activity, while the water, albumen, and some other parts are probably filtered from the blood by the glands.

Milk may be drawn from the udder through the teats after the death of the cow.

Strippings (last drawn milk) are richer in fat than the first or middle portions of the milking, because the fat globules are retarded in their flow from the vesicles by the walls of the ducts through which the milk flows on its way to the milk-cistern.

Cows' udders may be classified as "well-balanced," "deficient in front," "poor behind," "deficient in onequarter," "bottle-shaped," "pendulous," "fleshy," "small," "large," and " elastic." 
Very few udders are "well-balanced," i.e., equally developed in the fore and hind quarters. Usually the forequarters are deficient. This is said to be due to the fact that the blood enters the hindquarters of the udder, and consequently they are better nourished.

An ideal udder is one which comes well forward and well up behind; which has teats of good, even size, and squarely placed; and which is covered with elastic, mellow skin and fine hair. A fleshy, pendant udder is usually deceptive.

Cows may be milked once, twice, or three times in twenty-four hours. When the daily yield of milk is ten pounds (one gallon) or under, milking once a day is sufficient. If the daily yield is sixty pounds (six gallons) or over, cows should be milked three times a day. Cows giving forty pounds (four gallons) or over should be milked an equal number of hours apart.

The persons who do the milking should observe: kindness, cleanliness, promptness, system, milking quickly, and milking out clean. Kindness is very important, as it tends to secure a larger and richer flow of milk. This is due to the fact that milk is largely made at the time of milking, and the quantity and quality of the flow depend to quite a large extent upon the attitude of the cow towards the person doing the milking.

The cow's udder and flank should be wiped with a damp cloth before commencing to milk. The milker should wear clean clothing, preferably a clean white suit. The hands also should be washed before commencing to milk. Cows should be milked with dry hands into a clean pail. 
The air of the stable should be pure at the time of milking, else the stream of milk will carry impurities into the pail, and we shall then have a mechanical mixture of clean milk and impure air, which is a common cause of "tainted" milk.

The milking is not completed until the milk from each cow has been weighed daily, or at stated intcrvals, and samples taken for testing the fat content.

Milking machines have not been altogether successful up to the present, but they are being perfected, and we may soon expect to find a satisfactory machine for milking cows placed upon the market. Among those which have been more or less successful are, Laval's Lactator, the Murchland, the Thistle and the Lawrence \& Kennedy. The last three are Scotch machines. 


\section{COMPOSITION AND PHYSICAL PROPERTIES OF MILK.}

Cow's milk is chiefly used for household and commercial purposes in Canada. The flow of milk from other animals is not sufficient to induce the Canadian farmer to make use of it. The cow has responded to man's efforts for large milk production better than any other animal. It has a specific gravity (weight as compared with water) ranging from 1.028 to 1.036 , and averages about $\mathrm{I} .032$, i.e., it is about thirty-two thousandths heavier than water. This increase in weight is due to the heavier "solids not fat," and not to the fat, which is lighter than water.

Colostrum milk, or the milk which is first given by the cow after freshening, is a sticky, yellow, sweet fluid, containing a high percentage of albumen, which takes the place of casein in normal milk. It has a high percentage of solids, but the percentage of fat varies considerably with different cows. With some cows the fat content of colostrum milk is high, and with others low. It may vary from two to eight per cent. Colostrum changes to normal milk in from five to twelve days after freshening. The addition of sulphuric acid to colostrum will cause a purple precipitate in the Babcock test-bottle. It should not be 
used for other purposes than feeding calves before the ninth milking, and in some cases it may require longer to become fit for table use. With Jersey or Guernsey cows, the colostrum may be too rich for the young calf, in which case it should be diluted with poorer milk, or with water. Many young calves are lost by feeding them this very rich milk. The young calf requires the colostrum, but it should be fed carefully.

Milk is sometimes said to consist of fat and milk serum, but a more complete analysis shows it to be made up of :

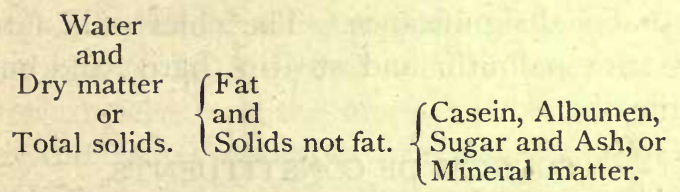

A percentage composition of milk is about as follows :

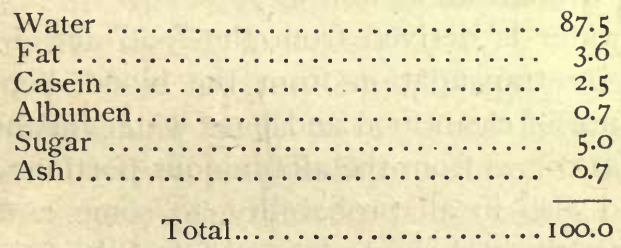

When first drawn, milk is either amphoteric (both alkaline and acid) or alkaline in character, but soon becomes acid, due to the absorption of carbonic acid gas from the air, and to the lactic acid produced in the milk itself. When tested with an acidimeter fresh milk usually shows over one-tenth of one per cent. acid, due in part to the acid character of the casein. 


\section{FORM IN MILK.}

The fat and a portion of the casein are held in suspension, and the remainder of the solids are dissolved in the water. The fat is in the form of tiny. globules, which vary in size. Guernsey and Jersey cows give milk containing large-sized fat globules, while Ayrshires and Holsteins give milk with small fat globules. The size of the fat globules decreases with a diminished flow of milk, and the number increases. Whether these globules are surrounded with a membrane or not has been the subject of considerable controversy, but the question has little practical significance. The chief milk fats are olein (soft), palmitin and stearin (hard), and butyrin (volatile).

\section{SOURCES OF CONSTITUENTS.}

The sources of the different milk constituents are probably somewhat as follows :

The water is derived from the food and drink of the cow by transudation from the blood, hence the importance of clean food and pure water for the cow.

The fat comes from the albuminous portions of the food, and also in all probability, to some extent at least, from the carbohydrates and fat of the food.

The casein, albumen, and sugar of the milk are probably derived from the nitrogenous parts of the food, through a special cell activity.

The ash or mineral matter comes partly from the mineral matter in the food by transudation, and partly as a result of cell activity in the gland. 


\section{VARIATION OF MILK CONSTITUENTS.}

The fat is the most variable portion of milk. It may vary from two to ten per cent. with individual cows. Herd milk will seldom vary more than onehalf of one per cent. from day to day. The chief causes of variation in the percentages of fat in cows' milk are : the individuality, breed, frequency of milking, night's or morning's milk, period of lactation, care and comfort of the cow, and to a very slight extent, possibly, the feed of the cow.

The more' frequently cows are milked the higher will be the percentage of fat in their milk. As the period of lactation advances, the milk usually becomes richer in fat and total solids. The better care the cows receive, and the more comfortable they are made, the more favorable are the conditions for secreting rich milk. Whether cows are "stripped" or not will also make a difference in the fat content of milk. Manipulation of the udder will also increase the percentage of fat in the milk.

Feed, however, has very little, if any, influence on the percentage of fat in milk. Feed influences the quantity, but not the quality, except in rare cases. The cow governs the richness of the milk, hence rich milk must be got by breeding and selecting the cows, rather than by depending upon feed for this purpose.

The solids not fat are fairly constant in all samples of milk, tending to increase slightly with, but not in the same proportion as, an increase in the percentage of fat.

Casein is similar to albumen in chemical composi- 
tion, but coagulates by the addition of an acid or with rennet, while albumen coagulates with heat.

Sugar gives to milk its sweet taste. The souring of milk is due to a change of milk sugar into lactic acid, through the action of lactic acid bacteria (small plants).

The ash constituents of milk bear a very close relation to the casein, hence anything which causes a change of the ash, especially the lime compounds, affects the casein. The pasteurization of milk destroys its usefulness for cheesemaking by changing its mineral matter, and rennet will not act properly on the casein unless the milk be treated with a soluble lime-salt, such as calcium chloride.

The yellow color of milk is due to special coloring matter known as lactochrome, which is associated with the milk fat. The character and breed of the cow, as well as the food fed to the cow, affect the color of milk. Tests based on the color of milk are not reliable.

The opacity of milk is due to the fat globules and to the casein. Fat in the form of small globules will retard more light than will the large ones. This fact, together with the fact that the casein is not all in solution, renders optical milk tests of very little use.

- The odor of milk is due to a volatile oil, which is more pronounced in some samples than in others.

Gases, composed of air, carbonic acid, ammonia, oxygen, and nitrogen are found in milk, especially soon after milking, hence samples for testing should not be taken within an hour after milking, or the results will be too low. 
The boiling point of milk is slightly higher than that of water, and it freezes at a slightly lower temperature. Boiling imparts a cooked flavor to milk. When frozen the richer portions are usually in the unfrozen part. This is not so if a thick cream forms on the milk before freezing takes place.

Milk is at its maximum density at a fraction of a degree above freezing point. The expansion and contraction of milk does not occur at the same rate at all temperatures. When heated, milk becomes less viscous, will flow faster, and the cream will separate more readily.

Its power to absorb heat is less than that of water. Electric currents, so far as known, have little effect on milk. The souring of milk during thunder-storms is not due to the excess of electricity, but to the fact that atmospheric conditions are favorable at this time for the growth of the lactic acid germs which cause souring. 
CHAPTER VII.

\section{TESTING MILK.}

MILK varies considerably in its physical and chemical composition, hence the need for testing it. Milk should be examined first with reference to its color, smell, and taste-test with the eye, the nose, and the tongue. If the color be abnormal, the smell objectionable, or the taste sour or otherwise unpleasant, such milk should not be used in the dairy.

Among the common testing instruments which have been, or are, in use in the dairy, are:

I. The Thermometer, which is an instrument for testing temperatures. A reliable thermometer, preferably made of glass, should be found in every dairy.

2. The Lactometer is used for testing the specific gravity of milk. This should have a thermometer in connection. What is known as Quevenne's is the one most commonly used. It, gives the difference between the specific gravity of milk and water in thousandths. The milk should be at a temperature of about 60 degrees. Between 50 and 60 degrees, one-tenth of a degree should be subtracted from the lactometer reading for each degree in temperature below 60 degrees; e. $g$., when lactometer reading is 
30 at 56 degrees, the correct reading would be 29.6 at 60 degrees.

Between 60 and 70 degrees, one-tenth should be added for every degree above 60 degrees; e. $g$., when lactometer reading is 30 at 66 degrees, the correct reading would be 30.6 at 60 degrees. The reading should be taken as soon

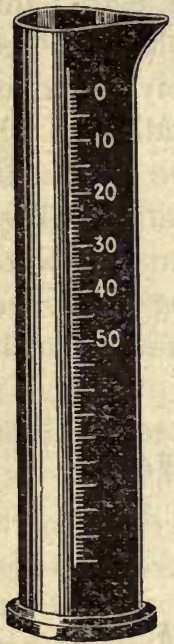

CREAMOMETER. as possible after placing the lactometer in the milk. It is not necessary to read closer than onehalf a degree, or half way between two lines of the scale.

3. The Creamometer, Lactoscope, Lactobutyrometer, Lactocrite, and Pioskop, may be regarded as obsolete tests, along with several others which preceded the Babcock test, for fat. A popular milk test must be accurate, cheap, durable, rapid, safe, and simple. The Gerber in Europe and the Babcock in America combine most of these qualities. The Gerber is used to a very limited extent

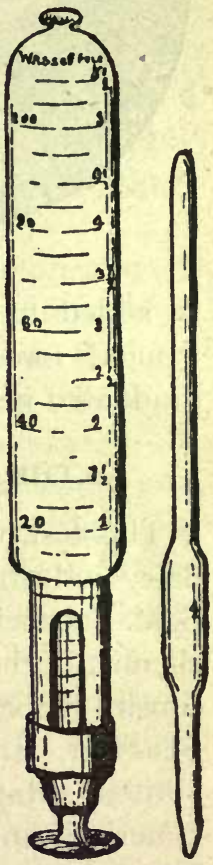

LACTO- PIPSCOPE. ETTE. in Canada; hence we shall speak in detail only of the Babcock. Both tests depend upon chemicals to dissolve the caseous matter surround- 


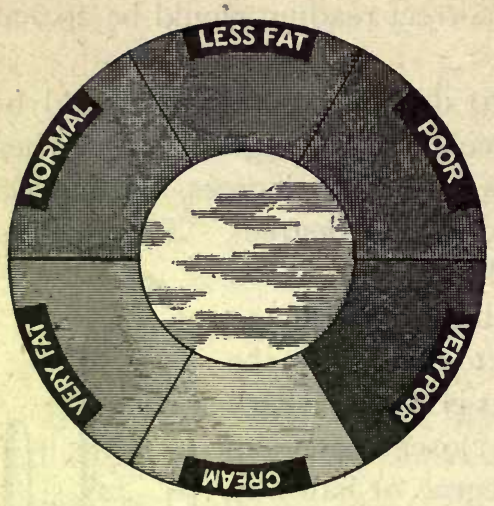

PIOSKOP.

ing the fat globules, and use centrifugal force to cause a further and more complete separation of the fat. In the Gerber test two chemicals (sulphuric acid and amyl alcohol) are used. In the Babcock test sulphuric acid only is used, but hot water is added to the sample, after subjecting it to centrifugal force, in order to float the fat into the graduated neck of the bottle.

\section{THE BABCOCK-TEST FOR MILK-FAT.}

This test, which has been of great service to the dairy industry of Canada, was discovered by Dr. S. M. Babcock, chief chemist of the Wisconsin Experiment Station, in the United States of America, and was first given to the public in July, I 890.

The materials required for making a test ${ }^{\mathrm{r}}$ are, a properly

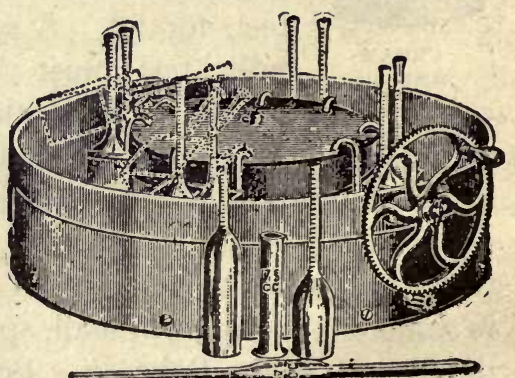

BABCOCK TESTER. 
graduated bottle, a 17.6 c.c. (cubic centimetres) pipette, a 17.5 c.c. acid measure, commercial sulphuric acid, a centrifugal machine, and hot water.

The bottles should be made of heavy glass and should hold about 40 c.c. The neck of the bottle is graduated into ten large spaces, each of which represents one per cent. Each large space is divided into five smaller ones, representing two-tenths of one per cent. each. The volume of the graduated space should be 2 c.c. The bottles should be numbered, preferably by etching on the glass, and it is advisable to have the bottles numbered consecutively.

The pipette should have a rather wide opening at the lower end for rapid delivery, and should be small enough in the lower part to drop readily into the neck of the bottle and allow room for the air to escape as the milk flows in. The 17.6 c.c. mark, for ease in filling, should be four or five inches from the upper end.

The acid measure should have a good-sized base, a lip on one side for pouring, and a plain mark on the side showing the proper quantity to use, viz., I 7.5 c.c.

The sulphuric acid should have a specific gravity of 1.82 to 1.83 . This should be kept in a tightly stoppered bottle, and in a safe place. Great care should be taken in handling this acid, as it is very corrosive. If spilled on the hands or face, it should be washed off at once with plenty of water. Ammonia will restore the color on clothing which is not burned with the acid.

The centrifugal machine should be from twelve to 
twenty inches in diameter, and should revolve at the rate of eight hundred to twelve hundred revolutions per minute. A smooth running cog-gear is preferable to any belt or friction gearing. For factory use, a steam turbine machine is best. No really good hand Babcock machine has yet been put upon the market in Canada.

The hot water for filling the bottles should be at a temperature of 140 to 160 degrees, the latter temperature when working in a cool room with a hand machine.

\section{MAKING THE TEST.}

The sample to be tested must be thoroughly mixed by pouring from one vessel to another four or five times, so as to have the cream well distributed through the milk. If the sample be taken from a cow, all the milk she gives should be put into a pail, and the sample taken from that. It is useless to take the first milk, the middle milk, or the last milk.

After mixing, measure the sample by placing the large end of the pipette in the mouth and drawing the milk above the mark. Then place the ball of the right forefinger over the top of the milk, before it drops below the mark, and tip the finger slightly so as to allow the milk to run out slowly. When it reaches the mark cover the end of the pipette with the finger and place the lower end of it in the bottle. Then remove the finger and allow the milk to run in slowly, so as to permit the air to escape. If the pipette be large the bottle should be placed in a slanting position, with only the end of the pipette in the mouth of the bottle. 
Blow the milk which remains on the inside of the pipette into the bottle. Next, measure the acid, and pour it carefully into the sample, holding the bottle in a slanting position, that the acid may run along the side of the bottle and under the milk-not through it. Mix the acid and the milk by a rotary motion, being careful not to get any curdy matter in the neck of the bottle. When the curd is all dissolved, and the contents are a dark brown color, caused by the burning of the milk sugar and other compounds of the milk, the sample or samples may be placed in the pockets of the machine. It is very important to have an even number of bottles in the machine, and to have them properly balanced. Whirl the samples at full speed for about five minutes, then add the hot water with a pipette, or from a small can having an outlet at the bottom to which is attached a small hose, closed at the lower end with a pinch-cock. A small piece of glass-tubing, drawn to a point and inserted in the rubber, is convenient for filling. Fill the botttles to the eight or ten per cent. mark. Be careful not to run the fat over the top of the bottle, and have sufficient water to float the fat into the scale when it is read.

When troubled with cloudy readings it is advisable to add the water at two different times, instead of all at once. After adding the water, whirl the samples again for two minutes, when the readings may be made. If testing many samples, especially in a cold room, it is advisable to remove them from the machine to a dish of hot water at a temperature of about I 40 degrees. 
Read from the "highest to the lowest limits of the fat." Hold the bottle in a perpendicular position, and have the fat on a level with the eye. Calipers are useful for accurate readings.

Empty the bottles as soon as possible after reading, and before the fat becomes cold. Rinse them twice with hot water, when they are ready for use again. If the bottles become greasy, rinse with a hot solution of soda.

For testing skim-milk, buttermilk, or whey, it is customary to use what is known as a "double-neck" bottle having a fine graduation. Use more than the usual amount of acid with cold skim-milk, and slightly less for buttermilk and whey, especially the latter. The first space on these bottles is read as one-tenth of one per cent., and each succeeding space as .05 per cent. Hence, if a sample of skim-milk contains sufficient fat to cover one-half a space, it should be read as .05, and if covering two spaces, as .15 of one per cent. fat.

For testing cream, use an i 8 c.c. pipette, and a special cream bottle graduated to read from 30 to 50 per cent. fat. If no cream bottle is available, measure I 8 c.c. of cream, and add two pipettes of water, mix thoroughly, then measure 18 c.c. of the diluted cream into an ordinary bottle ; use less acid, and proceed as with whole milk. Multiply the reading by three to obtain the percentage of fat. If a 6.04 c.c. pipette is convenient, add one measure of cream and two of water to an ordinary Babcock bottle, and proceed as before. More accurate results are obtained by 
weighing the cream on scales, but this is hardly necessary in ordinary work on the farm or at the creamery.

To test cheese, it is necessary to weigh from four to six grams of the sample and place carefully in a Babcock bottle, preferably a cream bottle. Then add I 2 to I 5 c.c. of hot water, and shake thoroughly until the cheese is nearly all dissolved. Then add the sulphuric acid, and proceed as in testing milk. If six grams be taken, the percentage of fat is got by multiplying the reading by three. If four or five grams are taken the percentage of fat equals $\frac{\text { Reading } \times 18}{\text { No. of gramstaken, }}$ e.g., four grams of cheese give a reading of 8.8 . The per cent. fat $=\frac{8.8 \times 18}{4}=39.6$.

\section{SPECIAL POINTS.}

Accuracy is necessary in all parts of the work, else it is without value.

Burnt readings are usually caused by too strong acid, by allowing the acid to fall through the milk, by allowing the sample to stand too long after adding the acid, or by having the milk or acid at too high a temperature-60 to 70 degrees is favorable.

Curdy matter in the fat is usually caused by the acid being too weak, the milk, or acid too cold, or through improper mixing of the milk and acid.

Churned samples should be heated to about i ro degrees $F$., then be mixed and sampled quickly while the liquid fat is mixed with the serum.

Partly frozen milk should not be sampled, if it can be avoided, until the frozen part is melted and mixed with the liquid. 
Sour milk which has thickened may be rendered liquid by adding an alkali, such as concentrated lye, in small quantities, and mixing them until the curd is dissolved.

\section{THEORY OF THE BABCOCK TEST.}

A 17.6 c.c. pipette delivers about 17.5 c.c. of milk into a Babcock bottle. This quantity of milk, will weigh about 18 grams ( $17.5 \times 1.032$ the av. sp. gr. of milk). The volume of the graduated neck of the bottle is 2 c.c. The average specific gravity of milk fat is about .9, therefore 2 c.c. fat will weigh $\mathrm{I} .8 \mathrm{grams}$ $(2 \times .9=1.8)$. A sample of milk which contains sufficient fat to fill the graduated neck of the bottle from $O$ to $\mathrm{IO}$ is read as IO per cent. fat, because $\mathrm{I} .8$, the weight of the fat, is IO per cent. of I8, the weight of milk used in making the test. If the volume of fat fills five spaces on the neck of the bottle, it is read as five per cent., because its weight is about .9 of a gram, - which is 5 per cent. of $\mathrm{I} 8(5 / \mathrm{I} .00$ of $\mathrm{I} 8=.9)$, and so for all the readings. The Babcock test is based on average weights of milk and fat. The milk and fat are not weighed, but measured, . because it is more conventent to measure than to weigh. Any errors arising from a difference in the specific gravity of milk are so slight as not to materially affect the test, if care be taken to do the work properly.

\section{WATERING AND SKIMMING MILK.}

By the use of the lactometer and the Babcock tester, a skilful person can detect samples which have 
been adulterated by watering or skimming. The following are general rules :

A low lactometer reading (under 28) combined with a low percentage of fat (under $3 \%$ ) indicates watering of milk.

A high lactometer reading (above 36 ) combined with a low percentage of fat indicates skimming of milk.

A normal lactometer reading (30 to 32 ) combined with a very low per cent. of fat (under $2 \%$ ) indicates both skimming and watering.

\section{CALCULATING SOLIDS NOT FAT FROM LACTOM. ETER AND FAT READINGS.}

A simple formula, recommended by Babcock, is as follows : To the lactometer reading at 60 degrees add the percentage of fat and divide by four. Briefly, it is $\frac{\text { L. R. at } 60^{\circ}+\% \text { fat }}{4}=\%$ S. N. F.

Sometimes the following is recommended: $1 / 4 \mathrm{~L} . \mathrm{R}$. +.2 fat $=\%$ S.N.F.

The total solids of milk are made up of the solids fat and the solids not fat. The normal percentage of water in a sample of milk may be got by subtracting the percentage of total solids from 100.

\section{USES OF THE BABCOCK TESTER.}

I. To determine the relative value of cows in the herd.

2. To determine the relative value of milks for butter and cheese making. 
3. To detect losses of fat in the manufacture of butter and cheese.

4. In conjunction with the lactometer, to detect adulteration of milk by skimming or watering. And also, by the use of a formula, it enables the operator to calculate approximately the percentage of solids in milk. 


\section{CHAPTER VIII.}

\section{CARING FOR MILK ON THE FARM.}

THE cows should be healthy and clean. Colostrum (Beistings) should not be sent to the factory. The stable and pasture should be clean, dry, and free from bad odors and bad-smelling weeds. The food should be clean, pure, sweet, and wholesome. Cows giving milk should not be allowed to eat brewers' grains, distillery slops, turnips or tops, rape, mouldy meal, spoiled hay or spoiled silage, cleanings from the horse-stable, or anything which would tend to taint the milk.

Either rock or common salt should be accessible to the cows at all times. Plenty of pure water ought to be within easy reach of milking cows. Foul, stagnant, or very cold water are injurious.

Cows should be milked with clean, dry hands, after wiping the teats and udder with a damp cloth. The milk should be strained at once after milking through a fine wire strainer, and also through two or three thicknesses of cheese cotton. The strainer needs special care in keeping it clean. The pails and can must also be clean. The milk should be removed from the stable or milking yard as soon as possible after milking. It should be cooled at once to a temperature 
of 60 degrees, certainly below 70 degrees, by setting the cans in tanks of cold water, and by stirring the milk in order to facilitate cooling rapidly. Where a supply of cold water, under pressure, is available, one of the many forms of coolers will do the work more quickly, but it is very necessary that the air be pure where this form of cooling is adopted. After the milk is cooled to 60 degrees-and where Saturday night's and Sunday morning's milk is to be kept over until Monday morning, the cooling should be so low as 50 degrees in the hot weather-the cans may be covered with the lid or with a piece of damp, clean cotton. By leaving one end of the cotton in the water, evaporation will tend to keep the milk much cooler. Night's and morning's milk should be kept separate as long as possible.

If the milk be placed on a milkstand for some time before it starts to the factory, the stand should be covered and boarded in on the sides, and the whole neatly painted a white color. Milk should be protected from the rays of the sun, from dust, and from rain-water.

If possible, the cans should be covered with a canvas cover while on the way to the factory, especially in hot, dusty weather. It is needless to say that the waggon, the man, the horses, and the harness should be clean, and a credit to the great Dairy Industry of Canada.

Where practicable, the cans which are not used for returning skim-milk should be washed and steamed at the creamery or cheesery as soon as possible after 
being emptied. Sour whey or buttermilk should not be put in cans, as the acid destroys the tin and causes the cans to rust. Rusty cans cause bad flavors in the milk. It is safer not to return whey in the milk can. A separate vessel should be used for this purpose, if the whey must be returned to the farm. If the whey must be returned in the milk can, it should be emptied at once on its arrival at the farm, and the can thoroughly washed and aired in the sunshine before milk is put into it again. The whey tank must also be kept clean.

The two main points in caring for milk are to have everything clean, and to cool (especially the night's milk) as rapidly as possible to a temperature below 70 degrees, and to 50 or 60 degrees if possible. 


\section{CHAPTER IX.}

\section{THE FARM DAIRY.}

THE tendency in some districts is to manufacture dairy products on the farm rather than send the milk or cream to a factory. This plan may be adopted where there is plenty of help on the farm, when not convenient to a cheesery or creamery, when there is a sufficient number of cows to make it profitable, where a good dairy, properly equipped, is provided, where someone on the farm knows how to make firstclass butter or cheese, and where a good market is available. To make ordinary or inferior dairy goods on the farm is a waste of time, money, and valuable food material. Fortunes are lost every year in Canada through the making of poor dairy butter.

In order to make the work pleasant and profitable, a suitable dairy should be provided, and it should be well equipped with modern utensils. The location should be convenient to house and barn, with an abundant supply of good water. The work-room should contain 200 to 300 square feet, and have a ceiling io to 12 feet high. A refrigerator and icehouse, the latter of about 50 to 75 tons capacity, should be convenient to or connected with the dairy proper, and preferably situated on the north side of 
the dairy. Good drainage should be provided to remove all waste water to a convenient distance. The material for the dairy may be cement, brick, stone, or wood. The walls should be made so that the inside temperature can be controlled. This is best done by having hollow spaces in the walls. Hollow cement blocks, hollow bricks, or still air spaces got by the use of lumber and building paper, are all good for this purpose. The floor may be made of cement, or pine wood, and should slope

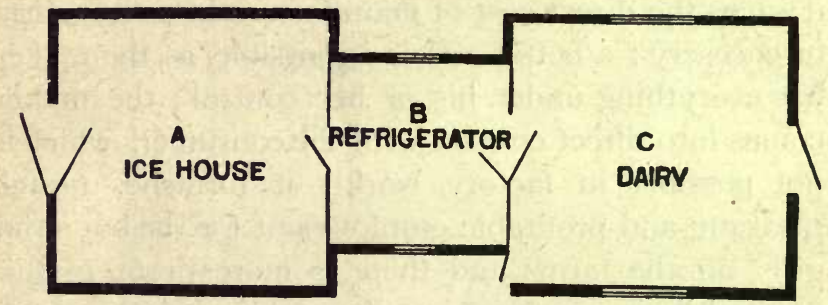

GROUND PLAN FOR FARM DAIRY, REFRIGERATOR AND ICE-HOUSE COMBINED.

about one inch in six feet to a gutter for ease in cleaning. The wooden floor should be made of wellselected matched lumber $1 \mathrm{x} / 2$ inches thick, having the joints put together with white lead. The surface should be treated with two or three coats of hot linseed oil (8 parts), turpentine (I part), and dryer (I part), applied with a brush and well rubbed into the wood. This dressing should be applied to the floor at least once a year to preserve it and make it easy to clean. 
The utensils for a farm dairy, including a cream separator but no power, will cost about $\$ 200$. If cheese is made, a steam boiler is very convenient. It is useful for making hot water, so essential in a dairy. It may also be used for heating the dairy in winter. Dairy utensils should be first rinsed in cold water, then be washed with a brush in hot water, then be steamed or scalded, and tinware, cloths, etc., may be put out in the sun. Wooden-ware should not be put in the sun, as it cracks or warps them.

The chief advantages of private dairying are: That it saves the direct cost of manufacture in a creamery or cheesery ; a better article is possible, as the maker has everything under his or her control; the maker comes into direct contact with the consumer, which is not possible in factory work; it furnishes useful, pleasant, and profitable employment for the boys and girls on the farm; and there is more profit in this method if circumstances are favorable and the dairy is well managed.

The disadvantages are: The lack of suitable labor on many farms; a lack of proper dairy ánd utensils, which compels the farmer's wife to make butter in the kitchen or down cellar, with the crudest utensils and under the most discouraging circumstances; and the difficulty of getting a proper market, as many private dairymen have to sell their goods at country stores or nearby towns, where no discrimination is made in price in favor of good quality. The trading of dairy goods for dry goods and groceries is one of the greatest hindrances to the development of dairying in Canada, as 
it places little or no premium upon brains and skill, which are necessary factors in the making of a fine quality of dairy goods.

The yield of butter per IOo lbs. of milk and the price per pound of butter are usually greater at a creamery than in the average farm dairy. Either of these increases will usually pay the cost of manufacturing, and the farmer's wife is saved the labor and worry of making butter on the farm. 


\section{CHAPTER $\mathrm{X}$.}

\section{CREAMING MILK AT THE FARM.}

THE cream, which contains a large portion of the fat of milk, is lighter, or is of less specific gravity, than the serum or skim-milk, hence it tends to separate from the heavier part. This separation, however, does not take place unless force be applied. The two forces made use of in creaming are gravity and centrifugalthe former in the case of milk set in pans or cans for the cream to rise; the latter in the case of centrifuges, or cream separators. Both forces are natural and have been in existence throughout all time, but only the force of gravity was made use of for creaming milk up to about 1876 . The force of gravity is obtained free of cost, hence the reason for its having been used so long before centrifugal force, and also a reason for its continued use by many. Gravity acts in a downward direction upon the heavier skim-milk, while centrifugal force causes the skim-milk to travel in an outward direction in the bowl of the centrifuge. We have also centripetal force, causing the cream to seek the centre of the centrifuge or separator-bowl. The skim-milk travels in the same direction as the centrifugal and gravity forces are acting, while the cream travels in an opposite direction 
In addition to the forces which cause creaming of milk, other factors influence the completeness of the separation. Chief of these are, the viscosity of the milk, currents in gravity methods, the length of time during which the milk is subject to creaming force, the size of the fat globules in the milk, the temperature of the milk during the separation, the volume of the milk subjected to the action of the creaming forces and the special construction of the pan, can, or machine in which the creaming takes place.

Briefly, these factors influence creaming as follows : The more viscous or sticky the milk, the more difficult it is to cream. Currents in gravity creaming should be of short duration. This is accomplished by cooling all the milk in a pan or can to a uniformly low temperature, as rapidly as possible.

The longer the time during which milk is subjected to creaming forces, the more completely is the cream separated, although there is a limit to the time which may be used economically.

The larger the size of the fat globules in the milk, the more easily and completely may the cream be extracted.

The warmer the milk, up to at least 160 degrees for the centrifuge, unless it be fresh from the cow, the more favorable are the conditions for creaming; but, in the case of gravity creaming, where separation takes place somewhat slowly, it is necessary in practice to cool the milk in order to prevent souring. So far as the creaming of milk is concerned, a higher temperature is more favorable, chiefly because the milk is less viscous. 
The less the volume of milk subjected to creaming force in a given time, the more favorable is the condition for separating the cream. Hence it is not advisable to have cans or pans too large; nor should too much milk be crowded into the bowl of the centrifuge, if we wish thorough creaming.

The inside of the pan, can, or centrifuge should be as smooth as possible, and should be so constructed that all parts may be readily cleaned, as these conditions favor complete separation of the cream from the milk. Special contrivances on the inside of the bowl in the form of discs, plates, etc., also favor "close skimming."

\section{METHODS OF CREAMING.}

The most common methods of creaming milk are by the use of small, shallow pans, deep cans, and the more modern centrifugal cream separator. Which method is best to adopt will depend upon circumstances. When deciding this matter it will be well to consider the effect upon the quality of cream, butter, and skim-milk ; the loss of fat sustained in the skimmilk and buttermilk; the labor and expense involved in first cost and in operating the method; the number of cows in the herd at present, and also the number which a prospective purchaser is likely to have in the future. In general, the method to adopt is the one which will produce the best quality of products with the least loss of fat, and with the smallest expenditure of labor and money for the results obtained.

Shallow Pan Creaming.- To get the best results with shallow pans, they should be made of pressed tin 
or good granite-ware, and should not be more than four inches deep and twelve inches in diameter. The milk should be strained into the pans as soon as possible after milking, and then be allowed to stand perfectly still in a pure air, free from draughts, at a temperature of about 50 to 60 degrees, for twentyfour to forty-eight hours.

Milk set in shallow pans at the Ontario Agricultural College, and skimmed at 56 degrees, contained an average of .38 per cent. fat in the skim-milk, while similar milk, cooled to 46 degrees, at skimming contained .28 per cent. fat in the skim-milk. A lower temperature than is commonly supposed to be advisable may be used for shallow pan creaming.

The cream should be removed while sweet by first loosening the cream around the edge of the pan with a thin-bladed knife; then glide the cream carefully over the edge of the pan, first wetting it with some skim-milk to prevent the cream sticking to the pan, being careful not to take any more skim-milk than is necessary, as it dilutes the cream and makes it more difficult to churn, besides giving more bulk to handle. The perforated skimmer should not be used, as it wastes cream. If the windows are open in the room where the cream is set in pans, a draught should not blow over the milk, as this causes a tough leathery cream, difficult to churn, and sometimes causes "white specks" in the butter. The windows should have fine screens to keep out dust and insects. The pans should be thoroughly washed after each time of using, and if possible they should be placed outside in the fresh air and sunshine before filling again with milk. 
This method may be adopted where only one or two cows are kept and a good clean, well-ventilated cellar or other cool room is available for summer, and a clean place where the milk will not freeze may be got in the winter. It may also be used where neither ice nor cold water are available for deep setting, and in preference to deep setting with " stripper" cows' milk, or other milk which is difficult to cream.

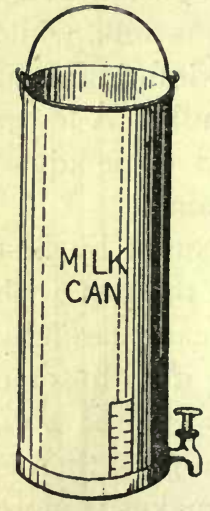

CAN FOR DEEPSETTING OF MILK.

The chief objections to shallow' pan creaming are the great danger of having the cream tainted from impure surroundings, the loss of fat in the skim-milk, the loss from the skim: milk and cream being sour in hot weather, and the large amount of space and labor required with a herd of ten or more cows.

Deep-Setting Methods.-Cans for creaming milk by deep-setting are of two general classes - those which are submerged in cold water, and those which are surrounded with cold water. The Cooley can is a good example of submerging ; and the common "shot-gun " can, of those set in water. Some cans are skimmed by removing the cream from the top with a cone-shaped dipper, which is first wet in skim-milk or water. Some have a tap at the bottom of the can through which the skim-milk is first drawn, and afterwards the cream is emptied from the can. Some cans are stationary in a cabinet or box, while others are 
movable. The former save labor, but are more difficult to clean, and are more likely to become rusty so that they leak.

Cold water, at a temperature of 40 to 45 degrees, a suitable tank to hold the cans and water, can six to eight inches in diameter and fourteen to twenty inches deep, are the chief requisites for good results in deep-setting. Soon after milking the milk should be set in the cans for twelve to thirty-six hours. It is immaterial whether cans are covered or not when first set in the water, if the milk is pure and clean flavored, and if there be no dust or insects to get into the milk. As a rule, it is better to cover the cans at once. This, of course, is necessary in the case of cans submerged.

The cream should be carefully removed, taking as little skim-milk as possible, before the milk sours. Souring is not likely to occur inside of

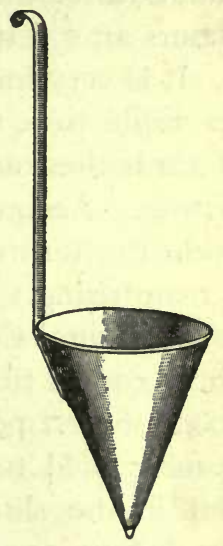

CONE-SHAPED SKIMMER. thirty-six hours if there be ice in the water at all times, which should be the rule in hot weather. Fresh cows' milk will cream quite well in twelve hours in summer; while the milk from cows advanced in lactation and cows on dry feed in winter requires a longer time-twenty-four to thirty-six hours-for the cream to separate.

The colder the water in which the milk is set, so long as freezing does not take place, the thinner (less 
fat) the cream in a given time, but the greater will be the volume. The longer the time the cream remains on the milk, after the first twelve hours, the less the volume of cream, but it will be richer, i.e., contain more fat. The shrinkage in volume of cream on a can of milk $81 / 2$-inches in diameter and 20 inches deep, is about one-eighth of an inch for each twelve hours, after the first twelve hours, up to forty-eight hours after setting.

It is very important to cool the milk as rapidly as possible to a temperature below 45 degrees, as this retards the souring of the milk and so hinders cream rising. According to Babcock, it also tends to prevent the formation of lacto-fibrin, which hinders the cream rising. Experiments conducted at the Ontario Agricultural College gave results as follows : Cans of milk cooled to an average temperature of $4 \mathbf{I}$ degrees contained .2 per cent. fat in the skim-milk. Similar cans cooled to 47 degrees gave a loss of 3 per cent. fat in the skim-milk; while lots of the same milk cooled to 52 degrees contained .7 per cent. fat, or over three-quarters of a pound of butter in one hundred pounds of skim-milk. These results show very forcibly the need of cooling to below 45 degrees in order to recover most of the fat or cream.

While experiments indicate a slightly greater loss of fat in the skim-milk by delaying the setting of milk from one-half to one hour after milking, the difference is not sufficient to cause any anxiety in case the setting is delayed a short time through pressure of other work. The rule is-set at once if possible. 
There is no advantage in heating milk before setting it in winter; nor does it pay to add either hot or cold water to the milk in order to improve its creaming quality. "Dilution separators," so-called, are a "fake."

The first pint of skim-milk drawn from the bottom of deep cans contained an average of .26 per cent. fat, while the last drawn pint, i.e., the skim-milk next to the cream line, contained an average of .34 per cent. fat. In some cases it was as high as .7 per cent. fat. If very little loss of fat in the skim-milk is desired, it is not advisable to draw the skim-milk too close to the cream. The disadvantage of leaving some skimmilk next to the cream is that it dilutes the cream, making it more bulky and more difficult to churn.

The average of three years' experiments at the Ontario Agricultural College, in which about 4,000 pounds of milk, testing an average of 3.66 per cent. fat, were creamed by each method, the shallow pan skim-milk contained an average of .3 I per cent. fat; the skim-milk from deep-setting methods contained an average of .29 per cent. fat; and the separator milk contained an average of .09 per cent. fat. This is probably the relative losses of fat in the skim-milk from these three methods of creaming under good conditions, though the very latest centrifuges may reduce slightly the loss of fat in separator skim-milk.

The chief advantages of deep-setting over shallow pans are the less space and labor required, and the improved quality of cream, butter, and skim-milk under average conditions. 
Devonshire, or "clotted" cream, may be made by setting milk in shallow pans for about twelve hours; then heat the pan of milk and cream to a temperature

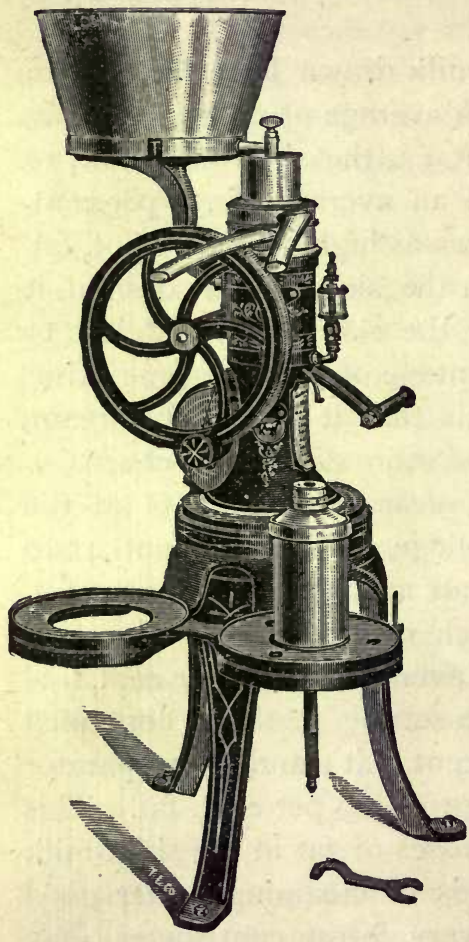

NATIONAL CREAM SEPARATOR. (Made in Canada.) of about I 70 degrees; then cool to 40 or 50 degrees, and allow to stand for another twelve hours, when the cream may be removed for use.

The Hand Centrifuge. - No machine is receiving so much attention among farm dairymen as the hand centrifuge or hand separator. It has been a great help to farmers who make butter on the farm or who sell cream. It also gives a better quality of skim-milk for young stock than that returned from the average creamery.

The essential part of the machine is the bowl. In this part the separation of the cream takes place through the action of centrifugal and centripetal forces produced by the rapidly revolving bowl. The force generated depends upon the diameter of the 
bowl and the speed at which it travels. The general rule is that the centrifugal force increases in the same proportion as the diameter of the bowl is increased, speed remaining constant. In other words, if the

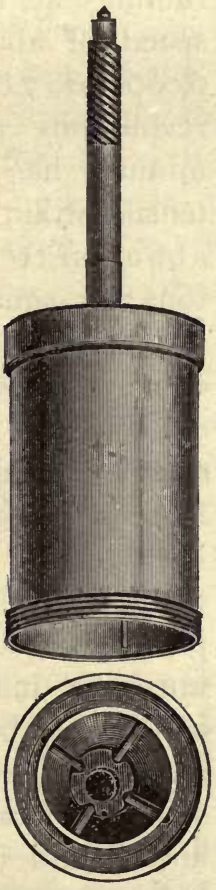

BOWL OF NATIONAL SEPARATOR.
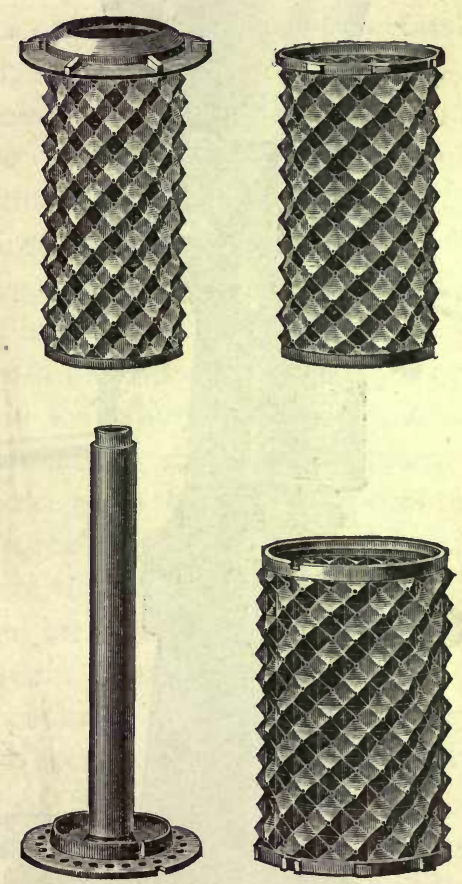

INSIDE DEVICES OF NATIONAL SEPARATOR.

diameter of a separator bowl be doubled, the centrifugal force is doubled, and its capacity to cream milk is doubled. On the other hand, if the diameter of the bowl remains constant, and the speed is doubled, the 
centrifugal force is increased four times, as centrifugal force increases as the square of the speed of the bowl.

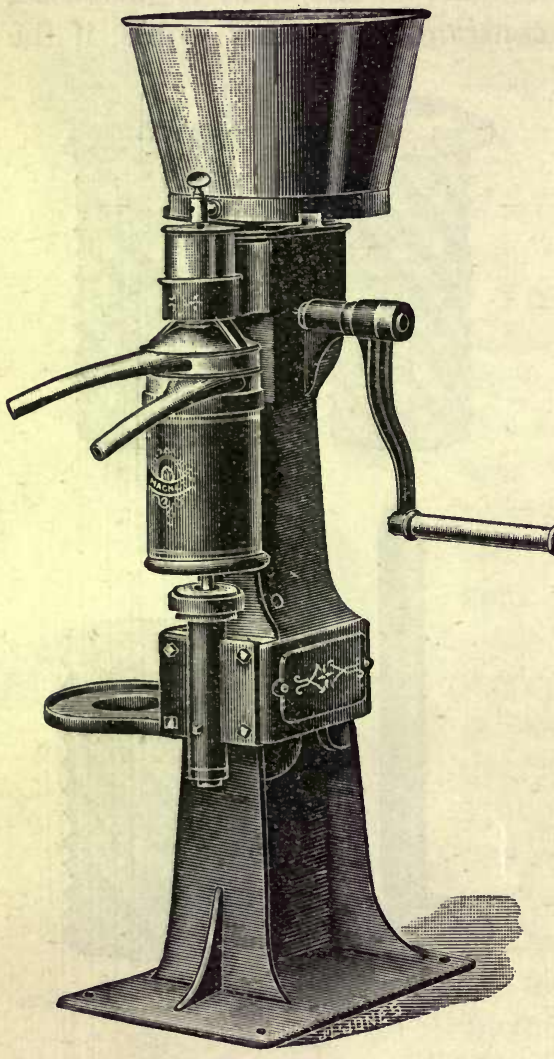

MAGNET CREAM SEPARATOR.

(Made in Canada.)

An ordinary hand separator running at full speed of about 6,000 to 7,000 revolutions per minute has a tensile strain of about sixteen tons per square inch, i.e., a force equal to about sixteen tons on every square inch of surface is tending to tear the bowl in pieces; hence it must be made of the very best steel to withstand the strain, and should not be run at a speed much above that recommended by the manufacturer.

There are two general types of separator bowlsthose which are hollow, and those having plates or 
other contrivances on the inside to facilitate separation of the cream. Hollow bowls, as a rule, are more easily cleaned, but do not, generally speaking, produce so complete a separation of the cream from the milk, unless run at a very high speed.

When purchasing a centrifuge, it is well to consider the size of the herd, the price and capacity of the separator, the closeness of skimming, the smoothness of the cream, the ease of cleaning, the power required to operate it, the durability of the machine, the amo:ınt of oil required, and the convenience of repairs. The best separator is the one which will cream the most milk in a given time, with the least loss of fat in the skim-milk and with the least expenditure in first cost and for labor and repairs, and at the same time will produce a satisfactory cream. A good centrifuge should skim to less than one-tenth of one per cent. fat in the skim-milk, and at the same time produce a cream which will test not less than twenty-five per cent. fat. Separator manufacturers like to take a thin cream, because it pleases the purchaser to see a large volume of cream from a small quantity. of milk, and because this condition is favorable for a small loss of fat in the skim-milk. Such cream is difficult to churn, is too bulky, and if sent to a creamery it is too expensive to haul and handle at the creamery; and at the same time it robs the farmer of valuable skim-milk. As a rule a separator should be adjusted to take not more than ten or twelve pounds of cream from one hundred pounds ot milk. 
The chief advantages of centrifugal creaming are : almost complete separation of fat from the skim-milk, . a better quality of cream, butter, and skim-milk, a saving of ice and labor, and a cleansing of the skimmilk and cream through the action of centrifugal force, which causes a deposit of slime or mud on the inside of the separator bowl, consisting of albuminous matter, dirt, and also to some extent disease or other harmful germs if they be present. This slime should be carefully removed from the bowl and be burnt at once. Never allow this to dry and be blown about the farm, as it may spread disease; neither should it be allowed to go into a drain from the dairy, as it may clog the drain.

The separator may be placed in a room convenient to the stable, but this must be kept clean and well ventilated. It may be put in some room at the house, if no special dairy-room be available. Having the separator at the barn saves the labor of carrying the milk to the house and the skim-milk back to the barn. Where extra labor, or some power such as an engine or a tread power, is available, the creaming may go on at the same time as the milking; and soon after the milking is done the cream will be separated and the skim-milk be ready for calves and pigs. The disadvantage of having the separator at the barn is the lack of hot water for wetting and warming the inside of the bowl and for washing purposes. If located at or near the house, the room and machine are usually kept cleaner, except there be a steam boiler at the barn for making hot water. 


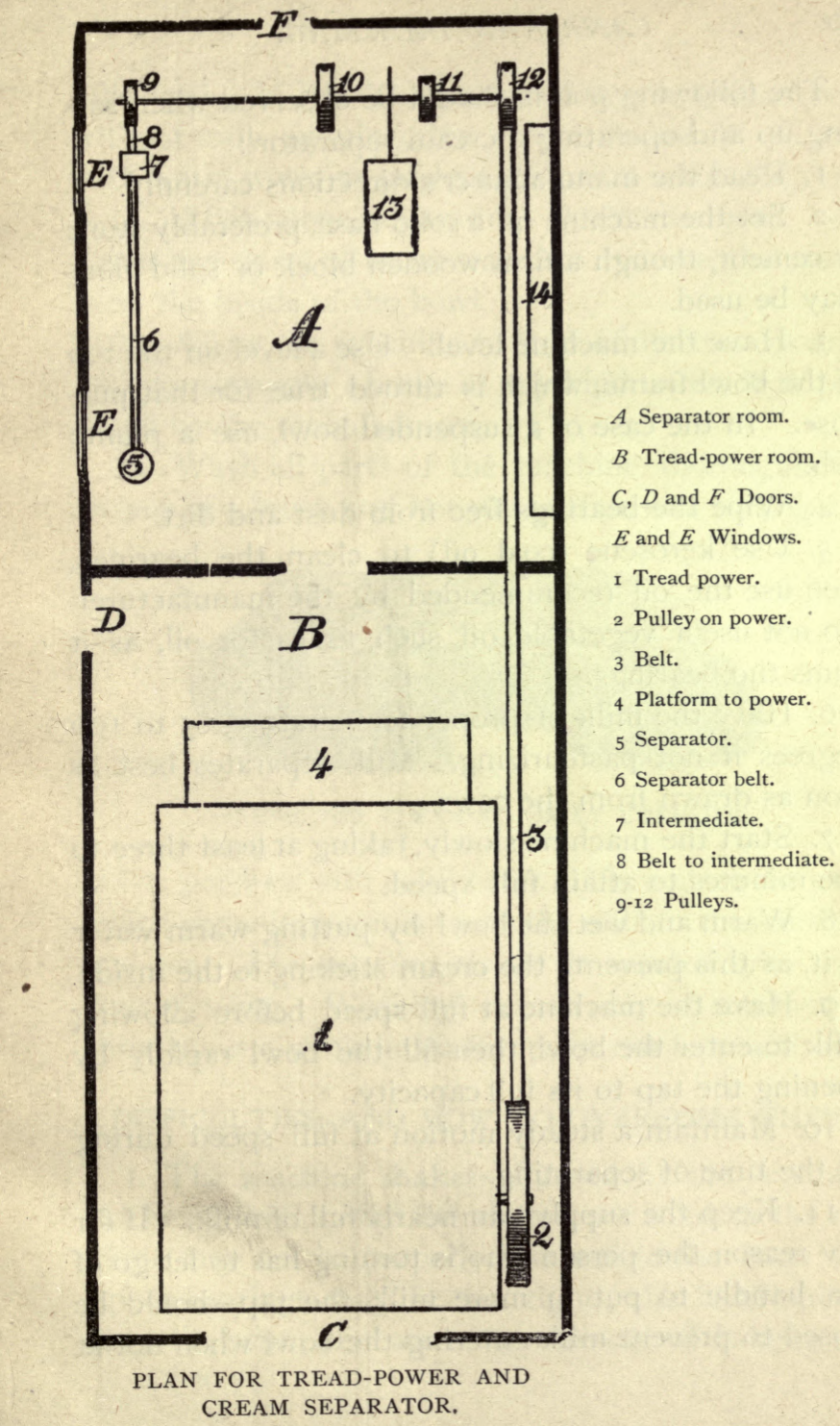


The following points should be observed when setting up and operating a cream separator :

I. Read the manufacturer's directions carefully.

2. Set the machine on a solid base, preferably stone or cement, though a firm wooden block or solid floor may be used.

3. Have the machine level. Use a level on the top of the bowl frame, which is turned true for that purpose. In the case of a suspended bowl, use a plumb bob.

4. Wipe the bearings free from dust and dirt.

5. Use kerosene (coal oil) to clean the bearings, then use the oil recommended by the manufacturer. Do not use a vegetable oil, such $^{\circ}$ as castor oil, as it gums the bearings.

6. Have the milk of proper temperature, 85 to 100 degrees if not pasteurizing. Milk separates best as soon as drawn from the cows.

7. Start the machine slowly, taking at least three to five minutes to attain full speed.

8. Warm and wet the bowl by putting warm water in it, as this prevents the cream sticking to the inside.

9. Have the machine at full speed before allowing milk to enter the bowl, then fill the bowl rapidly by opening the tap to its full capacity.

IO. Maintain a steady motion at full speed during all the time of separating.

I I. Keep the supply can nearly full of milk. If for any reason the person who is turning has to let go of the handle to put in more milk, the tap should be closed to prevent milk entering the bowl when not at 
full speed. If the bowl runs for any length of time without milk entering, the cream should be flushed with warm water to prevent the cream outlet clogging.

I2. When done separating, flush the bowl with about one quart of warm water to remove the cream from the inside of the bowl.

13. Allow the machine to stop of its own accord, and do not apply a brake of any kind unless it is provided by the manufacturer.

I4. Wash all parts of the machine thoroughly by means of a brush and hot water after first rinsing the

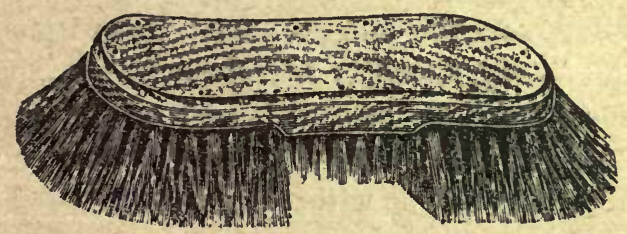

BRUSH FOR CLEANING DAIRY UTENSILS.

milky portions with cold water. Then place the parts which come into contact with the milk in the sunshine and air. The machine should be washed after each time of using. Washing once a day in summer, or three times a week in winter, must not be practised.

\section{DIFFICULTIES, AND HOW TO OVERCOME THEM.}

I. The machine shakes-Caused by the separator not being level, or the foundation not solid, or the machine may not be properly fastened to the floor; the upper bearings may be too tight; the bowl spindle may be bent; the bowl may be out of balance; or 
the milk may have been allowed in the bowl before speed has been reached. The remedies suggest themselves. In case of the spindle being bent or the bowl out of balance, these parts would have to be returned to the manufacturer.

2. The cream too thick-Caused by the feed being too little; the speed may be too great for the feed; the milk may be too cold or too rich for the adjustment; or the cream outlet may be too small. Solong as the cream will flow freely from the cream spout, it is not advisable to change the adjustment or creamscrew, unless in special cases.

3. The cream too thin-Caused by the feed being too large for the speed or adjustment; the speed too low; the outlet may be too large; or the skim-milk tubes may be clogged, which would cause too much skim-milk to pass out with the cream.

4. The separation not complete-May be caused by lack of proper speed; the milk may be too cold; the feed may be too great, especially where the float does not work properly; the machine may be vibrating; the cream outlet may be partially clogged; or the machine may be defective.

5. Milk in the frame may be caused by the covers not fitting properly ; the joint of the bowl may not be tight; or the bowl may be too low for the skim-milk and cream to be properly delivered in the covers.

6. If the machine runs heavily the oil may not be good; the bearings may be gummed, in which case use kerosene oil ; the separator may not be level; the bowl may be out of balance; or the gearing may be defective. 
7. Variation in the percentage of fat in the cream may be caused by a variation in the temperature of the milk or a variation in the percentage of fat in the milk; by the quantity of milk in the supply can ; by irregular speed; by the bowl not being properly cleaned; or by a change in the size of the cream outlet or its relation to the centre of the bowl. Owing to these influences, the cream will vary more or less in the percentage of fat it contains; hence persons using cream separators may not expect to have exactly the same degree of richness or the same percentage of fat in their cream from day to day.

The two chief weaknesses of the hand separator method of creaming milk are, that the machine is often not properly washed after each time of using, and the fact that the cream is not cooled to a temperature below 60 degrees before it is mixed with the cream from previous separations. Warm cream mixed with old cream will spoil the whole product. This is a very important point to bear in mind when handling separator cream. 


\section{CHAPTER XI.}

\section{RIPENING AND CHURNING CREAM- MARKETING DAIRY BUT'TER.}

CREAM may be churned sweet, but the butter lacks flavor and keeping quality. It is also necessary to churn sweet cream at two to four degrees lower temperature than similar cream ripened, taking a longer time to churn in order to churn completely, and not have too great a loss of fat in the buttermilk.

The cream from gravity methods of creaming should be kept sweet and cold until sufficient be collected for a churning, which should be not less than twice a week. In winter, when troubled with bad flavor, the sweet cream should be pasteurized, i.e., heated from 160 to 180 degrees; and when cooled to 70 degrees, add about ten per cent. of a pure culture of good-flavored sour skim-milk or buttermilk, which may be got from a neighbor who makes good butter, or the culture may be purchased. If pasteurization is not practicable, from two to five per cent. of a good culture may be put in the cream as soon as it begins to collect, as this will control the ripening and produce better flavor. It may be necessary to add eight or ten per cent. more culture after warming to 65 degrees, which is a good ripening temperature, 
twenty-four hours before churning. The cream should be well stirred at each addition of fresh cream, using a tin stirrer-never a wooden one.

Cream from the centrifuge should be cooled at once to 50 or 60 degrees, if it is to be held for two or three days. If it is to be churned next day, it should be cooled to 65 or 70 degrees, and have ten to fifteen per cent. of a pure culture added.

For a large quantity of cream a vat is convenient. For a smaller quantity use a can which is light and easily cleaned. Crocks are heavy, easily broken, and are not suitable for producing changes of temperature in the cream. All heating or cooling of cream should be done by surrounding the vessel of cream with cold or warm water, then stirring it until it comes to the desired temperature. Warm or cold water or ice should not be put in the cream, if it can be avoided, as it tends to injure the flavor and grain of the butter.

When the cream commences to thicken it may be gradually cooled to churning

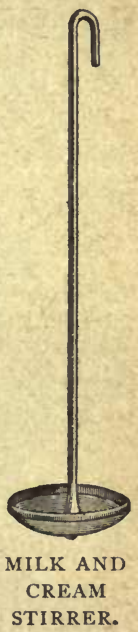
temperature. It is ripe when thick and glossy in appearance, when it smells and tastes slightly sour, when it pours like good molasses, and has .5 to .6 per cent. of acid. The cream for a churning should be mixed in one vessel at least twelve hours before churning, in order to ensure uniform ripening. If lots of cream having different degrees of ripeness be mixed and churned at once, there is too great a loss 
of fat in the buttermilk, as the riper cream churns first.

Churning is the packing together of the fat globules which are concentrated in the cream. The churn should be simple in construction, convenient for getting the cream into it and the butter out, and be easily cleaned. Wood is the best material, because it can be prepared with water so that the cream and butter will not stick to the inside of the churn. Oak, pine, ash, or spruce wood may be used. A barrel churn is the most convenient shape for a small dairy, and a square or oblong box-churn may be used in a larger one. Dairy sizes of combined churns and workers are now on the market, and they save considerable labor. Prepare the churn with hot water, which fills the pores of the wood, then cool it with cold water before adding the cream, unless working in a cold room.

The churning temperature of the cream will depend upon the richness and ripeness of the cream; the size, kind, and temperature of the churn; the temperature of the room; the feed of the cows; and the character of the fat given by the cows. There is no standard temperature for churning cream, as the temperature must be varied according to conditions. Adopt a temperature which will cause the butter to come firm in twenty to thirty minutes for a small churning. If the butter comes too quickly and soft, lower the temperature, i.e., make the cream colder at the next churning. If the time required be much over half an hour, raise the temperature for the next 
churning two to four degrees. Rich separator cream may be churned at from 42 to 52 degrees. Gravity cream requires a temperature of 58 to 65 degrees in summer and 65 to 72 degrees in winter.

Cream should be strained through a coarse strainer into the churn, in order to take out the particles of curd, or dried cream, which would cause white specks in the butter. If butter color be used, it should be added to the cream when in the churn. Use sufficient coloring to give a "June grass" shade to the butter, but do not over-color, as the tendency is to demand a lighter-colored butter in the markets of the world. In case the butter-maker forgets to color the cream, it may be mixed with the salt and added to the butter in this way, thus securing an even shade.

A barrel or box-churn should not be over one-third to one-

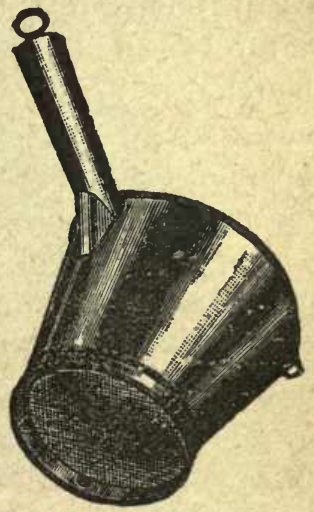

CREAM STRAINER. half full in order to allow the cream to drop in the churn. The speed of the churn should be from fifty to seventy turns to the minute, decreasing the speed as the butter begins to appear. Closed churns need ventilating two or three times during the first ten minutes when churning ripe cream, in order to allow the cream gases and expanded air to escape. When the butter is like grains of clover seed, a dipperful of water may be added to assist separation. In warm 
weather the water should be cold, and in the winter the temperature should be about the same as that of the cream. When the butter is about the size of wheat grains, the churning is completed, and the buttermilk may be drawn through a strainer, or the butter may be dipped from the buttermilk. If using a barrel or box-churn, add about as much water to the butter as there was cream at the beginning, having the temperature from 45 to 50 degrees in summer, and from 50 to 60 degrees in winter, depending upon the temperature of the room and the condition of the butter as to firmness. If the buttermilk does not separate readily with the first washing it may be repeated, using brine if necessary. As a rule one washing is sufficient, unless the butter is to be packed and held for some time. Too much washing destroys the fine flavor of butter. Bad-flavored butter cannot be washed too much. The churn should be revolved as rapidly as possible while washing the butter in order to prevent it forming lumps. Butter in lumps is more difficult to get the buttermilk removed, and is also more trouble to salt evenly.

Difficulty in churning is usually due to one or more of the following causes :

I. The cream may be too cold, too thin, or too thick.

2. The churn may have too much cream in it.

3. The cream may have been kept for too long a time.

4. A farrow (or stripper) cow's milk may be causing the trouble. 
5. The cows may be getting feed which is too dry.

6. The butter-maker may be incompetent, and should take a course at some dairy school.

Fine, dry, easily dissolved, velvety, even-grained, pure salt, at the rate of one-half to one ounce of salt per pound of butter, should be sifted over the granular butter in the churn or on the worker. Light

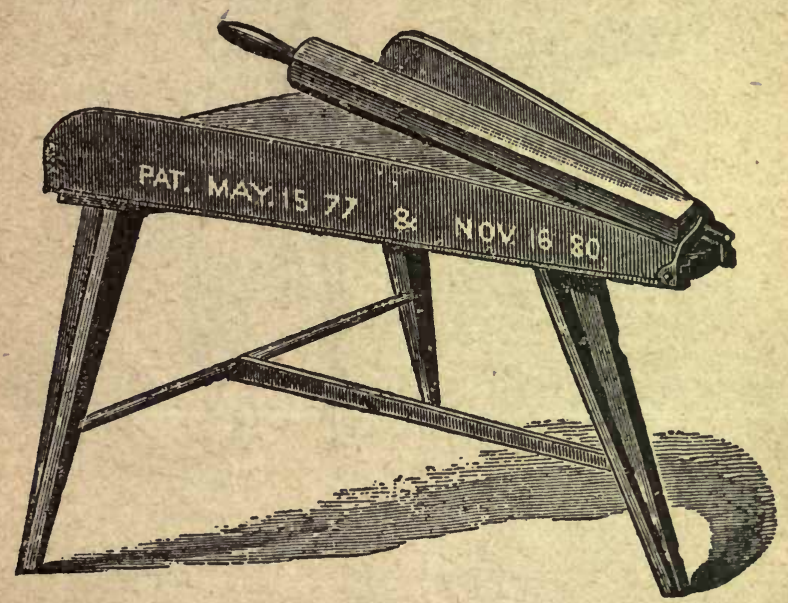

LEVER BUTTER WORKER.

salting may also be done by means of brine. Salting should be done according to the taste of the consumer, but good butter should not be heavily salted, as it tends to destroy its creamy flavor. Poor butter may be salted heavily. Salt also preserves butter; hence a larger amount should be used where the butter is to be packed and held for some time. In all cases the salt should be dissolved in the butter. Allowing the 
salt to stand on the butter in the churn for an hour or two ensures even distribution and even color of the butter.

Butter may be worked once or twice, according to circumstances, but always with a downward pressure. Avoid a sliding or grinding motion, which makes the butter greasy. A lever or roller worker is suitable for

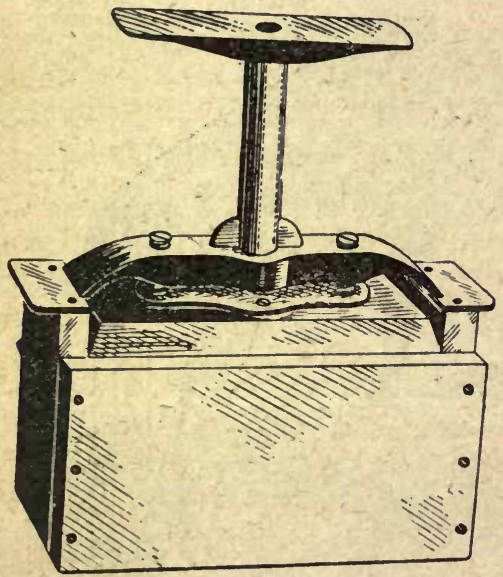

BUTTER PRINTER.

a farm dairy. The object of working butter is to free it from excessive moisture, to remove the buttermilk if

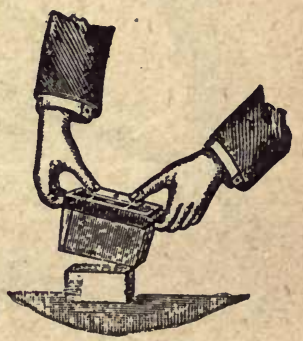

REMOVING THE BUTTER FROM THE PRINTER.

any be present, to mix the salt through the butter, to make it close and compact in body, and to secure a waxy texture. It has been worked sufficiently when close in body, even in color, and free from an excess of water. Avoid over-working, which produces a greasy, salvy, inferior butter.

Butter for immediate consumption in local markets may be put in pound prints with a printer set to give 
RIPENING AND CHURNING CREAM. 9I.

prints weighing about sixteen and a half ounces when wrapped in damp parchment paper. Use the best parchment paper, with the name of the farm or dairy neatly printed on the paper or branded in the butter.

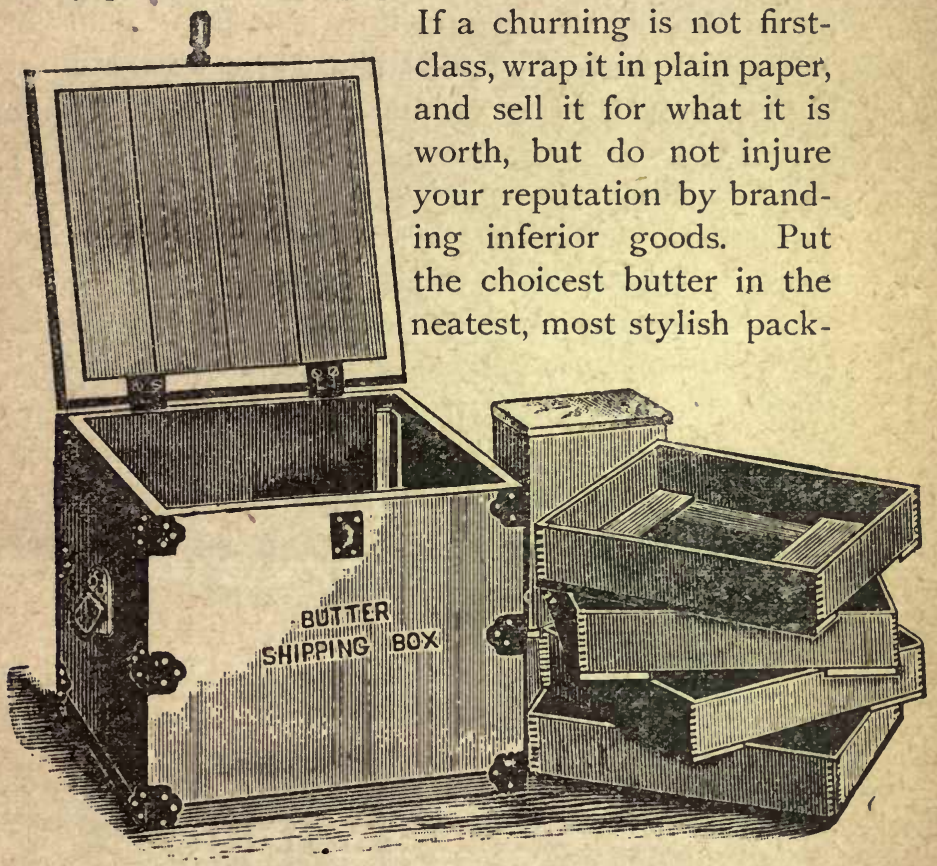

BUTTER SHIPPING BOX SHOWING TRAYS AND ICE CHAMBER.

age that can be got at a reasonable cost, and it will soon make a name for itself, which will bring pleasure and profit to the owner.

In case butter is to be packed use a clean crock, or what is better, a paraffine-lined wooden package, 
which is also lined with heavy parchment paper before packing the butter. Pound the butter in firmly, and fill to within one-quarter or one-half an inch from the top; then finish neatly; cover with paper, and fill to the top with a salt paste made of salt and water. If possible, place in cold storage at a temperature below 40 degrees $\mathrm{F}$; ; better at 20 degrees F.

When shipping some distance in hot weather, place the butter in wooden trays with an ice-box in the centre to keep it cool and firm. In winter the trays may be dispensed with. Sell the butter to private customers, or to a reliable commission house, which should not charge over one cent per pound for selling the butter. It is usually poor policy to trade good butter for dry-goods and groceries.

Good butter has about the following percentage composition :

Fat $\ldots \ldots \ldots \ldots \ldots \ldots \ldots \ldots \ldots \ldots, 84$

Water.................... 12

Salt ..................... 3

Curdy matter............... I

When judging butter the following scale of points is convenient :

Flavor $\ldots \ldots \ldots \ldots \ldots \ldots \ldots \ldots \ldots, 45$

Grain and texture $\ldots \ldots \ldots \ldots \ldots \ldots \ldots 25$

Color .................... 15

Salting $\ldots \ldots \ldots \ldots \ldots \ldots \ldots \ldots$ ro

Package.................. 5

Total................... 100 


\section{CHAPTER XII.}

\section{SKIM-MILK, BUT'TERMILK, AND WHEY.}

THE growing importance of the bacon industry makes the proper feeding of dairy by-products a very profitable study for dairy farmers. The value of sweet skim-milk for young pigs and young calves is well known. For pigs weighing over fifty pounds, sour skim-milk and buttermilk are equally valuable. Whey has a feeding value equal to about one-third that of skim-milk for growing pigs. It may not be fed to very young pigs or to calves, unless it is sweet, which is not practicable in ordinary factory districts.

The best quality of skim-milk is got from the hand centrifuge by separating immediately after milking. At creameries the skim-milk should be heated to about $180 \mathrm{~F}$. before it is returned to the farm. On its return to the farm it should be cooled at once to below 60 degrees. The tanks for holding the skimmilk at the creamery, and also the pipes through which the milk passes, should be cleaned thoroughly every day. The pipes should be filled with a solution of soda, which should be allowed to stand in them over night, at least once a week. Galvanized steel $\tan k s$ are more easily kept clean than wooden tanks. Buttermilk should not be allowed to stand for any 
length of time in tin or galvanized tanks, as the acid cuts the tin or galvanizing, and the tank or can soon becomes rusty. It should never be put in the same tank as the skim-milk at the creamery.

At the Ontario Agricultural College a whey tank, made on the same plan as the shell of a steam boiler, has been in use for a number of years. This has given us very satisfactory results. Whey tanks should be elevated and kept clean. Those in the ground are an abomination to the cheese industry.

When feeding pigs, give from two to four pounds of skim-milk for each pound of meal fed. The meal may be corn or barley. There is little danger of soft bacon where skim-milk forms a part of the ration. This combination will produce frrm bacon, and give economical results. It is a mistake to feed large quantities of skim-milk to pigs, as the best results are obtained by feeding in limited quantities combined with other feeds. The same rule applies to the feeding of other animals.

For poultry, skim-milk is a very valuable food. It enables fowls to digest other foods more completely, and secures increased weight at a small cost.

If cows will drink the sweet skim-milk, it will undoubtedly stimulate the milk-flow. Some dairymen claim a value of forty cents per one hundred pounds when fed to dairy cows giving milk.

Giving cows sour whey to drink taints the milk, and should not be practised.

Warm skim-milk combined with bran and crushed oats, mixed in about equal proportions by weight, 
makes the best food to produce healthy, thrifty dairy calves. Such calves will likely make good dairy cows. If the object be to fatten calves, flaxseed or corn may be combined with the skim-milk.

Whey appears to be about equally valuable for grown pigs whether fed sweet or sour. One hundred pounds of whey, according to experiments made at the Ontario Agricultural College, is equal to from six to nearly fifteen pounds of meal. The average of five experiments showed a saving of nearly twelve pounds of meal by the use of one hundred pounds of sweet whey, and about eleven pounds of meal was saved as the result of feeding one hundred pounds of sour whey. If meal cost one cent per pound, whey would be worth from eleven to twelve cents per one hundred pounds, according to these experiments. If meal be worth one-half a cent per pound the value of the whey would be decreased one-half. The best results were obtained by using from two to two and one-half pounds of whey for each pound of meal fed to the pigs.

Speaking generally, we may allow sweet skim-milk to be worth from fifteen to thirty cents per one hundred pounds. Buttermilk for grown pigs has a feeding value of ten to twenty cents per one hundred pounds. Sweet whey is probably worth from five to ten cents per one hundred pounds.

These by-products of the dairy are valuable additions to the food supply of the farm, and if intelligently fed to the right kind of animals, they will bring profit to the farmer. 
They are also being used for commercial purposes in the manufacture of glue, sizing for papers, etc. Milk sugar is made from whey. Condensed skimmilk is now manufactured. It is doubtful, however, if the by-products of the dairy can be so economically used in any other way than as food for animals. Sweet, clean skim-milk is very valuable for human food, and ought to be used more largely than it is. Under proper restrictions, there is no reason why skim-milk and buttermilk may not be sold in towns and cities, so long as it is sold for what it is, and not palmed off as whole milk. The skim-milk contains all the nourishing qualities of whole milk except the fat. As a rule, we have too much heat-producing material in our dietaries, and skim-milk would balance the ration at many tables.

Buttermilk, owing to the lactic acid it contains, has a valuable action upon the digestion of food by human persons. It is recommended by medical authorities as a wholesome and nourishing drink. Many farmers might add to their dairy revenues by supplying families in towns and cities with fresh buttermilk. 


\section{CHAPTER XIII.}

\section{FARM DAIRY CHEESE.}

THERE is a limited demand for small-sized dairy cheese. These may be profitably made upon the farm, as the average factory man does not wish to bother making small cheese. They require too much time and trouble for him. The objection to making cheese on the farm is that the process, as usually carried on, requires too much time. There is no reason why farm dairy cheese should not be made in about four hours, or in such time that the farmer's wife or daughter may get through before noon, as most women object to work of this kind after dinner -and rightly so.

To make dairy cheese, the following utensils are needed :

I. A clean vat, tank, tub, or can of some kind, to hold the milk. A small vat holding from 200 to 600 pounds, according to the size of the herd, is most convenient ; and where there is a small steam boiler on the farm, the milk and curd may be most conveniently heated in a vat. However, a clean vessel of any kind may be used for the purpose. A clean wash-boiler is satisfactory.

2. Some method of cutting the curd. A regular 
curd knife or knives is best ; but failing this, a long butcher-knife may be used for cutting the curd into small particles.

3. A hoop, or hoops, is needed to hold the curd. A convenient size is one from seven to eight inches in diameter, and eight to ten inches high, made of heavy tin or steel, with a perforated bottom. It must have a wooden follower, which will fit neatly on the inside, and have two handles on the outside. A hoop of this kind, made of heavy tin, should not cost more than a dollar.

4. A tin bandager, for putting the cotton bandage on the cheese before filling the curd into the hoop, saves time and patience, but is not essential, as the bandage may be put on after the curd is pressed into shape.

5. Some form of press is needed. A press made of a piece of scantling for a lever, having one end fastened under a partition, and the other end weighted with iron or a pail of water, has been used in the Farm Dairy at the Ontario Agricultural College with very satisfactory results. The hoop containing the curd is placed on a smooth board, and then the lever is put squarely on the follower, and the weight is put on the farther end of the lever. A gang press is more convenient.

In addition to the utensils named, it will be necessary to have on hand some rennet, preferably a commercial extract, salt, and cheese cotton bandage. Some means of heating or cooking the curd will also be needed. This may be done on an ordinary kitchen 
stove, by setting the vessel containing the curd and whey on the stove, or by heating some of the whey to the desired temperature, and adding it to the whole mass.

\section{MAKING THE CHEESE.}

The milk for cheesemaking should be clean, sweet, and of good flavor. When at a temperature of 84 to 86 degrees, add the rennet at the rate of six to eight ounces per I,000 pounds milk, or at the rate of about four to six teaspoonfuls per IOO pounds (IO gallons) of milk. The rennet should be diluted in about a cupful of cold water, and then be thoroughly mixed through the milk by stirring with a dipper for three to five minutes. The milk should now be allowed to stand perfectly still until coagulation takes place. This is determined by inserting the forefinger carefully in the curd, then break on top with thumb, and raise the forefinger carefully. If the curd breaks clean over the finger, it is ready to cut. If using curd-knives, cut once with the horizontal knife, and twice with the perpendicular so as to have the curd in cubes. When cutting with an ordinary knife, cut the curd as carefully and evenly as possible into small pieces. In about five minutes after cutting, commence stirring the curd very gently, and continue this for five or ten minutes, when heat should be applied and the whole mass cooked to 94 or 96 degrees. It is important to keep the curd in motion while heating to prevent scorching of the curd, and in order to secure uniform cooking. In about two hours after the rennet has been added, the whey may be run off the curd, 
or the curd may be dipped out of the whey and placed on some sort of a wooden rack to drain. If no rack be available, the draining may take place in the vessel used for making the cheese. The whey should be removed as fast as it accumulates. During this time the temperature of the curd should be from 90 to 92 degrees. When the curd is somewhat firm and shows a tendency to meatiness, it may be broken into small pieces, and the salt applied at the rate of one to two pounds per 100 pounds of curd, or at the rate of two to four ounces for $100 \mathrm{lbs}$. milk. Use the larger weight of salt on a soft, wet curd.

Thoroughly mix this salt with the curd, and as soon as it is dissolved, which will be in about fifteen minutes, the curd may be carefully packed in the hoop, and pressure applied gently. At the end of half an hour or more, the curd should be taken out of the hoop, and the bandage pulled neatly up about the cheese, allowing about one-half inch to lap over each end. A cotton circle may be placed on each end, and the green cheese be put under pressure again for twenty-four to forty-eight hours. The cheese may then be removed from the press, and be placed in a cool room at a temperature not above 60 degrees. At the end of a week they may be dipped in paraffine wax, or be given some other coating material which will prevent the evaporation of too much moisture, causing the cheese to be hard and dry. They require turning every day for about a month. When from two to three months old, they should be in good condition for eating. They will ripen sooner if at a 
higher temperature, but it will be at the expense of the quality.

Square hoops which mark the cheese into pound and half-pound blocks may be used instead of the circular hoop, if the maker prefers this style. Owing to the large surface exposed, it is very important to coat these cheese, or ripen them in a cool, moist atmosphere to prevent drying. It is somewhat difficult to secure the blocks of correct weight owing to the variation in curds. 


\section{CHAPTER XIV.}

\section{TOWN AND CITY MILK AND CREAM TRADE.}

A PURE and wholesome milk supply is as important for any town or city as a pure water supply. Many towns spend a great deal of care and money on securing a pure and adequate supply of water, but give practically no attention to an equally or more important subject, viz., a supply of pure milk, which is so very necessary, especially for children.

In order to get the milk delivered in proper condition, the source and distribution of the milk must be under proper supervision. This is best secured by municipal control, such as that followed in Glasgow, Scotland, where all the shops which sell milk are licensed and inspected, and the farms producing the milk are under city supervision; or the object may be attained by having a company supervise the production and distribution of the milk, such as is done in Copenhagen, Denmark, and by the City Dairy Company of Toronto, Canada, as well as in other cities.

The advantages of this plan are that better prices are usually paid to the producers of milk, while the price is not, as a rule, increased to the consumer. This is accomplished by doing a large business and 


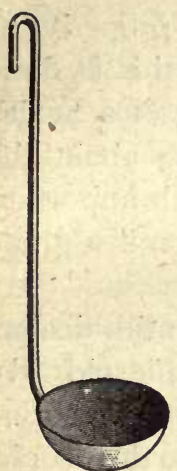

WIRE-HANDLED DIPPER FOR STIRRING MILK

reducing the operating expenses. Other advantages are, that the milk is likely to be more cleanly and healthful, and there is less danger from contagious diseases, as these establishments have facilities for sterilizing bottles, cans, etc., not found in small dairies.

The disadvantages are, the dangers of bad management in the case of municipal control, and exorbitant prices in the case of a monopoly by a company which controls the milk franchise of a city.

The same precautions in caring for and handling milk should be observed in this trade * as in caring for mlik to be sent to the factories. Even more care is necessary, because people of towns and cities who consume the milk usually have acute senses of taste and smell. It is safer to cool the milk to from 40 to 50 degrees $\mathrm{F}$. for city trade in order to reduce the danger from souring. If the milk is bottled, great care should be exercised in cleaning the bottles. The cans, measures, pails, waggons, etc., need constant care and cleaning. Some milk-cans and waggons used for delivering milk in cities are not a credit to the trade, and are a menace to health.

Under present circumstances, where there is neither municipal nor company control, it would be advantageous to have the farms, BRUSH. 
stables, cattle, waggons, cans, milk, etc., properly inspected by a competent person. Where this is done at all, it is usually placed in the hands of a health officer, who often knows little or nothing about the requirements of such work. To place such important work in the hands of an unqualified person is a grave mistake.

It would also be advisable to have milk dealers guarantee the purity and quality of the milk sold. In all large cities a municipal laboratory for the analyzing of foods would be a great protection to the people, and would soon pay for itself in the improved quality of the foods offered for sale. Most of the American States have a dairy and food commissioner, whose - duty it is to analyze foods; but the work is altogether too great for one small laboratory.

To add to the keeping quality of milk and to lessen the danger of souring in hot weather, the milk should be heated to I 40 or 160 degrees, and afterwards cooled to below 50 degrees. This will cause the milk to remain sweet from twenty-four to forty-eight hours longer than milk not heated. The higher temperature adds to the keeping quality, but tends to prevent the cream rising, and possibly renders the milk slightly. less digestible. There is also danger of a "cooked" flavor on the milk heated to 160 degrees.

Filtering the milk through cotton . batting apparently does not produce milk of any better keeping quality, nor does clarifying (running milk through a centrifuge) and afterwards mixing the cream and skim-milk add to the flavor and keeping quality of the 
milk. Both processes remove dirt that may be in the milk, but with clean milk there appears to be little or no advantage in filtering or clarifying.

"Certified" milk is produced under specially good sanitary conditions, and such milk usually sells in large cities for a much higher price than average milk.

"Modified" milk has its composition changed according to special requirements of the human system, and is usually prepared for infants under medical direction.

Commercial cream should contain about twenty per cent. fat. This branch of the dairy business is one of the most profitable, and has this advantage, that the skim-milk is available in good condition for young stock. A hand or small power centrifuge is convenient for producing commercial cream. When customers ask for cream testing thirty or forty per cent. fat, they should pay for it according to its fat content. Cream testing forty per cent. fat is worth nearly twice as much per gallon as cream testing twenty per cent. fat.

Heating the cream to 140 or 160 degrees will improve its keeping quality, but renders it somewhat thin in appearance, hence is looked upon with suspicion by customers. The addition of viscogen (sucrate of lime) has been recommended in order to restore the viscosity of pasteurized cream, but this may be regarded as a harmless adulterant.

Whipping-cream should be at least twenty-four hours old from the separator, or after pasteurization, and should be cold at the time of preparing. 
Whipped cream contains gases or air which expand the viscous part of it, hence it is important that the cream should have age and be cold. If too warm at the time of whipping, the cream will churn into butter. Separator cream, when fresh, does not whip so well as gravity cream, because the separator removes the albuminous or viscous matter which expands during the whipping process. Age restores this condition, hence separator cream should be held longer than gravity cream before whipping. 


\section{Part II.}

\section{CO-OPERATIVE DAIRYING.}

CHAPTER I.

\section{ORIGIN AND ADVANTAGES OF CO- OPERATIVE DAIRYING.}

"MEN cannot co-operate successfully if the sole bond between them is self-interest," hence one of the chief advantages of co-operative dairying is, that it tends to make those engaged in this form of dairy work less selfish. The private dairyman is concerned chiefly in the furtherance of private interests, while the co-operative dairyman is interested also in the welfare of the whole. He takes pride in our factory rather than in $m y$ dairy. This form of dairying also gives farmers a knowledge of business, as the business is frequently managed by the producers of milk. It also promotes neighborliness, courtesy, intelligence, and good citizenship. Where co-operative dairying is followed in its highest sense, the best class of dairymen and more general thrift will be found.

However, we do not have in Canada that true 107 
co-operation which should exist. Among the patrons and managers of factories there is often too much selfishness apparent. In many localities each is striving for his own advantage and not for the good of the whole. Co-operation, in its widest sense as applied to the dairy industry, should include the producers of milk, the manufacturers, the carriers and the distributers of dairy products. In practice each of the last three named exact their " pound of flesh," and the first class takes what is left. The chief reasons for this is that the producers of milk are not, as a rule, willing to assume any risks, and these the manufacturer and buyer have to assume, while the carriers have practically a monopoly and can exact almost any price for carrying dairy goods to market. If, instead of placing the losses during a bad season on one or two classes, these losses were shared by all concerned, it would be less burdensome. On the other hand, in case of a good season, instead of one or two classes absorbing a large share of the profits, if these were divided among all it would tend to give a stability to the industry which would make it more secure than it is at present, though it is now one of the most stable in the world.

A partial sharing of losses and gains may be accomplished in a simple way, by the manufacturer charging a less rate for making cheese or butter during a bad season, and by the patrons agreeing to give an extra price for manufacturing during a good season. The men who work in the factories should also share the benefit of a good season by receiving 
better wages. In order to induce the patrons to supply as large a quantity of milk as possible it is advisable to offer some inducement by way of extra price to those who continue throughout the year, or lower the price for manufacturing in case the make exceeds a certain quantity. Managers of factories can well afford to do this, as the cost of manufacturing a large quantity of butter or cheese is much less per pound than the cost of making a pound of goods in a small factory.

The chief advantages of co-operative dairying are:

I. A better and more uniform product is obtained, which usually sells for a higher price than private dairy goods. The product will also be greater from the milk, unless the private dairyman has good utensils and a proper dairy managed by a skilful person.

2. The actual cost of manufacturing a pound of butter or cheese is less. The expense of equipping one hundred private dairies at $\$ 200$ each would be $\$ 20,000$, whereas one-tenth of this sum would equip a co-operative concern to handle all the milk from these one hundred farms. Instead of having one hundred persons making the milk into butter or cheese, two or three persons would be able to do all the work in a factory, thus saving human energy.

3. More skilful labor and better machinery may be employed in the co-operative dairy as compared with average private dairies.

4. Co-operative dairying reduces the labor on the farm, thus relieving the tired farmer's wife from much 
drudgery. Labor is so scarce on many farms in Canada that some are obliged to go out of the dairy business altogether.

The weaknesses of co-operative dairying are the selfishness existing in the majority of sections, the tendency to multiply small and poorly equipped factories, and the fact that many factories are run but for a short period of each year instead of all the year.

Co-operative dairying originated in Switzerland, but has been adopted to a greater extent in America than in any other country. It is seen in its most perfect condition in Denmark.

The history of co-operative dairying in the United States and Canada is somewhat as follows: A Mr. Norton, of Connecticut, manufactured curd, which was delivered at his place by farmers, into cheese, so early as I844. In I 85 I the first co-operative cheese dairy was operated by Jesse Williams \& Son at Rome, in Oneida County, New York. The neighbors, seeing the success of the Williams', requested them to handle their milk also, so the first co-operative cheesery was built by them in I852. In I $863 \mathrm{Mr}$. Harvey Farrington came to Canada from Herkimer County, New York, and settled in Oxford County, Ontario, near the town of Norwich. The contract for the first cheese factory was let that fall, and it was built during the winter. In I 864 it began operations on lot IO, concession 4, of the township of North Norwich. In I 888 the factory was removed to near the village of Harley, in the township of Burford, Brant County, by his son, Mr. I. Farrington. This factory is still in operation. 
Two years after the first factory was operated in Western Ontario, factories were built in the counties of Hastings and Northumberland, in eastern Ontario, by Messrs. Graham and Wade. The following year, I 867, the Ontario Dairymen's Association, which has been a very important factor in the development of co-operative dairying in the Province, was formed at Ingersoll. Nearly all the provinces now have dairy associations for promoting the interests of dairying, and they have been very helpful in developing what is best of the dairy industry. In 1877 the first Ontario Association divided into Eastern and Western, with separate Boards of Directors. The Creameries Association was formed in 1886 , but it was disbanded in 1897 , owing to the withdrawal of the Government grant. In 1898 the cheese and butter makers of Western Ontario formed an organization for the promotion of makers' interests. After two years they amalgamated with the Western Association. The Provincial Government gives a grant of about $\$ 8,000$ yearly to the two dairy associations. The first Government grant was made in 1874. This money is expended in holding meetings, sending out instructors to the cheeseries and creameries of Ontario, and in giving prizes for exhibitions of butter and cheese at the various fairs. The other Provincial Governments also make similar grants, though usually not so large, to the dairy associations of the various provinces. The first cheese instructors employed in Canada came from New York State. Now, Canada sends men to act as cheese instructors in nearly every dairy country in the world. 
The establishment of cheese and butter markets, or dairy boards of trade at different centres, have been helpful in the marketing of cheese and butter.

Another factor which has had much to do with the promotion of uniform methods of manufacturing dairy goods, and of spreading scientific knowledge, is the establishment of dairy schools in the various provinces. One of the first to be established was that in connection with the Ontario Agricultural College at Guelph, which held the first session in I893. "There is said to have been a dairy school in the Province of Quebec as early as I88I. 


\section{CHAPTER II.}

\section{ESTABLISHING AND MANAGING CREAM- ERIES AND CHEESERIES.}

MANY co-operative dairies are established in places where they cannot succeed because they lack essentials of success. Many also fail because of bad management. All over Canada are to be seen idle factories which are monuments to some person's ignorance or bad management.

In a section where the people are inclined to favor co-operative dairying, but are not acquainted with the requisites and methods followed in order to ensure success, the following points should receive consideration :

I. A public meeting, addressed by some competent person, should be called in order to lay the matter before those interested. The daily and agricultural press should be used to arouse an interest in dairy matters.

2. The number of cows in the locality which can be secured should be accurately determined by competent persons who can explain the object and advantages of a creamery or cheesery to cow owners. Not less than 300 cows within a radius of five miles 
from the proposed factory would warrant the establishment of a co-operative dairy.

3. If there is no one in the locality who understands the main features of factory work it will pay to send two or three competent men into a co-operative dairy section to gather information. A few dollars spent in this way may save many dollars in the future.

4. Select a good site for the proposed building. This should be in the centre of the milk or cream supply as far as possible, should be easily drained, have an abundant supply of pure water, and be on a good road. Personal considerations of a few interested persons should not allow one of these fundamental principles to be overlooked when selecting a site.

5. Secure proper plans for a suitable building. Too many factories are built without a plan and are consequently neither convenient nor adapted for the work. (See Appendix for suitable plans). It is also important to have sufficient funds available to carry out the work without delay. A 500 cow creamery on the cream-gathering plan will cost, when built and properly equipped with modern machinery, from $\$ \mathrm{I}, 500$ to $\$ 2,000$. On the whole milk plan a creamery of this size will cost from $\$ 2,000$ to $\$ 3,000$. A 500 cow cheesery will cost from $\$ 1,000$ to $\$ 2,000$, depending upon the kind and cost of material and the quality of the machinery.

6. It is important to decide whether the business shall be conducted on the joint-stock company or upon the private enterprise plan. If it is decided to 
form a joint-stock company, it will be necessary to become incorporated under Provincial or Dominion Statutes. In Ontario five responsible men appear before the registrar of the county in which it is proposed to establish the factory, and sign a declaration to the effect that they wish to form a company to manufacture cheese or butter or both. By so doing, and paying a registration fee of fifty cents, the company becomes legally incorporated.

In both cases it is necessary to have proper rules and by-laws governing the factory. The advantages of the joint-stock company plan are that the patrons who own the cows also own the factory and equipment, thus giving them a double interest in reducing the cost of manufacturing. However, many factories established on this plan pass into the hands of private persons, owing to bad management or to dissensions among the shareholders. In order to promote harmony, it is well to secure the best men as directors, to have the number of shares limited and in value from ten to twenty-five dollars each, and also to have as few "dry" shareholders as possible, $i$. e., shareholders who do not keep cows.

A suitable heading for a stock-book is as follows :

"We, the undersigned subscribers, each severally promise to pay to the proper officer of the [insert name] Association or Company the amount set opposite our respective names, in such sums and at such times as it shall be called for by the Directors of said Association or Company; provided always that not more than [insert 20 or 30] per cent. shall be called for during any one year." 


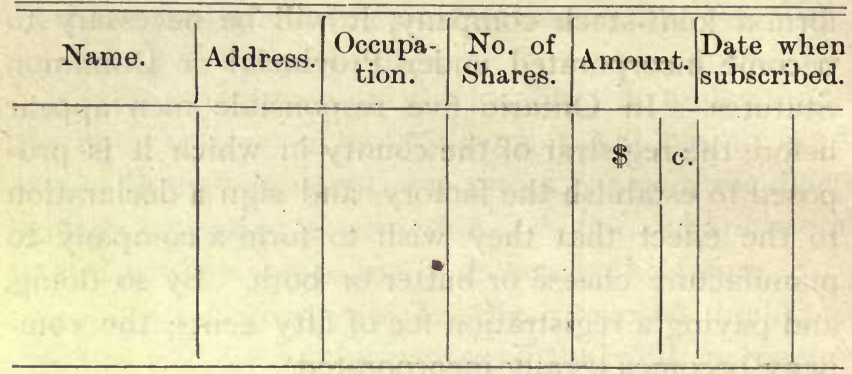

The advantages of the private enterprise plan are :

I. The business usually receives good business management, as the owner has everything to lose if the business be not well conducted.

2. The patrons are relieved from any risk of failure so far as the money invested in the factory and its equipment is concerned.

3. Private enterprise factories are often better equipped and kept in better repair than those owned by companies.

The disadvantages are :

1. The higher rate charged for manufacturing, in order to cover the risk involved and to obtain interest on the money invested. Interest on money invested. is not or should not be a consideration in stock company concerns.

2. The danger of the factory man losing through loss of patronage, with or without cause, the money which he has invested.

3. The risk which patrons run of losing the value of their milk through dishonest owners or managers. In order to ensure against this loss it is well for the 
patrons to appoint their own salesman and treasurer, as the manufactured goods belong to the patrons and not to the factory owner, unless he buys the product before or after mamufacturing.

The cost of manufacturing milk into butter or cheese is usually assessed at so much per pound. In the case of whole milk creameries the rate varies from three to four cents per pound of butter, after the milk is delivered. In cream-gathering creameries the cost is somewhat less. In cheeseries the price varies from one cent to as much as two and one-half cents per pound, including the cost of hauling the milk. If the cost of hauling the milk and making the cheese is above two cents a pound, it is difficult to make the business pay, as in seasons of low prices there is little for the producers of milk after deducting the cost of manufacturing. In the case of joint-stock factories it is customary to charge non-shareholders an excess rate of ten to twenty-five cents per hundred pounds of cheese or butter. To guard against a shareholder having a large quantity of milk manufactured at the lower rate, it is customary in some factories to allow so much milk to be made at shareholder's rate, but any milk in excess of this must be paid for at the non-shareholder's rate. In order to induce as many patrons as possible to send milk, some factories have a uniform rate for all, as the shareholders claim they get sufficient pay in the lower cost of manufacturing where the quantity is large. In the case of a surplus after paying all running expenses and paying for repairs, this is divided among the shareholders of the company according to the stock which they hold. 
In some cases the manufacturer buys the milk or cream from the patrons at a fixed rate per one hundred pounds of milk of standard quality, or at so much per pound of fat in the milk or cream, or at a certain rate per standard inch as determined by the oil-test churn. In these cases the product belongs to the manufacturer.

A few factories manufacture for a certain proportion of the product, usually one-fifth or one-sixth. This plan resembles "taking toll" by, the miller for grinding grain, and is not to be recommended.

Some creameries charge a certain rate for making the butter and take the "overrun." The rate is usually one cent per pound and the overrun. By the overrun we mean the butter made in excess of the fat in the milk or cream. There should always be more butter than there is fat in the milk or cream, as the butter contains about sixteen per cent. of water, curd and salt mixed with the milk fat. This overrun is not a constant factor, hence should not be taken by the manufacturer, as it varies considerably with the various conditions met with in a creamery, and according to the skill and care of the buttermaker. The overrun is usually from ten to fifteen per cent. in a whole milk creamery, and from fifteen to twenty per cent. in a cream-gathering creamery.

The chief factors influencing the overrun are :

I. The character of the milk or cream delivered. This is influenced by the length of time since it was drawn from the cow, the size of the fat globules, the percentage of fat in the milk or cream, and the care 
which the milk or cream has received on the farm and in delivery.

2. The skill and honesty of the buttermaker, or of the man who does the weighing and testing of the milk. A skilful buttermaker can procure a greater yield of butter from one hundred pounds of fat in the milk than can an unskilful maker. A dishonest person can obtain a large amount of overrun by taking a few pounds of milk from each patron, and by reading the tests lower than they should be read. An overrun of twenty to thirty per cent. in a whole milk creamery indicates something wrong.

3. The amount of moisture, curd, salt, etc., which is incorporated with the fat will influence the overrun. Butter which contains more than sixteen per cent. moisture is deemed adulterated. Some buttermakers claim to be adept at incorporating an excess of moisture in butter, but this may not be regarded as an evidence of skilful buttermaking.

4. Mechanical losses, which usually amount to from three to five per cent. of the fat in the milk or cream, also influence the overrun. These losses are made up of spilt milk and cream, fat left in the milk and cream remaining in the vats, cans, pails, dippers, etc., butter left in the churn or on the worker, overweight of butter in boxes and prints, loss by holding in coldstorage, etc. These, in some cases, are quite a heavy drain on the yield of butter. By lessening the number of vessels which come in contact with the milk, cream, and butter, and by carefulness in handling the milk and cream, these losses may be reduced. 
CREAM-GATHERING US. WHOLE MILK CREAMERIES.

The relative merits of whole milk and creamgathering creameries has been much discussed. The latter form of creamery is well adapted for a small cow population, scattered over a considerable extent of territory, and where the roads are not suitable for hauling heavy loads of milk. The chief advantages of the cream-gathering system are :

I. It saves the cost of hauling the whole milk to the creamery and the skim-milk back to the farm.

2. The patrons have, as a rule, a better quality of skim-milk on the farm for their stock.

3. It costs less for a building, for machinery, and for labor to manufacture the butter.

4. A much wider territory can be covered by one creamery under this system. With proper railway facilities there is scarcely a limit to the extension of the creamery's operations. This ensures a large quantity of butter which is uniform in quality, though the quality may not be so high as whole milk creamery butter.

The chief disadvantages of the system are :

I. The cream is often spoiled before it reaches the creamery, owing to defective methods of caring for it on the farm, or because it is delivered at the creamery once or twice a week instead of daily, as it should be.

2. This results in an inferior quality of butter, which is the chief weakness of the cream-gathering method of conducting creameries. The experience of nearly every country which has adopted this system has been the same. There is no reason why good 
butter cannot be made in the cream-gathering creamery if the cream be delivered sweet and clean-flavored, but in practice this is found very difficult to accomplish.

3. A third disadvantage of the system is the difficulty of securing accurate tests of the cream. The oil-test churn is not a very reliable test, and should be superseded by the Babcock test for fat in all the cream-gathering creameries. There is always more difficulty in securing accurate tests of cream than of milk.

In order to make this method successful it is important that the patrons have proper means of creaming the milk, that the pans, cans, or separator, shall be kept perfectly clean, and that the cream shall be delivered at the creamery in a sweet condition, so that it may be pasteurized if necessary. The pasteurization of the cream when sweet is much to be preferred to the pasteurization of sour cream, although the latter improves the flavor of the butter.

The whole milk or separator creamery is suitable for a dense cow population, and where there are good roads.

The chief advantages of this plan are :

I. The buttermaker has control of the cream ripening, and consequently can make a better quality of butter throughout the year.

2. More accurate testing of the milk may be done, and consequently there is less dissatisfaction among the patrons.

3. It saves the labor of creaming the milk and 
caring for the cream on the farm. It also reduces the expense for creaming machinery, as one hundred separators would cost from $\$ 7,000$ to $\$ 10,000$, while about one-tenth of this sum would purchase power separators for creaming the milk at the creamery.

The labor of running and washing a separator and caring for the cream will amount to about two hours daily, which will be worth $\$ 70$ to $\$ 75$ per year. Add to this the interest on money invested and tepn per cent. for depreciation in value, and it will be found that if the milk can be hauled for five cents per one hundred pounds it will be cheaper to send the whole milk to the creamery.

The disadvantages are the extra cost of hauling, the poor quality of skim-milk returned from many creameries, and the extra cost of manufacturing a pound of butter.

To sum up, the cream-gathering creamery is well adapted for certain districts - in fact is the only form of creamery which is practicable-but we may not expect to make a quality of butter suitable for the highest export trade by adopting this system. The whole milk creamery is more expensive to operate, but is favorable for producing the highest quality of butter, and in the end is the form of creamery which will pay farmers best in the well settled dairy districts.

The practice of taking in both milk and cream, and mixing the cream gathered from the farms with the cream separated at the creamery, is fraught with danger unless the cream be pasteurized sweet or churned separately, which is not practicable in many cases. 
The combination of a central creamery with a number of skimming stations or auxiliary creameries, where the cream is separated and sent to the central for churning, overcomes the difficulty of long hauls for the milk, and tends to produce a large quantity of butter having a uniformly good quality. However, such creameries require excellent management, else the expense of operating them consumes all the profits. 


\section{CHAPTER III.}

\section{BUILDINGS AND MACHINERY FOR CO-OPERATIVE FACTORIES.}

DAIRY buildings should be set on stone or cement foundations. The old plan of putting factories on posts, so that the air may circulate underneath, should not be adopted, as the posts soon get out of place and the factory becomes dilapidated and the floors uneven in their surface. If a wooden floor is put in the factory it should be supported with cross walls to carry the weight of vats or machinery. The floor for the separator and churn needs to be specially well supported, also the floor carrying the vats of milk. Well selected one and a half inch matched pine lumber is probably the best material for a wooden floor. The joints should be put together with white lead. This floor should receive as soon as laid, at least two coats of hot linseed oil (half a gallon), turpentine (one pint), and dryer (one pint) applied with a whitewash brush having a long handle on the side. This dressing should be applied at least once a year to preserve the floor and make it easy to clean, as the hot oil fills the pores of the wood, thus preventing water, grease, milk, etc., from entering. However, a wooden floor should not be used in a well-built factory, 
as it soon rots and causes a great deal of trouble through leaks and unevenness, making it difficult to keep clean and sweet. The best floor, considering cost, is made of gravel, sand, and cement. The ground should be properly graded so as to give a fall of about one inch in six feet to a gutter in the workroom. (The floor of a cheese ripening-room should be nearly level). On the firmly packed ground should be placed from four to six inches of gravel. This should be well pounded. On this a layer of about four inches of sand and cement, mixed in the proportion of four or five of sharp sand to one of good cement, should be well packed, and then a finishing coat of sand and cement (two to one) of about one inch thickness should be trowelled and nicely finished so as to give a smooth, hard surface to the floor. If the ground slopes very much, so as to require filling, this should be done with field stone, if possible, and the gravel should be washed among the stone so as to make a compact bottom. If stone be not available and dirt is used, it must be pounded in very firmly before putting on the gravel and cement, else the floor will crack. It is important to have all the floor laid in one day if possible, as it is difficult to get a good connection between the hardened edge of the cement laid one day and that of the fresh put down a few days, or even one day, later. It is also important that the drain be properly laid with a good fall to the outlet. It is better, when making the drain, to have a pattern made of proper width (about four inches on top) and having the right slope. If a bell-trap, which 
is one of the best, be used, this should be set in the cement and slightly below the bottom of the gutter. It pays to secure a competent person to superintend the laying of a cement floor, and to use none but the best material.

The cement ought to extend at least six inches from the floor on the walls, so that there will be no wood within six inches of the floor. If the wainscotting be two or three feet from the floor and the intervening space smoothly finished with cement, all the better.

A cement floor in a cheese ripening-room will help to maintain a lower temperature in the room, but in the case of refrigerators it will be necessary to protect the floor from the warmer earth underneath, else it will be found difficult to hold a sufficiently low temperature for storing butter. This can be done by using an insulated wooden floor on the cement, or by placing insulating material such as asbestos under the cement when laying the floor.

The walls of the building should be strong enough to carry the roof, and be well insulated so as to protect the inside from the effect of the outside cold or heat. Hollow cement blocks, hollow bricks, or ordinary brick, cement, stone, or wooden walls may be used. The advantage of having a hollow space in the material is that it saves the expense of insulating. Brick, cement, stone, or wooden walls should have still air spaces in them. These are usually obtained by building paper and matched lumber nailed on wooden strips set on the inside of stone or brick walls. 
If the walls be made of wood, there should be at least two still air spaces in the wall, made of five thicknesses of lumber and at least three of good building paper. These spaces should be made tight at the top and bottom so that the air in them cannot circulate. In the case of refrigerators and well made cheese ripening-rooms there should be in addition a six inch space filled with dry sawdust, mill shavings, or tan bark. It is also a good plan to confine the air of the wall in refrigerators in small spaces by nailing inch strips between the sheeting in such a way as to form squares from one to two feet in size.

The best inside finish for a brick, stone, or cement building is the wall, without any lumber except on the ceiling. The walls and ceiling should be whitewashed as often as needed in order to keep it clean. A spray pump may be used for the purpose. A lath and plaster finish is not suitable for a factory, as the plaster becomes loosened by the jar of the machinery and by the steam and soon falls and disfigures the inside. The ceiling of the work-room in a creamery or cheesery should not be less than twelve feet high. This makes the room much cooler in summer and more healthful at any time, though somewhat more difficult to heat in winter. The heating of all parts of the building should be done from the steam boiler. By arranging for the condensed steam to return to the boiler the expense is not very great, and it saves the expense, risk, and trouble of stoves. For each twenty cubic feet of space to be heated, one linear foot of inch pipe is needed. A room thirty by thirty by 
twelve would contain-10,800 cubic feet and would require about 540 feet of inch pipe to heat it properly. These pipes are most conveniently placed on the wall of the building.

The weighing porch should be located on the south side of the building, if possible, and the refrigerator and cheese ripening-room on the north side. The weigh-can should be elevated so that the milk will flow by gravity into the vats through a conductor pipe. The boiler-room should be convenient to the making-room, and it is a good plan to have the steam gauge in the making-room, or have a window where the steam pressure and water glass on the boiler may be readily seen while at work. Creamery, cheesery, and boiler-room floors should be on the same level as far as possible. The labor of going up and down steps is too great in the gravity creamery where no pumps are used. Milk and cream pumps are now made which are easily cleaned, hence the milk and cream may be elevated at less cost than the butter maker. The building should be so arranged that the finished product is always travelling towards the refrigerator or ripening-room. The water tank is best placed above the boiler, where there is less danger of the water freezing in winter. In summer this water would be too warm for washing butter, hence it should be pumped directly from the well. The skim-milk tank may be placed in the attic, but it should be easy of access, so that it may be cleaned readily. It is important to have plenty of hot water to clean the skim-milk tank. 
Screens should be provided for doors and windows in summer to keep out flies. No factory is properly equipped without these barriers to a great nuisance in factory work.

The size of rooms required in 500 cow creameries and cheeseries will be somewhat as follows :

Making-room for both about $30 \mathrm{ft}$. by $30 \mathrm{ft}$.

Ripening-room for cheesery about $30 \mathrm{ft}$. by $30 \mathrm{ft}$.

Boiler-room for both about i $2 \mathrm{ft}$. by $\mathrm{I} 6 \mathrm{ft}$.

Refrigerator-room for creamery about $\mathrm{I} 2 \mathrm{ft}$. by $20 \mathrm{ft}$. by $8 \cdot \mathrm{ft}$. high.

Bath-room, $6 \mathrm{ft}$. by io $\mathrm{ft}$.

Office, $6 \mathrm{ft}$. by io $\mathrm{ft}$.

If the central cold storage or ripening-room plan be adopted, which will be discussed under cheesemaking and marketing cheese, then a very small room for storing about one week's cheese is all that would be necessary instead of the large curing or ripeningroom. The bath-room for health and cleanliness of the men employed should be a feature of every factory. An office for books, etc., is also necessary.

\section{MACHINERY.}

The most important machine is the steam boiler. This should be a large (not less than twenty horse power), horizontal, tubular boiler, properly bricked, and having a brick chimney so as to give proper draft. It should be provided with both pump and injector methods of feeding water. Small boilers are wasteful of fuel and time. The engine for a $500 \mathrm{cow}$ creamery should have a capacity of ten or twelve 
horse power. If mechanical refrigeration is used a larger engine and boiler are necessary. An engine is not a necessity in a cheesery, but is convenient in a large factory for milling the curds. Where electric power is available, a ten or twelve horse power motor is one of the most convenient powers for creamery work. The shafting should be centrally located, so as to drive all the machinery in the building from one line shaft if possible. This shaft should be about one and a half inches in diameter and make from 200 to 300 revolutions per minute. Wooden pulleys are convenient and satisfactory if made of good material. Iron pulleys rust and are difficult to change on the shafting. It is important to have pulleys of proper size in order to give the desired speed to the machinery. The following are rules for determining size of pulleys and length of belts :

To find the diameter of a driven pulley, multiply the diameter of the driver by its number of revolutions, and divide the product by the number of revolutions the driven pulley should go. The result will be the diameter of the driven pulley.

Example: Diameter of pulley on engine, 40 inches ; speed of engine, 160 revolutions ; speed of main shaft, 200 revolutions; $40 \times 160 \div 200=32$, which is the diameter in inches required for the driven pulley.

To find the required size of a driving pulley, multiply the diameter of the driven pulley by the number of revolutions it should make, and divide the product by the revolutions of the driver.

Example: Diameter of the pulley on intermediate 
is 4 inches, which is required to run 900 revolutions per minute. Revolutions of shaft 200 . $4 \times 900 \div 200$ $=\mathrm{I} 8$, which is the diameter in inches of the pulley required to drive the intermediate at proper speed.

To find the length of belt for any two pulleys, add the diameter of the two pulleys together, divide their sums by two, and multiply their quotient by $31 / 4$. Add the product to twice the distance between the centres of the shafting, and the result will be the required length of belt.

Example: Two pulleys are 8 and 24 inches in diameter, and 8 feet is the distance between the centres of the shafting. $8+24=32,32 \div 2=16,16 \times$ $3 \mathrm{x} / 4=52$ inches $=4$ feet 4 inches, and 4 feet 4 inches +16 feet (twice the distance between the centres of the shafting) $=20$ feet 4 inches, which is the length of belt required.

It is also important that hot and cold water tanks, and at least one washing-sink be in every factory. These are best made of galvanized iron, painted on the outside, with a large tap on the bottom of the water tanks and a suitable plug in one end of the wash sink. Wooden tanks or sinks are difficult to clean, while wooden tanks lined with tin or galvanized iron soon leak and cause a great deal of trouble.

The following is a list of the utensils required, and their estimated cost for a 500 cow cheesery:

Boiler, 20 h. p., two 600-gallon vats, two I2-hoop gang presses, acidimeter, one $800-\mathrm{lb}$. scale of double beam, one 50-gallon weigh can, milk conductor, head and pipe, two curd three-eighths inch knives, curd 
scoop, dipper, pails and thermometer, one 24-bottle steam Babcock tester, one curd mill and curd agitator, steam pipe, shafting, pulleys, hangers, etc.

Estimated cost, $\$ 500$.

Outfit for a creamery on the separator plan for 500 cows :

Boiler, 20 h. p. and engine io h. p., one separator, two 300 -gallon cream vats, one 400 -gallon receiving vat, one 400-gallon churn and butter worker, one $800-1 \mathrm{~b}$. scale, double beam, one 50-gallon weigh can, one conductor, head and pipe, one 24-bottle steam Babcock tester, dippers, pails, thermometers and acidimeter, butter ladles, printer and packer, one milk heater or pasteurizer, shafting, belts and pulleys, one $240-1 b$. scale, milk pumps.

Estimated cost, $\$ 1,000$ to $\$ 1,200$.

Cream-gathering outfit for a creamery of 500 cows:

One boiler and engine. two 300-gallon cream vats, one 400-gallon churn and butter worker, one 800-1b. scale, double beam, one $240-1 b$. scale for butter, ten refrigerator carrying cans or cream tank, one No. 2 oil-test churn or steam Babcock tester, five driver's cases, pails, ladles, packers, printers, acidimeter, etc., shafting, pulleys, belts, etc.

Estimated cost, $\$ 600$ to $\$ 800$.

Outfit for cheesery and creamery combined, with separator, for 500 cows:

Boiler and engine, one separator, one 400-gallon receiving vat, two 300 -gallon cream vats, one $400-$ gallon churn and worker, one $800-1 b$. scale, one 5o-gallon weigh can, one conductor, head and pipe 
acidimeter, one 24-bottle steam Babcock tester, dippers, mops, thermometers, etc., butter ladles, pails and packers and printers, one milk heater or pasteurizer, two 600-gallon cheese vats, two gang presses, two curd three-eighths inch knives, curd scoop, pails, etc., power curd mill and curd agitator, shafting and pulleys, one $240-1 \mathrm{~b}$. butter scale, milk pumps.

Estimated cost, $\$ 1,200$ to $\$ 1,500$.

Next to the boiler the most important machine in a whole milk creamery is the cream separator or centrifuge. It should be set level, on a firm stone, cement, or brick foundation. This machine should have sufficient capacity to separate all the milk without causing too much delay in waiting for the skimmilk. Where the daily delivery exceeds 8,000 pounds two machines are advisable. One of these may be a turbine, so that in case of accident with the power the milk may be separated and not cause a loss which is likely to occur by the milk souring in the hot weather. The "Accumulator," "Extractor," "Radiator," etc., which not only separate the cream from the milk but also churn it into butter, have not up to the present time proven satisfactory.

Combined churns and workers save labor, floor space, pulleys and belting, but are more difficult to clean and operate than a box churn and Mason or National worker.

The pasteurizer is another very important machine which should be found in every creamery. It also takes the place of a milk pump and heater or tempering vat. If a pasteurizer be not used, a milk 
heater, which can be easily cleaned, and which will have sufficient capacity to employ the separator for three to five minutes, is necessary. The channel variety is satisfactory. It should be made of tinned copper and have a steam connection and an outlet for water. It must be placed high enough for the milk to flow from it into the separator. All pipes through which milk or cream passes should be tinned on the inside for ease in cleaning.

The cream vat should have plenty of space on the sides for ice and cold water, or be provided with cooling pipes from the refrigerating machine.

A skim-milk weigher ordinarily saves a great deal of trouble and should be found in every whole milk creamery. A rotary pump for elevating the skimmilk is convenient and satisfactory. An ejector will not work with hot skim-milk, as the liquid to be elevated by an ejector must be cold enough to condense the steam in order that the velocity of the steam may be imparted to the liquid to be elevated.

In cheeseries the machinery is more simple and less costly. The vats should be made strong and of the very best tin. Curd sinks are not necessary, as racks may be placed in the vats for draining the curd, and many sinks are a source of trouble in cheesemaking if they are not kept clean. The curd-knives should not have the blades more than three-eighths of an inch apart. Curd agitators, driven by steam power, save labor in a large factory. Hand agitators in smaller factories are very helpful. The horizontal gang press is much better than the upright single press for pressing cheese. 
A number of vat and floor brushes, as well as rubber mops for keeping the floor dry, is necessary in every factory. There ought also to be on hand a supply of common washing soda for washing milky and greasy utensils, and concentrated lye for the drains.

Labor-saving machinery ought to be provided as far as possible, and the men in charge of the factories should make an honest endeavor to maintain the machinery and buildings in good repair. The boiler and engine should be clean and bright. Pulleys should be tight, bearings well oiled, and belts properly laced. Separators, pasteurizers, skimmilk pumps, pipes and tanks, churns, etc., should be kept perfectly clean and in good repair. All this takes some time and care on the part of some one, but it pays to have this done, as dairy machinery is expensive and deteriorates in value very rapidly if not well cared for.

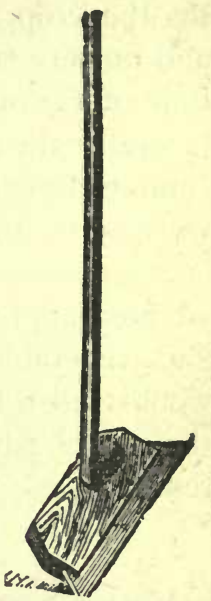

RUBBER MOP FOR DRYING FLOORS.

\section{FACTORY SEWAGE.}

One of the most difficult problems about a factory is the proper disposal of the sewage. To run it into an open ditch, or into a creek, or any body of water which is used for drinking purposes, by man or beast, is injurious to health. If it accumulates about the factory it soon creates a nuisance which is danger- 
ous to the business, and a source of annoyance to every one who comes near the place.

Irrigation.-Where the factory is above a sloping field or plot of land, the sewage may be used for irrigating purposes with satisfactory results. It is necessary to have a large storage tank or tanks in order that the sewage may be applied when needed by the crop. Roots, grass, garden truck, orchards, and nursery stock are most benefited by the application of factory sewage. Where the conditions are favorable the factory owner may use this curing the summer time for forcing garden and other crops. 'It will pay for the expense in a very short time. There is no reason why a small plot of ground favorably situated might not be used for growing all the fruit and vegetables required on the table. The men would relish this addition to their regular fare, and the cost of "boarding the hands" may be very much reduced.

\section{TANK OR BLIND WELL.}

With a porous subsoil the sewage may be allowed to soak from a tank or blind well. It is very important that this tank or well shall be located in such a position that there is no danger of polluting the water supply for the factory. If the water supply be drawn from a well, then the two must be at least 300 feet apart.

The sewage may be pumped from a tank and be drawn to adjoining fields, but this plan as a rule involves too much labor to be profitable. 


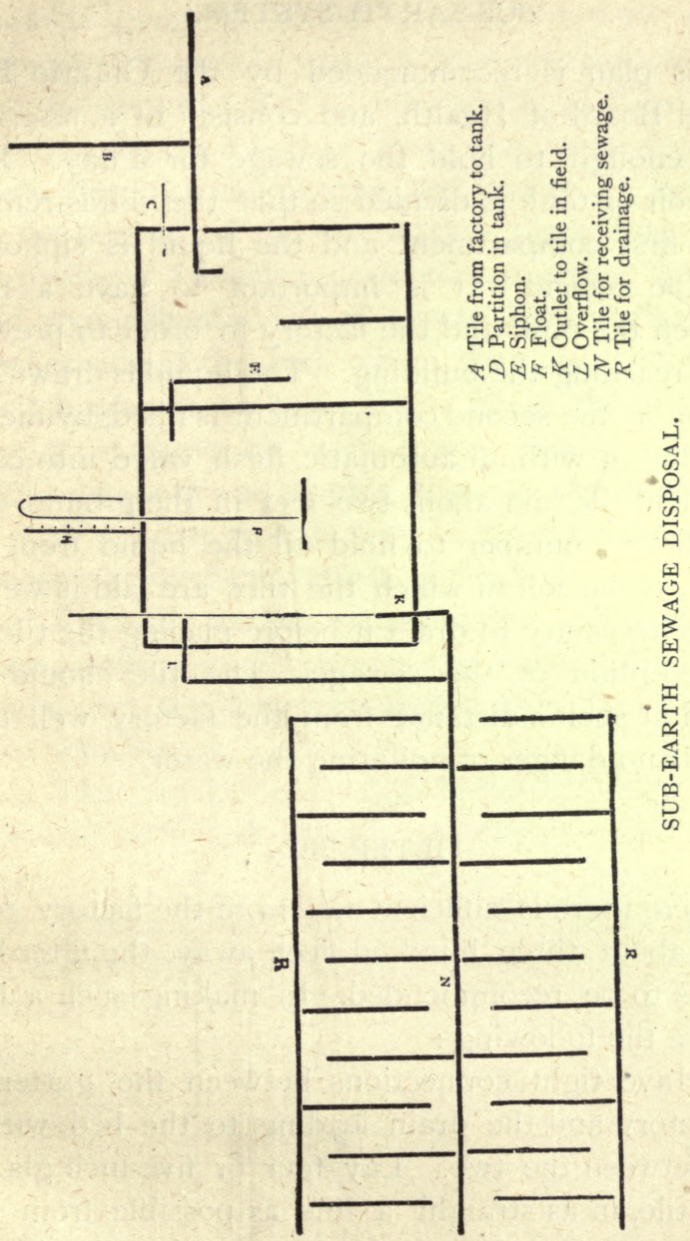




\section{SUB-EARTH SYSTEM.}

This plan is recommended by the Ontario Provincial Board of Health, and consists of a reservoir large enough to hold the sewage for a day. This reservoir or tank is divided so that the solids remain in the first compartment and the liquid is siphoned into the second. It is important to have a trap between the tank and the factory in order to prevent odors reaching the building. The liquid is drawn off, as soon as the second compartment is filled, by means of a plug or with an automatic flush valve, into common field tile laid about two feet in the ground, and of sufficient number to hold all the liquid from the tank. If the soil in which the tiles are laid is wet, it will be necessary to drain it before placing the tile for the reception of the sewage. The tile should be placed at such a distance from the factory well that there is no danger of polluting the water.

\section{FILTER-BED. .}

Where there is sufficient fall from the factory to a point about three hundred feet away, the filter-bed plan is to be recommended. In making such a bed observe the following :

I. Have tight connections between the gutter in the factory and the drain leading to the bed, with a trap between the two. Lay four or five-inch glazed sewer tile, in as straight a line as possible, from the factory to the filter-bed. These tiles should be cemented at the joints and be laid below frost. At 
a safe distance, say, one hundred feet from the factory, ordinary tile may be used, as they are less expensive.

2. Excavate a bed about twenty feet by twenty feet to a depth of two or three feet, using the dirt to bank the sides, making the bed four to six feet deep. In the bottom of the excavation place from two to four rows of four-inch drain tile, covering the joints, and giving them a fall of two to four inches to the further side of the bed, where they may empty into a ditch, stream, or bay. Then fill in the excavation on top of thesé tile with coarse gravel. Make the surface smooth and sloping towards the farther side.

3. A wooden trough may be used for distributing the sewage over the surface of the bed.

4. Rake the surface occasionally, and keep it free from weeds. In the winter the surface may be furrowed and the furrows covered with boards to prevent freezing.

5. The top three or four inches may have to be renewed with fresh sand or gravel every four or five years.

6. Where possible the "blow-off" on the boiler may be connected with the factory drain to clear it of grease, dirt, etc. Hot solutions of lye should be poured down the drain at least once a week. 


\section{CHAPTER IV.}

\section{METHODS OF PAYING PATRONS OF CREAMERIES AND CHEESERIES.}

IN a co-operative dairy, the most correct way of dividing proceeds from sales of butter or cheese, would be to make each patron's milk or cream separately, and after deducting the cost of manufacturing and marketing give each patron the remainder. In this way those furnishing milk or cream of good flavor would receive the benefit of the improved quality of the finished product. This plan, however, is not practicable in actual factory work, as the milk or cream must be all mixed together, and the quality of the finished product represents the average of the whole delivery. Another factor also enters into the question, and it is the one usually considered, though the first is just as important, probably more so. This second factor is the difference in the butter and the cheese capacity of milk and cream obtained from the various farms. In the early days of co-operative dairying all the milk and cream was considered to be of equal value, according to its volume or weight. For instance, it was assumed that one hundred pounds of milk would make so much butter or cheese, regardless of its richness. This was also assumed to be the 
case with reference to the butter production of cream, and the gallon or the "creamery space" was the standard. After a time people realized that there was a difference in the amount of cheese or butter made from one hundred pounds of milk, and also that cream varied in its richness, hence various tests were devised, which are discussed in Part I. The first test used in cream-gathering creameries was a test churn, in which a small quantity of each patron's cream was churned as often as possible, and the yield of butter ascertained. The results of these churn tests were taken as the average quality of the cream delivered by each patron. Then came the oil-test churn, in which a small quantity of cream is churned and the fat is melted into oil. The theory of this test is somewhat as follows: A standard creamery inch is one inch of cream in a pail (known as the driver's pail), which is twelve inches in diameter, and which tests one hundred on the scale. It is supposed that one pound of average butter contains twenty-five cubic inches of butter oil. A creamery inch contains about I 3 cubic inches, therefore 25 is about 22 per cent. of I 3. Any sample of cream which produces 22 per cent. of its bulk in the form of butter oil is supposed to yield one pound of butter per creamery inch.

The driver fills a glass tube to a depth of about five inches with cream. If the sample yields I.I inch of butter oil it is said to test 100 and is equal to one pound of butter per inch, because I.I is 22 per cent. of five. Sometimes the readings are made by means of a chart, and sometimes by means of a graduated 
rule. The chart is more accurate, as it is not important to have an exact depth of cream in the test tube, which is absolutely necessary when measuring with a rule.

The oil-test may not be considered a very reliable test for cream, and a buttermaker has to do a good deal of guessing to make his oil tests and churn results agree. In order to get approximately accurate tests, it is important that the drivers be accurate in measuring the cream, and careful in mixing it before taking a sample. It is also necessary to take samples from all the lots of cream delivered by or got from a patron each time. The buttermaker should be careful to get a complete and distinct separátion of butter oil, water, and curdy matter in each test tube. He should also be careful to read accurately.

The following are the directions given in Bulletin I 14, from the Dairy School, in connection with the Ontario Agricultural College:

"To make an Oil-Test. Upon their arrival at the creamery, place the samples in a warm place, as over the boiler, and leave over night to ripen thoroughly. They will not churn froperly unless zell ripened.

"The next morning place the samples in water at a temperature of about 90 degrees; and as soon as the cream will flow freely from one end of the tube to the other, place in the oil-test churn and begin churning. Should the cream at any time cool and thicken, place the samples in warm water to liquefy the cream again. Continue churning until there is evidence of a clear separation of the fat ; then place the samples in hot water, at a temperature of from 160 to 170 degrees, for from fifteen to twenty minutes.

"If the separation be complete, the fat will be clear and 
yellow, and there will be three distinct columns with sharp lines or divisions between them, viz., a column of clear fat on top, one of whey next, and one of curdy matter at the bottom. If there be not a clear separation, cool to about 90 degrees, churn again and proceed as before.

"To take a Reading. There is a chart prepared for the purpose. Placing the bottle in an upright position on the 'base line' of the chart, move it along until, when looking by the right side of the bottle, the top of the column of fat comes even with the uppermost slanting line on the chart. Next, still looking by the right side of the bottle, observe the line to which the bottom of the fat comes; the number on this line gives the reading.

"A small rule made especially for the purpose is more convenient than a chart. This, however, will give an accurate reading only when the test-tubes have been filled precisely to the mark. The chart consists of a sliding scale and gives the proportion of oil regardless of the depths of cream taken in the test-tubes.

"Sometimes the fat, though clear, is somewhat open. In such cases, or when the fat is not clear, allow the samples to become cold, and then place in water at a temperature of about $\mathbf{1} 20$ degrees $\mathrm{F}$. before taking a reading. About $\mathbf{I} 20$ degrees is a very suitable temperature at which to take readings.

"Meaning of the Reading. Cream that gives a reading of 100 in the oil-test will make one pound of butter for every inch of such cream in a cream pail twelve inches in diameter; cream testing I 20 will make I.20 pounds of butter per inch. To find the pounds of butter, multiply the number of inches by the reading and divide by Ioo."

The Babcock test for determining the fat in the cream is a much more accurate test and should be introduced into cream-gathering creameries as rapidly as possible. In order to overcome the difficulty of carrying scales, the cream may be measured as for 
the oil-test, and the weight of cream may be calculated by using the factor 4 .I to convert the inches of cream into pounds, e.g., a patron has ten creamery inches, IO $\times 4 . \mathrm{I}=4 \mathrm{I}$ pounds of cream. If this test 30 per cent. fat, he is credited with 12.3 pounds of fat.

To reduce the labor and expense of testing, the drivers may take samples at the farm in the ordinary oil-test tubes, and this may be examined by the buttermaker for flavor and acidity, on arrival at the creamery. This may then be transferred to a pint jar, labelled with the patron's name, and containing a preservative to prevent souring. At the end of two weeks or a month this composite sample may be tested for fat, and this test will represent the average cream delivered by the patron during the month. To find the total pounds of fat delivered multiply the pounds of cream by the percentage of fat and divide by IOo, e.g., the total delivery of cream during the month is $I, 000$ lbs. The composite sample tests 30 per cent. fat, then the pounds of fat are $1,000 \times$ $30 \div 100=300$ lbs. fat.

Ordinary pint milk bottles may be used for composite samples of both milk and cream. Paste a gum label with the patron's name written on it in ink. Coat this with white shellac, which will prevent the label being washed off, and if given two coats such a label will last for a year or more. An excellent preservative is made by mixing seven parts of potassium bichromate with one part of corrosive sublimate (bichloride of mercury). The quantity of preservative for each bottle is about what will lie on a ten cent 
piece. In hot weather a little more will have to be added at the end of two weeks. Take from each patron's delivery of milk or cream about one-half fluid ounce, and place in the bottle. At the same time give the bottle a rotary shake to mix the cream with the milk. Keep the bottles corked by using turned wooden corks. It may be necessary to put the samples in a cool place in warm weather. When testing these composite samples, first set them in water at a temperature of about $\mathrm{I} I 0$ degrees $F$., to loosen the cream. Then mix thoroughly by pouring from one vessel to another. If the samplesahave thickened, a small amount of potash in the form of lye may be added. Before adding the sulphuric acid the samples must be cooled to about 65 degrees $\mathrm{F}$. Then proceed with the test in the usual way.

It will thus be seen that the value of milk or cream for buttermaking depends upon the fat it contains, as fat is the only constituent of importance which enters into the manufacture of butter. In cheesemaking, however, we have two constituents of the milk which are of importance, therefore the methods of dividing proceeds among the patrons of cheeseries is more complicated. Three systems are now in use among Canadian factorymen. These three systems are briefly discussed in Bulletin II4 from the Ontario Agricultural College as follows :

"I. Paying according to the weight of milk regardless of its quality. The principle of this plan is that all milk is of equal value per $100 \mathrm{lbs}$. for cheesemaking. It rests on a false assumption, is unjust, and it tends to promote dishonesty. 
Factorymen and honest patrons who complain that some of the milk is skimmed and watered by dishonest patrons deserve little sympathy, because a remedy is within the reach of all at a very small cost. The milk of all patrons should be tested regularly, and be paid for according to its value for cheesemaking.

" 2 . Paying according to the weight of fat delivered in the milk, the same as at creameries. The principle of this system is that all milk is valuable for cheesemaking in proportion to the fat which it contains. The system is manifestly more just and equitable than the first-named, and is to be commended in preference to 'pooling' by weight of milk. The chief weakness of the plan is that the yield of cheese is not in direct proportion to the fat contained in the milk; therefore, it gives an undue advantage to the patrons sending milk containing a high percentage of fat.

" 3 . Paying according to the fat and casein in the milk, the casein being represented by the factor 2 , added to the percentage of fat. The principle of this system is that milk is valuable for cheesemaking in proportion to the fat and casein contained in it, and it further assumes that the percentage of fat plus 2 represents the available fat and curdy compounds in milk for cheesemaking.

"The application of the third system is very simple. To illustrate: The tests for fat of patrons' milk are 3.o, 3.5, 3.8, and 4.0. The percentage of fat and casein are $3+2=5.0$; $3.5+2=5.5 ; 3.8+2=5.8$; and $4.0+2=6.0$. The pounds of fat and casein are calculated by multiplying the pounds of milk delivered by the percentage of fat and casein. Thus, if the first patron had 1,500 lbs. of milk, he would be credited with $1,500 \times 5 \div 100=75$ pounds of fat and casein. If the second delivered 2,000 pounds of milk he would be credited with $2,000 \times 5.5 \div 100$, or I rolbs. fat and casein, and so on with the others. The value of one pound of fat and casein is ascertained by dividing the net proceeds of the sale of cheese by the total pounds of fat and casein delivered. 
"The following table gives a summary of the results obtained during five years' experiments, in which 250 experiments were made, with nearly 200,000 lbs. of milk, which contained percentages of fat varying from 2.7 to 5.5 :

\begin{tabular}{|c|c|c|c|c|c|c|c|c|}
\hline \multirow{2}{*}{$\begin{array}{l}\text { Aver- } \\
\text { age } \\
\text { per } \\
\text { cent. } \\
\text { fat in } \\
\text { milk. }\end{array}$} & \multirow{2}{*}{$\begin{array}{l}\text { Lbs. } \\
\text { cheese } \\
\text { made per } \\
\text { roo lbs. } \\
\text { milk. }\end{array}$} & \multirow{2}{*}{$\begin{array}{c}\text { Lbs. } \\
\text { cheese } \\
\text { made per } \\
\text { I lb. fat } \\
\text { in milk. }\end{array}$} & \multirow{2}{*}{$\begin{array}{l}\text { Lbs. } \\
\text { cheese } \\
\text { made per } \\
\text { x lb. fat } \\
\text { and } \\
\text { casein or } \\
\text { per cent. } \\
\text { fat }+2 \text {. }\end{array}$} & \multicolumn{2}{|c|}{$\begin{array}{l}\text { Lbs. loss of fat and } \\
\text { casein in whey. }\end{array}$} & \multirow{2}{*}{$\begin{array}{l}\text { Per cent. } \\
\text { lost in } \\
\text { curing } \\
\text { in four } \\
\text { weeks. }\end{array}$} & \multicolumn{2}{|c|}{ Average score. } \\
\hline & & & & $\begin{array}{c}\text { Per } \\
\text { sooo lbs. } \\
\text { milk. }\end{array}$ & $\begin{array}{c}\text { Per } \\
\text { roo lbs. } \\
\text { cured } \\
\text { cheese. }\end{array}$ & & $\begin{array}{c}\text { Flavur } \\
\text { max., } \\
35 .\end{array}$ & $\begin{array}{c}\text { Total } \\
\text { max., } \\
\text { Ioo. }\end{array}$ \\
\hline 2.87 & 8.75 & 3.04 & I.79 & $2.7 \mathrm{I}$ & 3.09 & 4.26 & 30.4 & 89.9 \\
\hline 3.22 & 9.03 & 2.80 & 1.72 & 2.75 & 3.15 & 4.43 & 30.2 & 89.4 \\
\hline 3.83 & 10.02 & $2.6 \mathrm{I}$ & 1.71 & $3 \cdot 34$ & 3.21 & 4. 10 & 30.8 & 90.3 \\
\hline 4.23 & I0.67. & 2.53 & I.7 I & $3.2 \mathrm{I}$ & 3.02 & 4.05 & 31.0 & 90.4 \\
\hline 4.74 & I 1.44 & $2.4 \mathrm{I}$ & 1.69 & $3.64^{*}$ & 3. $18^{*}$ & 3.07 & 31.0 & 89.8 \\
\hline 5.21 & 12.13 & 2.32 & I. 68 & $3.40^{*}$ & $2.80^{*}$ & 3.53 & 31.5 & 91.6 \\
\hline
\end{tabular}

* Fat only. Casein not determined.

"Amounts of money (cheese 8c. per lb.) credited by three systems and also value of cheese.

\begin{tabular}{|c|c|c|c|c|}
\hline $\begin{array}{l}\text { Average } \\
\text { per cent. fat } \\
\text { in milk. }\end{array}$ & $\begin{array}{c}\text { Weight of } \\
\text { milk-r,ooo lbs. } \\
\text { milk. }\end{array}$ & $\begin{array}{l}\text { Weight of fat } \\
\text { in } x, 000 \text { lbs. } \\
\text { milk. }\end{array}$ & $\begin{array}{l}\text { Weight of fat } \\
\text { and casein } \\
\text { in } 1, \infty 00 \text { lbs. } \\
\text { milk-or fat, } \\
+2 .\end{array}$ & $\begin{array}{l}\text { Value of cheese } \\
\text { made from } \\
\text { r, oo lbs. } \\
\text { milk. }\end{array}$ \\
\hline 2.87 & $\begin{array}{ll}\$ 8 & 27\end{array}$ & $\$ 59 \mathrm{I}$ & $\$ 669$ & $\$ 7$ oo \\
\hline 3.22 & 827 & 663 & 718 & 722 \\
\hline 3.83 & 827 & 789 & 802 & 802 \\
\hline 4.23 & 827 & 871 & 856 & 854 \\
\hline 4.74 & 827 & 976 & 927 & 9 I 5 \\
\hline $5.2 \mathrm{I}$ & 827 & I0 73 & 99 I & 970 \\
\hline
\end{tabular}

"Our five years' experiments prove that this third system comes nearest to the actual value of the cheese produced, 
though it still places a slight premium on the milk fat. It encourages the production of good milk, and at the same time does not discourage the majority of patrons who have average milk, and who are apt to envy those whose cows give a small amount of rich milk, and who draw a large share of the proceeds of cheese sales, when the money is divided on the basis of the fat only."-O. A. C. Report, I898, p. 52 .

In addition to weighing and testing the milk and cream delivered by each patron, it is important that a concise and clear statement be furnished at the end of each month. The following may be taken as a guide for a whole milk creamery:

\section{Creamery}

$$
\text { ....... I9. }
$$

Statement for month of ...........

Mr. ...........

Lbs. milk received.

Av. per cent. fat.

Lbs. butter.

Lbs. milk to one lb. butter.

Per cent. increase of butter over fat.

Selling price of butter per lb.

Cost per Ioo lbs. for hauling.

Net value I lb. butter.

Net value I lb. butter fat.

Net value Ioo lbs. milk.

Total amount received for butter.

Total cost of manufacturing.

Lbs. butter taken out by patron ...... value ......

Net amount due patron. 
The dairy department of the Ontario Agricultural College uses a blank form as follows, where the milk and cream are purchased outright, according to the fat which they contain :

ONTARIO AGRICULTURAL COLLEGE,

Guelph,............ . .

DAIRY SCHOOL

In account with $\mathrm{Mr}$.

From......................

Dr.

Cr.

\begin{tabular}{|c|c|c|c|c|}
\hline bs. milk & & & Lbs. cheese & \\
\hline Per cent. fat & & . & Lbs. butter :...@. & $\cdots \cdot$ \\
\hline Lbs. fat & $\cdots$ & ... & Hauling milk...@. & . \\
\hline Price per lb. fat .... & ... & $\cdots$ & $\cdots \cdot$ & .... \\
\hline Value of fat.... & & & 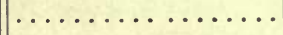 & ... \\
\hline $\begin{array}{c}\text { Allowance for skim- } \\
\text { milk } \ldots \ldots \ldots \\
\text { Total . . . . }\end{array}$ & & & $\begin{array}{c}\text { Balance due patron. } \\
\text { Total ......... }\end{array}$ & \\
\hline
\end{tabular}

Certified correct

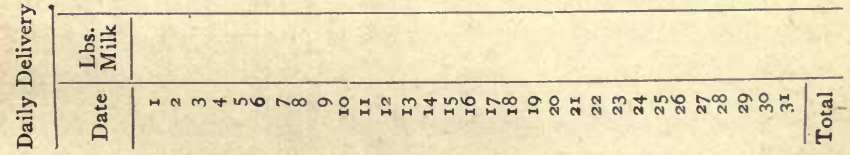

The Tavistock cheese factory uses a form as follows : 
Tavistock, Ont.,................

Monthly Statement of The Tavistock Cheese Factory,

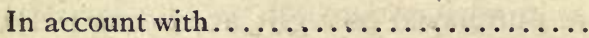

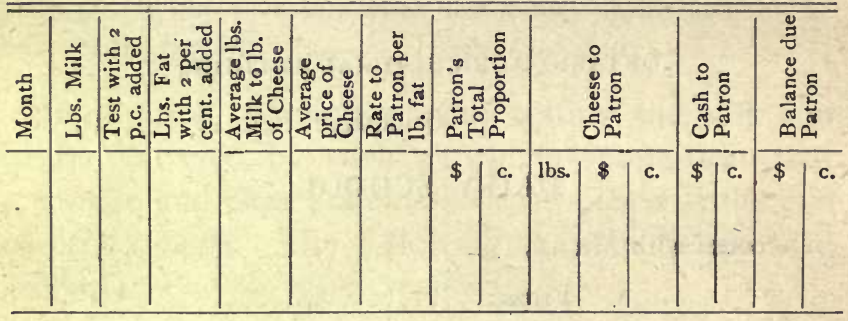

Some factories combine a monthly statement with a cheque. The cheque is detached by the patron from the monthly statement, and presented to the bank for payment. 
CHAPTER V.

\section{CANADIAN CHEDDAR CHEESEMAKING.}

THE cheese industry is the most valuable branch of agriculture in Canada. Our exports of this one article are valued at over twenty millions of dollars annually. There are about 3,500 factories for the manufacture of cheese in the whole of Canada, but over 3,000 of these are found in the Provinces of Ontario and Quebec. It is altogether likely that the cheese centres of Canada will move out West, and that the older provinces will engage more largely in buttermaking, because cheesemaking is much more exhaustive of soil fertility, and the newer provinces are much better able to withstand the drain than the older settled parts of Canada. However, cheesemaking pays the farmer much better during an average of years than does buttermaking, and for some time we are likely to continue making cheese, or at least until the butter industry is established on a better basis than at present.

The system of cheesemaking which is followed almost exclusively in Canada is that known as the Canadian Cheddar, which is an improvement upon the English Cheddar system in so far as its application to Canadian conditions is concerned. The system orig- 
inated in the village of Cheddar, which is in Somersetshire, fifteen miles from Bristol. According to a local poet, Cheddar is

"Famous for capital C's--

Cliffs, Caverns, and Cheddar Cheese!"

Here the monks, who loved good living, used to have this famous cheese on their tables, and travellers who visited the "Cliffs and Caverns" spread the fame of Cheddar cheese to all parts of the world.

The main features of Canadian Cheddar cheesemaking are:

I. The use of steam heat to regulate the temperature.

2. The ripening of the milk before adding the rennet.

3. Removal of the whey from the curd with a small amount of acid.

4. Matting or Cheddaring the curd.

5. Ripening the curd before milling.

6. Airing the curd to improve the flavor.

7. Applying the salt to the curd before pressing.

8. The cylindrical shape, weighing from seventy to ninety pounds.

To make good Canadian cheese it is important to have a good building equipped with modern utensils, a large supply of clean sweet milk, a maker who thoroughly understands his business, and, combined with all this, good business management on the part of someone. The object of the cheesemaker is to reduce the water content of milk, and to preserve in a palat- 
able, digestible, and concentrated form as much as possible of the solids of the milk. The two chief solids made use of are fat and casein. The other solids of milk nearly all pass off in the whey. Only about one-half of the total milk solids are available for cheesemaking. The remainder is almost wasted, which seems a great pity, as they are most valuable food constituents.

\section{RIPENING THE MILK.}

The first step in the making of cheese is the ripening of the milk to such a point before adding the rennet that the curd will be ready to "dip," $i$. e., have sufficient acid for removal of the whey, in about two and a half or three hours. Ripening consists of the development of lactic acid in the milk, and by securing the same degree of ripeness each day the cheese are more uniform, and the maker knows more definitely how "the milk will work." Formerly the ripeness of the milk was measured by means of a rennet test, the first of which was devised by the late J. B. Harris. It consisted of a cup of milk at a temperature of 86 degrees, to which a teaspoonful of rennet was added. The rennet was quickly stirred into the milk and the time in seconds required for coagulation was noted. As cups and spoons vary considerably in size, something more accurate was found necessary. An eight-ounce measuring glass for milk and a drachm measure for the rennet was the next improvement. The milk, at a temperature of 86 degrees, has a drachm of standard rennet extract added 
to it. This is stirred into the milk by means of a spatula. The time at which the rennet was added, and also at which coagulation takes place, are carefully noted. A piece of burnt match or a small stick in the milk helps to note the latter point. The milk should coagulate in from eighteen to twenty-two seconds, which will allow it to remain in the whey from two and a half to three hours.

The Monrad and Marchall rennet tests are also used to a limited extent in Canada.

However, if the ripening of milk is the development of lactic acid, it is important that the degree of lactic acid shall be measured in a more accurate way than can be done by means of a rennet test. The rennet test measures the susceptibility of milk to the action of rennet, and only indirectly does it test the acidity of milk. For this purpose an acidimeter is much more valuable, and it can also be used for measuring the acidity of curd at further stages of cheesemaking instead of using the hot iron test, which is very unreliable and of little or no value except to experienced cheesemakers.

The following description of the acidimeter has been prepared by the Dairy School in connection with the Ontario Agricultural College :

"By the term acidimetry we mean the process of determining the strength of acids, or degree of sourness, as by the use of alkaline solutions. The fact that acids and bases have the power to destroy the characteristic properties of each other is well known. Moreover, from many experiments conducted it has been discovered that the act of neutralization is a definite one ; 


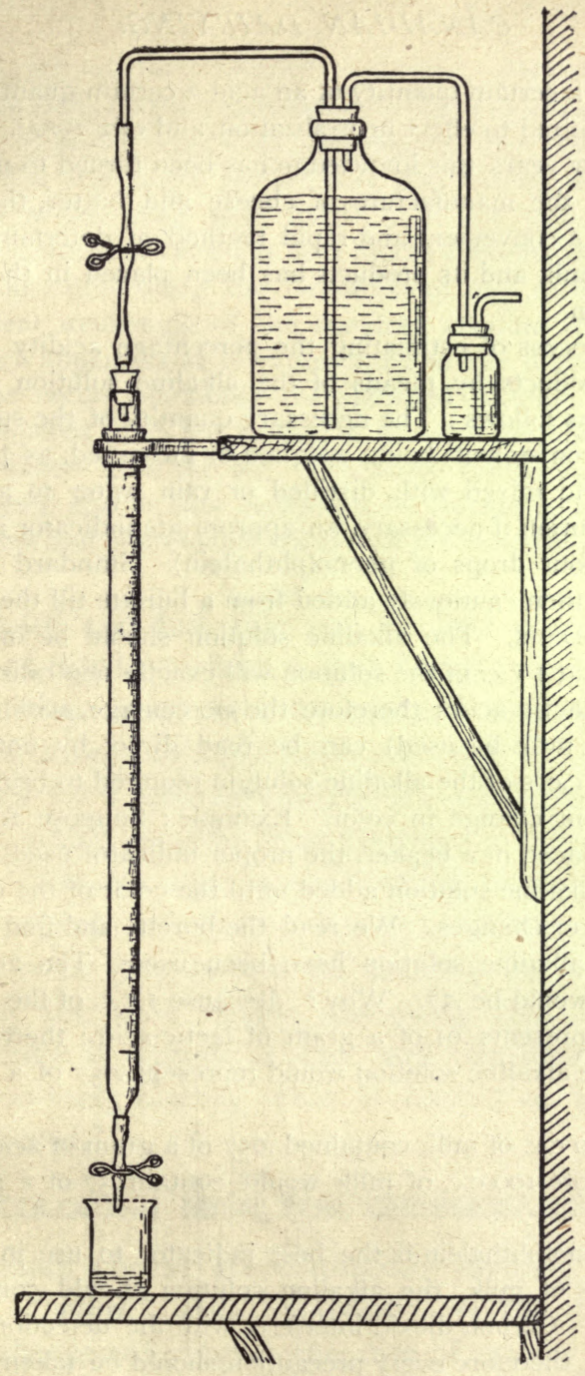

ACIDIMETER. 
that is, for a certain quantity of an acid a certain quantity of a base is required to effect neutralization, and vice versa. Within the past few years this knowledge has been turned to practical account in the manufacture of cheese and butter, the result being tha a convenient and rapid method of determining the acidity of milk and its products has been placed in the hands of dairymen.

"The process of estimating the percentage acidity of milk and its products by means of the alkaline solution may be described as follows: The necessary quantity of the substance (ro c.c. is convenient) being weighed or measured, as the case may be, and mixed with distilled or rain water to a proper state of dilution if necessary, an appropriate indicator is added (three or four drops of phenolphthalein). Standard alkaline solution is then cautiously added from a burette till the change of color occurs. The alkaline solution should be of such a strength that I c.c. of the solution will exactly neutralize .or of a gram of lactic acid; therefore the percentage acidity (if 10 c.c. of the milk be used) can be read direct by noting the number of c.c.'s of the alkaline solution required to bring about a permanent cliange in color. Example: Suppose Io c.c. of milk are placed in a beaker, the proper indicator used, and the standard alkaline solution added until the color of the contents of the beaker changes. We read the burette and find that 5.7 c.c. of the alkaline solution have been used. The acidity of such milk would be .57 . Why? Because I c.c. of the alkaline solution represents . OI of a gram of lactic acid ; therefore 5.7 c.c.'s of the alkaline solution would represent .057 of a gram of lactic acid.

"Now Io c.c. of milk contained .057 of a gram of acid.

- "Therefore I00 c.c. of milk would contain .57 of a gram of acid.

"As phenolphthalein is the best indicator to use in testing the acidity of milk, the alkaline solution should contain no carbonate. Carbon dioxid interferes with the detection of the end-point ; therefore every precaution should be taken to prevent the solution from absorbing this gas. The accompanying diagram shows a small bottle attached to the larger one, which 
contains the standard alkaline solution. This small bottle should be filled with a concentrated solution of caustic soda or potash. It will be seen from the diagram that the air which passes into the larger bottle must first bubble through the contents of the small wash bottle. In this way any carbon dioxid contained in the air is held by the contents of the wash bottle, thus preventing the formation of any carbonate and consequent weakening of the standard alkaline solution. If some such apparatus as is represented in the diagram is not used, the bottle containing the standard solution should be kept stoppered when not in use, to prevent the absorption of carbon dioxid from the air. The bottle containing the indicator should also be kept stoppered, to prevent evaporation of the alcohol and consequent change of the strength of the indicator."

No hard and fast rule can be laid down for the degree of ripeness which is best for all conditions. A cheesemaker must find for himself what degree of ripeness of the milk will allow the curd to remain in the whey for a sufficient length of time to be properly. cooked, which requires from two and a half to three hours. This can only be obtained by experience, and the rules given are to be taken as guides only. There is little or no gain in time for making the cheese by ripening the milk before renneting, but if set too sweet there is danger of the curd remaining in the whey too long, causing what is known as a "wheysoaked curd."

\section{COLORING MILK FOR CHEESEMAKING.}

Canadian cheese are commonly divided into two classes, "white" and "colored." If the latter are made, cheese-coloring at the rate of one to one and a half ounces of coloring per 1,000 pounds of milk is 
added soon after the milk is in the vat and the total weight known. Cheese color is usually made from annatto seed dissolved in potash, or from a mineral source, such as coal tar. The tendency is in favor of uncolored cheese. If people who ask for colored cheese saw the material used for giving it the deep yellow color there would be less demand for such cheese. The object is to deceive the purchaser of the cheese, who thinks that he is getting a richer cheese because it is more highly colored.

To color evenly add the required amount of coloring to a large dipperful of milk, then mix thoroughly by stirring it through the whole vat of milk.

\section{RENNET AND RENNETING.}

Rennet is an extract from the stomach of a calf, and contains, in addition to preservatives, peptic and lactic ferments. Some plants, such as the artichoke, melon tree, and butterwort, contain properties similar to rennet. It is usually sold in the form of a liquid extract. This should be clear, and have a pleasant, not too strong smell. Sometimes cheesemakers make the extract from calves' stomachs, but it is safer to purchase a reliable commercial brand. As rennet varies in strength it should be tested by means of the rennet test. Rennet is also sold in powder and tablet forms, but these have not been popular among Canadian cheesemakers, largely because of the trouble in getting them dissolved. The liquid is always ready for use, and the average man does not wish any extra labor when he gets ready to "set the vat." 
Rennet in powder form is much more concentrated, is less likely to be adulterated, and if kept dry is in less danger of spoiling as compared with the liquid form. It would also reduce the cost of transportation and expense of bottling or putting in casks, yet it does not seem to meet with favor. The rennet powder should be grayish white in color, with little smell, and be easily dissolved in water. We expect to see this form of rennet come into more general use in the near future.

The action of a weak acid is apparently similar to that of rennet, but there is a marked difference. The acid causes coagulation by neutralizing the lime salts, which cause the casein to be held in solution. The rennet acts on the casein of milk, splitting it into two parts-a soluble which passes off in the whey and is lost for cheesemaking, and an insoluble which forms a chief part of what is known as curd. However, the action of rennet is not as yet fully understood. By some it is considered that rennet acts by katalysis or contact, causing the coagulation of the casein by its presence. This view is not accepted very widely. We know it is a powerful agent, but as to the exact nature of its method of producing coagulation we are yet largely in the dark. It does not act on milk if it has been boiled, or if an alkali be present. Large quantities of water in milk also retard rennet action. In hot weather, when patrons use soda in the milk to keep it sweet, the cheesemaker has trouble in securing a proper coagulation. This is also true on wet mornings when considerable rainwater gets into the milk. 
Rennet acts most quickly on milk when it is at a temperature near that of the animal body ( 98 degrees F.). Its action is destroyed if heated to about 158 degrees $F$, and is very much weakened if heated to 140 degrees F. It is said to coagulate the milk of young animals more quickly than that of old animals. Rennet action, as to time, depends upon the acidity of milk, the temperature of the milk, the strength of the rennet, the proportion of the rennet to the milk, and the temperature of the water used for diluting the rennet. The greater the acidity of the milk up to .2 to .3 per cent., the higher the temperature of the milk up to about 100 degrees $F$., the stronger and the greater the proportion of rennet; and the warmer the water up to 100 degrees $F$., the less the time required for coagulation. In order to secure as complete a coagulation of the milk as possible it is desirable to have it take place as rapidly as consistent with good work in the after stages of cheesemaking. If coagulation takes place too rapidly the curd cannot be cut so well, nor can it be properly cooked, hence in practice it is customary to retard it to some extent by not ripening the milk too much, and by using temperatures and quantities of rennet which give an opportunity to carry on the after processes in a more satisfactory manner. Instead of using warm water to dilute the rennet it is better to use cold water. Instead of 98 degrees, 86 is a better temperature for renneting milk. From 86 to 95 degrees, each increase of 1 degree in temperature of the milk decreases the time required for coagulation by about one minute. From 86 to 80 
degrees each decrease of I degree in temperature increases the time for coagulation by one to two minutes. Adding the rennet to milk at a temperature of 80 degrees causes an extra loss of fat in the whey, although it appears to make little or no difference in the quality of the cheese.

An increase from one to two ounces per 1,000 pounds milk decreases the time for coagulation by about one half hour. An increase from two to three ounces per I,COO pounds milk decreases the time required for curdling by about ten minutes. Increasing the quantity of rennet from three to four ounces per 1,000 pounds milk decreases the time by about seven minutes, and from four to five ounces the time is decreased by about three minutes.

Rennet acts somewhat slowly, causing gradual precipitation of the casein unless the milk be very ripe. The firmness of the curd depends upon the percentage of fat in the milk, the acidity of the milk at the time of adding the rennet, the temperature of the milk during coagulation, the length of time which elapses after the rennet has been added, and upon the strength of the rennet. If less than about three ounces of standard rennet (such as Hansen's) per I,000 pounds milk be used, the curd does not appear to retain so large a portion of the fat in the milk as it otherwise could do, hence less than this quantity should not be used. Some makers economize on rennet at the expense of the yield of cheese. The average percentage of fat in the whey when using but from one to two ounces of rennet per 1,000 pounds milk is from 
.45 to .3 , while from similar milk treated with three ounces of rennet per 1,000 milk the whey contained but.I to .I 5 per cent. of fat. It is thought by some that a large quantity of rennet produces a cheese with a great deal of moisture. This is not so, but rather the reverse. Cheese made from milk to which two ounces of rennet per 1,000 pounds were added contained an average of 35.94 per cent. moisture. Cheese made under similar conditions, except that six ounces of rennet were used, contained 35.08 per cent. moisture, a decrease of nearly one per cent. The cheese made by using two ounces of rennet contained .089 per cent. of soluble nitrogenous matter, while those made with six ounces contained .I20 per cent. of nitrogenous matter soluble. What is usually considered extra moisture in cheese, made by using a large amount of rennet, is really a more soluble condition of the caseous matter. Rennet digests the curdy matter, and a large quantity causes the cheese to ripen more quickly. The length of time from " setting" to "dipping," and from "dipping" to salting of the curd, does not seem to be affected by the quantity of rennet used in the milk.

The amount of standard extract to use may be varied according to the time in which it is desired that the cheese shall ripen. Not less than three ounces per 1,000 pounds milk should be used, and as a rule it is not necessary to add more than five ounces at any time, and this only in the spring, when "quick curing" cheese are desired.

To ascertain the correct degree of ripeness for renneting, some form of rennet test has been used up to 
the present time, but, as previously pointed out, the Author considers the acidimeter a more correct test. The degree of acidity which will give best results cannot be stated positively, nor is it likely to be the same for all conditions or for all kinds of milk. Probably about .2 per cent. of acid in the milk at the time of adding the rennet, or what is commonly called "setting the vat," will be found satisfactory under most circumstances. Until the cheesemaker grows accustomed to the acidimeter it would be well to use both tests for a time. The acidimeter requires much less milk (hence less waste), less time, and the results are more certain. With the rennet test, rennet, temperature, time, and measure all influence the results, whereas with the acidimeter temperature and time do not affect the results; $h \wedge$ nce two sources of error are eliminated.

When adding the rennet to the milk, dilute with pure, clean, cold water, and stir it into the milk vigorously until it is completely mixed through all parts of the vat. This will take from three to five minutes in a large vat $(5,000$ to $6,000 \mathrm{lbs}$.) of milk. The milk should now be left perfectly still, unless there be some cream on the top, which should be removed, until coagulation is complete, which will be in from twenty to thirty minutes.

According to Snyder, from Ioo pounds of milk the following percentages of the milk constituents will be lost in the whey and recovered in the cheese :

Lost in Whey. Recovered in Cheese.

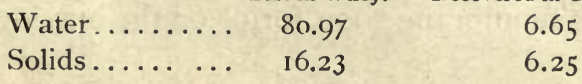




\section{CUTTING AND COOKING CURD.}

Curd is cut in order to expel the moisture and to ensure proper and even cooking. The test used to know when the curd is ready to cut is that known as the finger test, by which the forefinger is inserted carefully into the curd and then raised, when, if the curd break clean, it is ready for the knife. The cubes should be even and not over three-eighths of an inch in size. The horizontal knife should be used first lengthwise of the vat; then cut once crosswise and once lengthwise with the perpendicular knife. If the blades are not more than three-eighths of an inch apart, and. the cutting is done carefully, it is not necessary to cut any curd more than three times-once with the horizontal and twice with the perpendicular knife. The blades should be sharp and the knives kept in good repair. The horizontal knife should be allowed to cut its way into and out of the curd that there may be as little bruising of the curd as possible. Careless, rough handling at this stage causes an extra loss of fat and casein equal to about ten pounds of cheese on a vat of 6,000 pounds of milk.

Unless the curd be agitated after the cutting it will mat together, hence the curd should be gently stirred with the hand or by means of agitators soon after cutting. The curd on the sides and bottom of the vat should be in motion before heat is applied or before " cooking" begins. In large factories agitators run by a steam-engine are used. In small factories the hands or some form of curd rake are adopted for agitating the curd. A membrane soon forms on the outside of each 
particle of curd, which acts as a strainer, allowing the water to pass out and retaining the fat and casein. It also prevents the curd sticking together.

Steam heat should be applied through the medium of water under the pans, as there is less danger of scorching the curds. The heat should be applied slowly, taking from one-half hour to forty-five minutes to heat the curd from 86 to 98 or Ioo degrees. This heating causes a contraction of the curd by expelling the water from the interior of the cubes. The rapid development of the lactic acid at this favorable temperature also causes a rapid expulsion of the whey. In order that the moisture may be expelled uniformly throughout the whole mass of the curd, it is important to heat gradually and stir constantly during the heating process. After the curd is at the desired temperature of 98 to I0o degrees, constant agitation is not necessary, but it should be stirred often enough to keep it from matting and to ensure even and thorough cooking. In the case of "fast working" curds, it may be advisable to heat the curds to about I IO degrees to check the tendency to dry, crumbly cheese, which is characteristic of cheese made from over-ripe milk. In summer it is wise to remove most of the whey from the curd soon after heating, in orcler to better control the development of acid. In bad cases all the whey may be removed immediately after heating, and a quantity of clean, pure water, equal to the weight of the curd, at a temperature of 98 to 100 degrees, may be put on the curd and the cooking finished with this instead of the whey. This plan 
means more labor and greater loss, but improves the quality of the cheese. It is very important that water used in milk or on the curd shall be very clean and pure, else more harm than good may result. The practice of "washing " all curds either after dipping or after milling is not to be recommended, as it involves considerable labor, reduces the yield of cheese, and does not improve the quality of cheese from good milk. Washing curds is not recommended except for special cases, and then only when the supply of water is above suspicion. Washing retards the development of the lactic acid, which is not desired in normal curds.

The curd is properly cooked when it shows no tendency to stick together, after being pressed in the hand.

\section{DIPPING, MAT'TING AND MILLING.}

The term "dipping" is applied to that stage of cheesemaking when the whey is removed from the curd. Formerly the curd was dipped or baled from the whey, hence the term. It is important to know when the curd may be separated from the main body of the whey. It is advisable in hot weather to draw off the most of the whey before the curd has sufficient acid for dipping, in order that the remainder may be drawn quickly when ready. The test formerly used was known as the "hot iron test," which consists in heating an iron to near redness then cooling, and applying a well-drained piece of curd to the heated surface. By drawing this away carefully, fine threads 
one-eighth to one-quarter of an inch in length, will string from the iron. This corresponds with about .2 (two-tenths) of one per cent. acid, which is about the right degree of acidity in the curd at this stage. As the hot iron test does not rest on a scientific basis, it must pass away as cheesemaking becomes a science and the laws underlying the making of fine cheese become understood.

Makers who use the acidimeter may be surprised that the whey at dipping shows about the same acidity as did the milk when the rennet was added. This is largely due to the fact that the casein is acid in character, and most of the casein is removed from the whey by the action of rennet; hence the whey, some two or three hours after renneting the milk, shows no more, but usually less acid, than did the milk at the time of "setting" or of adding the rennet.

If too much acid develops on the curd before the whey is removed it causes an extra loss of fat in the whey, consequently less cheese is made, and the cheese is dry and crumbling and the color is "cut," i.e., it is whiter than from a normal curd.

After the curd has been dipped on a clean cloth spread over a rack, placed in the vat or in a curd sink, it should be stirred until the curd has the proper degree of moisture, which should be from forty to fifty per cent., but this must be determined largely by the judgment of the maker. No accurate and rapid test for this has yet been devised.

The Cheddaring or matting of the curd into pieces 
about one foot long and four to six inches wide is a distinctive feature of Canadian cheesemaking. In early days the curd was kept in the granular form until ready to salt. The chief advantage of matting is the improved texture and body of the cheese. The pieces of cheese should be turned frequently on racks or on the pan in order to prevent the whey forming in pools on the curd. The pieces of curd may be piled two or three deep and should be kept at a temperature of about 95 degrees until they become "meaty," and the whey which comes away from the curd shows from .7 to .85 per cent. of acid. (This will correspond with three-quarters to one inch or more of acid on the hot iron.). The curd may now be run through some form of mill which cuts the curd into pieces of uniform size. This stage was formerly known as "grinding," but a curd should never be put through any mill which "grinds" the curd, as this injures tlie body"and texture and causes too great a loss of fat.

If the curd be allowed to mature too much before milling it also causes an extra loss of fat. As a rule, the milling of the curd should come about half way between dipping and salting. After milling, the curd should be stirred frequently, to expel surplus moisture and to prevent matting and to improve the flavor. Curds having a bad flavor may be washed, directly after milling, with water at a temperature of about 98 degrees, with good results. 


\section{SALTING AND PRESSING.}

Cheese salt may be coarser than salt used on butter, as curd contains more moisture to dissolve the salt, and less of the coarse salt will leave the curd and be lost. The curd is in a fit condition to salt when it feels silky and mellow, and when the whey leaving the curd contains from I. to I.2 jer cent. of acid. The acidimeter should be used to determine the time of salting and thus secure uniform results from day to day.

Experiments conducted at the Ontario Agricultural College regarding the effect of salt in checking acidity indicated that salt reduces the percentage of acid in the whey leaving curds. The average of several trials gave an acidity of .98 at the time of salting. Onehalf hour after salting the percentage was reduced to $.8 \mathrm{I}$ and one hour after salting it was .94 . As salt when applied to the curd causes an increased flow of liquid, the reduction in percentage may have been due to an increased amount of moisture, hence a reduction in the percentage of acid. In order to settle this point the whey leaving the curd at a given time would have to be weighed.

The amount of salt to be added depends upon the moisture in the curd and upon the length of time for ripening. Moist curds require more salt, and quickripening cheese should have less salt. The rate may vary from one and a half to three pounds of salt per Ioo lbs. curd, or per 1,000 lbs. of milk, which latter is the more commonly adopted basis, while the 
former is more exact. The curd should be spread evenly over the vat or sink and half the salt be applied. After stirring this thoroughly and evenly through the mass of curd, the remainder should be put on and also be well mixed.

The effects of salt on curd are to expel moisture, improve flavor, body and texture of the cheese, and to retard ripening or curing and to add "keeping quality" to the cheese. If the salt be applied to the curd before it becomes "velvety" it tends to lessen the loss of fat from the curd, but the quality of the cheese is not so good. The chief defect is openness where curds are salted too soon. To some extent this can be remedied by ripening (curing) the cheese at a low temperature, as "open" cheese are seldom found among those ripened at a temperature of 40 degrees F. An extra quantity of salt (half a lb. per Ioo lbs. curd) will take the place of hand stirring to some extent, and increase the yield of cheese by about 10 lbs. per 6,000 lbs. milk.

In about twenty minutes after the salt has been thoroughly incorporated with the curd, and the harsh feeling, caused by the salt removing the moisture, has disappeared, the curd may be put into the hoops. Cheese hoops should be made of steel and be well galvanized to prevent rusting and marking of the cheese. In the bottom of the hoop place a clean cap cloth, made of good cotton. Seamless bandage of the proper length to lap about one inch on the cheese, should now be put on the bandager (a tin circle with a flange on the upper end, which fits 
neatly inside the hoops) and both are put on top of the cap cloth. The curd is now weighed or measured, and firmly packed into the hoop. The temperature of the curd at this time may be from 80 to 85 degrees F., although no special harm will result if the temperature be a few degrees above or below the range given. There is a tendency for "open " cheese to be produced if curds be put to press at extreme temperatures. When the hoop is full, the bandager is carefully removed and the bandage is left in the hoop and around the curd. On top of the curd another clean cap cloth is spread, and on top of this a wooden follower, which should fit closely in the hoop, is placed. After all the curd is in the hoops they are put under pressure.

Two kinds of presses are in use among Canadian cheesemakers - upright single screw presses, and horizontal gang presses. The latter are now more generally used, as they are more convenient. Continuous pressure is applied by means of a spring head, by a lever and weight, and by a water wheel, as well as by other devices.

Pressure should be applied very gradually to the curd, and the full pressure of about one ton for each cheese should not be applied until the cheese have been in the press for some time.

At the end of about one hour the cheese should be removed from the press, and the operation known as "dressing the cheese" be performed. This consists of pulling up the bandage to remove wrinkles, paring the end on which the follower rested so as to make it 
square and trim, cutting the bandage so that it will lap about one-half inch over each end of the cheese, putting a starched cotton circle on each end, wetting the bandage and cap cloths with clean hot water to assist in forming the rind, then placing in the press again. Pressure should be applied gradually until the maximum pressure is reached before leaving them for the night. The cheese should be turned in the hoops next morning and any defects in appearance should be remedied. They may be again returned to the press and allowed to remain as long as possible before they are required for the day's cheese. After being taken from the press the cheese are removed to the ripening-room. All the hoops, presses, followers, etc., should be washed thoroughly every day. The cap cloths should be kept clean and sweet. 'T he curd racks, curd sinks, and curd cloths need special care in washing in order to keep them in first-class condition.

\section{RIPENING CHEDDAR CHEESE.}

Cheese are said to be half made when placed in the ripening (curing) room. The ripening of cheese will eventually be a business by itself. Experts will take charge of the cheese from several factories and ripen them in rooms where the temperature can be regulated as desired. These experts will know what temperature, moisture, etc., is most favorable for each lot of cheese received at central depots, or coldstorage warehouses. Once a week will be sufficient to send the cheese to the central storages. The 
cheese will be safe from the bad effects of heat at the factory, the cheesemaker is relieved of the worry in caring for the cheese, one salesman can sell the cheese for several factories, and the buyer can inspect a large number of cheese in a short time, and at small expense, while the average quality of our cheese will be improved by adopting this plan. Large factories, which can afford to have properly equipped ripening rooms, may continue the present system, but smaller factories should co-operate in ripening and selling their cheese. Owing to the difficulty of getting factories to co-operate it is likely that this part of the business.will pass into the hands of capitalists, who are likely to be dealers in cheese.

The chief factors which influence the ripening of cheese after they are made are temperature, moisture, ventilation, length of time held at ripening temperature, and possibly to a slight extent, light.

The chief factor is temperature. A few years ago a temperature of 60 to 70 degrees was considered most favorable for ripening cheese. Recent experiments have demonstrated that a temperature of 40 degrees gives much better results than the higher temperature. Undesirable bacteria seem unable to grow in cheese at 40 degrees, hence bad flavors are less common in cheese ripened at 38 to 40 degrees. Whether 40 degrees is the best temperature or not cannot be stated at present, but experiments point to this as being a very favorable temperature. Whether or not it will pay to maintain cheese at this temperature has yet to be demonstrated. The chief 
advantages are a saving of about two per cent. in the shrinkage of the cheese as compared with ripening at 60 to 70 degrees, a cleaner, better flavor, more silky texture, and closer cheese. The disadvantages are the cost of maintaining a low temperature, the extra length of time required to ripen the cheese, hence more cost for manufacturing, and the tendency to the cheese being controlled by speculators.

A temperature of 60 degrees can be maintainẹd in a well-insulated room by having cement floors, and by cooling with a sub-earth duct, water, ice, or compressed gas. A maximum and minimum thermometer should be in every cheese ripening-room.

A cheap method of cooling and ventilating is had by digging a trench from six to ten feet deep, and from 150 to 200 feet long. In this trench place about two rows of eight or ten-inch tile. The farther end of the tile is connected with a stand-pipe, having a cowl on top which faces toward the wind. The end next the ripening-room is connected by means of a curb and a proper inlet to the room. An outlet for the warm air of the room is connected with the smokestack or a reverse cowl, and this causes a draft of cool air into the room from the tile laid in the ground. A temperature of about 60 degree; can be maintained in this way at small expense. This method of cooling was patented in the United States by a Prof. Wilkinson in 1874 and 1875 .

Where a large supply of cold water is available, cooling may be done by means of pipes placed around the room. 
Ice in boxes, placed in the ripening-room, helps to control the temperature, but requires too much labor to bring it in. A better plan is to connect the ice-house with the ripening-room and allow the cold air from the ice to cool the room, without handling the ice. (See plan in Appendix.)

A temperature of 60 degrees as compared with 70 degrees will effect a saving of from one-half to one per cent. in shrinkage during one month, and this will pay for the cost of " cool curing-rooms." Nothing is clearer than that Canadian cheese manufacturers must provide some method of ripening their cheese at a lower temperature than has been the custom in the past. Whether this means better individual ripening-rooms or central cold storage ripening-rooms, time will tell. Probably a combination of both will be followed for some years.

A moisture content of seventy-five to eighty-five per cent. seems favorable for the air in a cheese ripening-room. A hygrometer should be found in every room where cheese are ripened. One may be made from two ordinary thermometers which read alike. To the bulb of one attach a piece of lamp-wick and place the lower. end of the wick in a cup of distilled or rain water. After standing for some time note the difference in the reading of the two thermometers, and the table in the Appendix (p. 242) will indicate the percentage of moisture in the air of the room. If the air be too dry the cheese will crack and lose too much in weight. If the air be too moist it is favorable for the growth of mould on the 
cheese. This mould can be kept in check by spraying with formalin. It is a good plan to spray the walls, shelves, etc., in the spring with a bi-chloride of mercury solution of $\mathrm{I}$ to $\mathrm{I}, 00 \mathrm{O}$ parts of water, which will kill mould germs.

Ventilation in the room where cheese are ripening is also important. The air of the room requires to be changed. This can be done by opening the windows at night when the air is cool outside, if no sub-earth duct is available.

Light, as far as the Author's experiments have gone, has little or no effect on the ripening of cheese. It has been stated that light has a harmful effect on cheese ripening. Cheese made from the same vats of milk have been placed, one-half in a light room and one-half in a dark room, and so far as could be judged by the quality of the cheese there was little or no difference in them when ripe. There was also little difference in the mould on the cheese. The temperature and moisture content of the air were maintained as nearly alike as possible in both rooms.

These experiments have been conducted for several years, and would seem to settle the question of the non-effect of light on cheese ripening. To reduce the heat in light rooms, paint the windows with white lead, oil, and turpentine.

The longer the time cheese are held at any given ripening temperature the greater the loss in weight, and the more plastic becomes the cheese. The higher the ripening temperature the greater the loss of weight in a given time and the more completely does the "breaking down" process take place. 
The chief changes which occur in the ripening of cheese are :

I. A loss of water by evaporation. The higher the temperature of the air in the room, the drier the air, the more moisture in the cheese, and the more surface of the cheese exposed to the air the greater the loss by evaporation. In order to prevent this, coating of the cheese with paraffine wax has been tried. The cheese are dipped into wax at a temperature of about 180 degrees, and a slight coating adheres to the cheese. The best results are got by coating small cheese, and by coating when about one week old. It is a question whether this will pay anyone except the speculator, judging from the results obtained up to the present.

2. A gradual change of the insoluble curd to a soluble, digestible form takes place through the action of rennet, and possibly through the agency of bacteria to some extent.

3. If ripe cheese be exposed to a temperature of above 70 degress for any length of time, the fat leaves the curd and exudes through the bandage. A temperature of 80 degrees for a short time "starts the grease."

4. Some authorities consider that the fat is increased through a change of the albuminoid material into fat, but this is doubtful. In the fat itself little change takes place during ripening, according to Fleischman.

5. Any milk sugar which may not have been changed to lactic acid during the process of manufacture may change to butyric acid or to a ferment- 
able sugar, which produces gas $\left(\mathrm{CO}_{2} \& \mathrm{H}\right)$, and this causes the well-known "huffing" of cheese.

6. So far as known little change occurs in the mineral matter of cheese during the ripening process.

\section{COMPOSITION AND JUDGING OF CHEESE.}

The composition of cheese is affected by the quality and condition of the milk from which it is manufactured,.by the skill of the maker, and the class of cheese which is made. A well-ripened Canadian Cheddar has about the following percentage composition: 34 per cent. water, 3 I per cent. fat, 22 per cent. casein, 4 per cent. albumen, and 9 per cent. salt, ash, etc. Cheese made from milk testing 3.2 per cent. of fat contained 34 I per cent. of water, 30.7 per cent. fat, and 25.7 per cent. casein and albumen. Cheese made from 4 per cent. milk had 33 per cent. water, 34.3 per cent. fat, and $\mathbf{2 4 . 2}$ per cent. casein and albumen. An increase in the percentage of fat in the milk produced cheese with a higher percentage of fat, and less water and caseous matter, according to experiments made at the Ontario Agricultural College.

A scale of points for judging cheese may consist of :

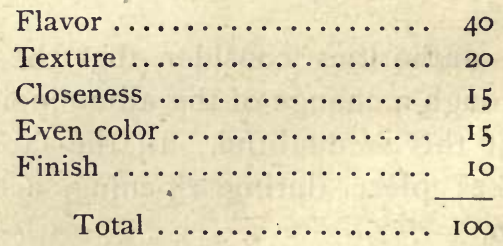

Good flavor in cheese is described as nutty, creamy, rosy, clean, rich, pleasant, etc. Flavor is spoiled by using tainted or sour milk, bad rennet, too much or 
too little acid, or exposure of the cheese to foul air in the making or ripening rooms.

Good texture is spoken of as silky, smooth, flinty, flaky, and firm. When moulded under the thumb and finger a cheese with good texture should mould like wax without being dry and crumbling or weak and pasty.

Texture is spoiled by rough handling, improper cooking, too much or too little acid, and by too much or too little salt.

The term "closeness" explains itself. There should be no openings in the plug of cheese when drawn with a trier. Having the curd properly ripened before salting, applying sufficient pressure, and ripening the cheese at a low temperature are favorable conditions for making "close" cheese.

The color should be uniform and bright, and may range in shade from white to a deep red, according to market requirements.

Uneven color results from improper mixing of the coloring with the milk and from too much acid, which "cuts the color." It may also be a result of the action of germs, which have the peculiar property of attacking the coloring, or causing spots of red, blue, etc., to develop in and on the cheese.

The finish of a well-made Canadian Cheddar cheese should be such as to give it a smooth, bright, clean, attractive, and stylish appearance. It should be even on the top, straight on the side, with no wrinkles on the bandage and no projecting edges on the cheese. All cheese should be as far as possible of uniform size and weight. 


\section{CHAPTER VI.}

\section{SPECIAL AND FANCY CHEESE.}

THE most common of the Canadian fancy cheese are the Imperial and Paragon. Both of these are soft cheese with a special flavor. They are put up in fancy earthenware packages, and retail at a high price. Their process of manufacture is more or less secret, and the trade is usually limited to large hotels, diningcars, etc.

Small cheese in the form of Flats (30 lbs.), Young Canadian (8 to ro lbs.), Canadian Stilton, Truckle, Cream and Sage cheese are also found on the market, but only in limited quantities. Some factories make a specialty of small cheese and receive an extra price for them. There is considerably more labor in making these small cheese, and the average Canadian cheesemaker does not care to trouble with them. Some are made in squares, having the block of cheese marked into pound or half pound squares. These should be coated with paraffine wax to prevent drying too much.

The most famous English cheese, after the Cheddar, are the Stilton and Cheshire. A true Stilton is a double cream cheese, i.e., the cream from one milking, usually the night's, is added to that of another 180 
milking. Rennet is added in sufficient quantity to cause coagulation in about one hour. The curd is then broken or cut very carefully, and after removal of the whey and draining of the curd, it is placed in hoops, salt is sprinkled between the layers of curd, and very light pressure is applied for several days. The cheese are ripened in a moist, cool atmosphere. The green mould and soft texture are characteristic of Stiltons. The outside is very much roughened through the action of mites. The cheese weigh about ten or twelve pounds and usually sell for twenty-five cents a pound. The system has not been reduced to a science as in the case of Cheddar cheesemaking.

The Cheshire cheese "of most exquisite smell" is considered by some as the second most famous cheese of the world. The rennet is added to the milk when the latter is at a temperature of about 75 degrees. The curd is cut in about an hour. It is afterwards drained, matted, milled, and salted. Pressure is applied for two or three days. They are ripened or cured at a moderate temperature. The finished cheese weigh from 50 to 100 pounds.

The Dunlop of Scotland is a mild, fat cheese weighing from twenty-eight to thirty-six pounds. The rennet is usually put into the milk at a temperature of 85 to 90 degrees. The curd is ready to be cut in about fifteen minutes. The remainder of the process is similiar to the Cheddar, which has now replaced the Dunlop system in most parts of Scotland.

Ròcquefort is the French cheese which we hear most about in Canada. It was formerly made from sheep's 
milk. The characteristic flavor is obtained by ripening the cheese in the limestone caves, which are 2,700 feet above the sea level. The caves are now controlled by a company which purchases the milk, curd, or new cheese from the farmers, and they control the ripening and sale of the product.

The Camembert, a small cheese made from whole milk and weighing ten to twelve oz., and the Brie, a soft French cheese weighing one to five lbs., are also met in a few shops in Canada.

The Edam, made in North Holland, and the Gouda, manufactured in South Holland, are the two best known Dutch cheese. The former is a hard cheese, shaped like a cannon ball, and weighing from three to four pounds. They are made from fresh milk, to which the rennet is added at 85 to 90 degrees, and in sufficient quantity to cause coagulation in from twelve to eighteen minutes. The curd is then cut and heated to about 95 degrees. When firm it is filled into moulds and pressed gently. The cheese are salted by applying salt on the outside of the green cheese when in the salting mould. They are ripened at a temperature of 50 to 65 degrees in a moist atmosphere.

The Gouda is also made from fresh milk. It is "set" at 90 degrees and coagulated in fifteen to twenty minutes. The curd is heated to 100 to I Io degrees and afterwards treated similarly to the Edam, except that the cheese are usually salted in brine. It is not so hard a cheese as the latter, and weighs from ten to twelve pounds. The edges of the cheese are bevelled. 
Both kinds of cheese are usually wrapped in tinfoil before sending to market. Some are dipped in fancy colors or oiled.

Swiss cheese are made extensively in Green County, Wisconsin, but are not made in Canada at all, so far as the Author is aware. The "Swiss eyes" are characteristic of this cheese. Its manufacture has not been based upon scientific principle up to the present time. The milk is set at 86 to 95 degrees and coagulated in about thirty-five minutes. The curd is cut or broken, then heated to $\mathrm{I} 34$ to $\mathrm{I} 48$ degrees. It is afterwards dipped and pressed into a flat shape about two or three feet in diameter and four to six inches thick. The salt is added at the end of two or three days, and the cheese are ripened at a moderately low temperature with eighty to ninety per cent. moisture in the atmosphere.

Gruyere is a half-skim Swiss cheese.

The Limburg of Germany and Belgium is made from both skim-milk and whole milk. The milk is set at about 95 degrees and coagulated in about forty minutes. The peculiar and pungent flavor of this cheese is well known.

Gorgonzola, an Italian cheese, is made from fresh warm milk directly it is drawn from the cow. It is of a peculiar pink-white color.

Cheese made from pasteurized milk lacks that consistency of body so essential in a good cheese. The rennet does not act properly when added to the milk, unless a soluble lime salt such as calcium chloride be added. This salt appears to restore the natural con- 
dition of milk for cheesemaking, but the experiments which have been conducted at the Ontario Agricultural College have not been altogether successful. Some of the cheese treated with calcium chloride appeared quite normal, while many of them lacked body and texture.

The list of varieties of cheese might be extended almost indefinitely, but the object is to call attention only to those which may be met with in Canada. Many of these fancy and soft cheese, which are now imported, could undoubtedly be made and will be made at home in the near future. 


\section{CHAPTER VII.}

\section{PASTEURIZERS, AND THE PASTEURIZA- TION OF MILK AND CREAM FOR BU'T'T'ERMAKING.}

The term pasteurize is derived from the name of the famous French chemist, Louis Pasteur, born in 1822 and who died in 1895 . The son of a tanner, he rose to the highest pinnacle of scientific fame. The system was first applied to agricultural pursuits in the manufacture of wine. He found that by heating the juice of the grape to a temperature of about 160 degrees, and afterwards cooling to fermenting temperature and introducing the desired ferment, he could control the flavor of the wines. This proved to be a great boon to the French farmer. It is not known that he did anything with reference to the dairy industry, but he is said to have remarked, "Ah, there is a rich field indeed for investigation!"

To Prof. Storch of Copenhagen, Denmark, belongs the credit of having perfected the system of pasteurization as applied to buttermaking. The Danish buttermakers have nearly all adopted this method, hence the uniform quality of Danish butter. Nothing has been of such value to the export butter trade of Denmark as the adoption of pasteurization, and what 
it has done for Danish buttermaking it will do for Canadian.

In dairy work, pasteurization means heating the milk or cream to a temperature between $\mathrm{I} 4 \mathrm{O}$ and $\mathrm{I} 85$ degrees, and afterwards cooling the product.

The system has been followed in the dairy department of the Agricultural College, Guelph, since I 895, with a marked improvement in the quality of the butter, especially in the winter time. When the milk or cream is in perfect condition there is no benefit from pasteurization, but this seldom occurs in ordinary creamery practice.

We commenced heating the cream in shot-gun cans set in a tank of hot water. The cream was stirred until it came to the desired temperature, then it was removed from the tank and allowed to stand for about twenty minutes, when it was cooled to ripening temperature. As this method involved a great deal of labor, we next used a channel heater especially constructed for heating cream by means of hot water. This plan gave very good satisfaction, but the cream was exposed to the air during the heating, and the heater was difficult to clean. We next purchased a continuous pasteurizer for milk and the results were more satisfactory. The first machines of this class were badly constructed mechanically and gave considerable trouble. They are now much improved, although the best coritinuous pasteurizers come from Denmark and Germany.

Pasteurizers are of two general classes-continuous and discontinuous. Pasteurizers which take the milk 
in a continuous stream at the bottom of the machine, and heat it by revolving the milk with suitable discs or paddles against a steam-heated surface, and deliver it at the top, are known as continuous. This class is suited for creamery practice, or for handling a large quantity of milk in a short time. The other class heats a limited quantity of milk at a time, and is suitable for small dairies, as the results are got by adopting lower temperatures for a longer time. Time and temperature are two important factors in deciding the effect on germ life. The object of pasteurization is to kill most of the germs or bacteria in milk or cream by means of heat.

As regards the method of driving, two classes of pasteurizers are found on the market-belt-driven and turbine, or steam applied directly. The former have proved more satisfactory, as it is more difficult to regulate the temperature in turbine pasteurizers.

The chief advantages of pasteurization for buttermaking are :

I. It destroys the germ life of milk or cream to a large extent, especially when heated to 185 degrees, which is the temperature to be recommended. A clean seed-bed is thus prepared for the proper germs to give fine flavor to the butter.

2. It tends to eliminate stable and feed flavors from milk and cream, especially with milk in winter.

3. The ripening of the cream may be controlled by the buttermaker, which is the most important point in making good butter.

4. In case of bad-flavored milk, it enables the but- 
termaker to improve very much the quality of his goods.

5. By the use of pure cultures. (commonly called "starters") a more uniform quality is produced from day to day throughout the year.

6. The butter possesses an improved keeping quality, hence is better suited for the export trade, as our butter does not reach the consumer for two or four weeks after being made.

7. An improved quality of butter may be produced at cream-gathering creameries by pasteurization of the cream when sweet. The pasteurization of sour cream is attended with more labor and more difficulties, and the results are not so good. It is difficult to pasteurize milk or cream which contains more than .2 per cent. of acid. However, after natural coagulation takes place in the cream, which will be when it contains ..4 to .5 per cent. of acid, the work may be done fairly well, but is usually attended with considerable loss.

8. There is less loss of fat in the skim-milk when the whole milk is pasteurized before separating, especiaily in winter. We have used nearly all the leading makes of separators for creaming hot milk. The upper bearing of the machine needs to be somewhat more loose than when running through milk at a temperature of 100 degrees, and plenty of good oil is required to lubricate the bearings when separating pasteurized milk.

9. A better quality of skim-milk may be returned to the farmers by sending it home hot. There is also 
less danger of spreading disease. In Denmark all skim-milk and buttermilk must be heated to 180 degrees before it is returned to the farm. This plan has materially lessened the spread of tuberculosis in that country. Hydrogen peroxide is used to test whether or not dairy products have been pasteurized, and the law is rigidly enforced.

The disadvantages of pasteurization are:

I. The extra cost for labor and machinery to heat and afterwards cool the milk or cream. A milk pasteurizer that will heat milk for two power separators will cost from $\$ 150$ to $\$ 200$.

2. There is difficulty in pasteurizing milk or cream which is "over-ripe," and this may cause trouble in hot weather, when milk or cream is not properly cared for and cooled at the farm and is delivered in poor condition.

3. Some trouble is experienced from the froth which rises on the milk as a result of heating. No practicable remedy for this has yet been discovered.

4. There is a tendency to lack of flavor, and sometimes there is a slightly "cooked" flavor as a result of pasteurization. The cooked flavor usually disappears in less than two weeks. Lack of flavor is objectionable for local markets.

Two points are essential if pasteurization is practised, viz., proper means of heating and cooling the cream, and the use of a proper culture to give the desired flavor to the cream and butter. Commercial cultures should be propagated three or four times in pasteurized skim-milk before they are used in cream 
for ripening in order to get the best results. A good pasteurizer and a good cream cooler, in which cold water or cold water and gas are used, provide the first requisites. To make a good culture, observe the following directions as given in bulletin I I 4 of the Dairy School :

"That there has been such a strong prejudice against the use of cultures or starters in the minds of some of our best buyers is not to be wondered at when we consider the careless, slipshod methods in which some makers prepare the culture, and the unrestricted use of them by others, regardless of the acidity of the milk or the flavor of the culture. The flavor of the culture used will largely determine the flavor of the cheese or butter made. Therefore the need of full and exact knowledge of the proper method of preparing and using cultures is manifest.

"First, provide suitable cans. It is better to have a duplicate set, if possible. Cans similar to the ordinary shot-gun cans, which are eight inches in diameter and twenty inches deep, are quite suitable. When the milk is in small lots it can be more readily heated and cooled than if it is kept in larger quantities.

"If large quantities of culture are needed, a special box or tank, large enough to hold the cans containing the culture for one day's use, should be provided. This should have steam and cold water connections. The cans may be left in the box, so as not to be influenced by the outside temperature.

"In starting a culture, we think it advisable to obtain a commercial culture. Empty the mother culture into a quart of cooled pasteurized milk. Allow it to stand at a temperature of 70 degrees for three or four hours, then add it to about ten pounds of pasteurized milk. This culture should be ready to propagate the next day.

"After selecting the milk, add about twenty per cent. of pure cold water and heat to 185 degrees, stirring constantly while it is being heated. Allow the heated milk to stand for twenty or 
thirty minutes at this temperature, then cool it rapidly to 70 degrees and add from two to four per cent. of the old culture ; stir well, cover the cans with a piece of close-fitting glass, and set away in a moderately warm, pure atmosphere. Do not disturb it until it is required for use.

"Before using, remove from one to two inches of the $\mathrm{m}$ lk from the surface of the can, as the flavor of the surface is not so good as below. Then break up the remainder by stirring it well in the can ; take out what is required and pour it a few times from one pail to another until it has a creamy consistency, in which condition it will be ready for use.

"The indications of a good culture are as follows: The whole mass is firmly coagulated, no water is found on the top, and it has a mild acid flavor, pleasant to both taste and smell.

"A wire-handled dipper is preferable for stirring the milk in the preparation of the culture.

"With the exception of a few special butter cultures, a culture that is good for cheesemaking is equally good for cream ripening, and vice versa.

"By thoroughly sterilizing cans, dippers and everything brought in contact with the culture, a good culture can be propagated for an indefinite length of time by adopting the pasteurizing method as explained in the foregoing."

The question is often asked, will the results be as good by pasteurization of the cream as by pasteurizing the whole milk before separating ? If the cream and skim-milk be heated soon after separating the results are much the same, except that the "conked" flavor is more pronounced on the cream heated to a temperature of 180 to 185 degrees than it is on similar cream heated when in the milk. At temperatures below 180 degrees the difference is not so marked. The higher temperature is to be recommended for the best results in buttermaking, as indicated in several 
series of experiments conducted at the Ontario Agricultural College. The chief results of this work are summarized as follows in Bulletin II 7 :

"I. The milk, as ordinarily delivered at a creamery, may be pasteurized. The milk used in these experiments was largely furnished by the patrons who had but ordinary facilities for taking care of it. In the winter we received our milk but three times a week ; in summer it is delivered daily.

" 2 . On but two occasions was the acidity of the milk over .2 per cent. The acidity averaged about .I 7 per cent. There is danger of the milk coagulating when heated, if it contains more than .2 per cent of acidity.

" 3. It was noticed that the lots heated from I85 to 195 degrees produced more foam than those heated to the lower temperatures of 140 to 160 degrees. This was most noticeable in the samples heated to 195 degrees. At 185 degrees the foam was not sufficient to cause much trouble in handling.

"4. The use of ten to fifteen per cent. of culture in the pasteurized cream enabled us to ripen the cream without any difficulty. The culture was a lactic acid bacillus.

" 5. Pasteurization of milk at 185 degrees, and the use of a pure culture is the best method of securing uniformity, keeping quality, and the mild flavor requisite for export butter.

" 6 . The cooked flavor, which was present in the butter made from milk heated from 185 to 195 degrees, usually disappeared at the end of about two weeks. In one or two lots heated to I 95 degrees the cooked flavor remained for some time. There is apparently no danger of cooked flavors on butter made from milk pasteurized at I 85 degrees, at the end of two weeks, or by the time it would reach the British markets.

"7. The species of bacteria present in the milk when the cows were kept in the stable, were very undesirable. Many putrefactive and fecal bacteria were present, hence the necessity of keeping the stable walls and rafters well cleaned. A good coat of whitewash increases the amount of light, and gives a general clean effect to the stables. 
" 8 . The average number of bacteria per c.c. ( 16 drops) found in milk pasteurized at 140 degrees ${ }^{\prime} \mathrm{F}$. was 631,046 , at 160 degrees F. was 12,848 , at 185 degrees F. was 81 , and at 195 degrees F. was 40."

These results are similar to those obtained in Denmark, and point very forcibly to the importance of pasteurization as a means of improving the quality of Canadian export butter. They also show how important it is to adopt a temperature of 180 to 185 degrees in order to free the milk from bacteria and add keeping quality to the butter. 


\section{CHAPTER VIII.}

\section{BUT'TERMAKING IN THE CREAMERY.}

WHEN receiving milk for buttermaking it is necessary at times to reject milk which is over-ripe, tainted, or too dirty to make a fine quality of butter. These defects should be kindly and tactfully pointed out to the fatron, if delivering his own milk. If the milk is brought in by a driver, a carefully worded note should be written calling attention to the defect and suggesting a remedy. If at all possible do not return any milk or cream without first giving warning. It is always better to have a patron a friend of the buttermaker than an enemy.

It is a good plan to send a monthly letter to each patron, calling attention to some important points to observe in the care of milk or cream, feeding cows, etc., showing them that the buttermaker or creamery man is taking an interest in the milk and cream producers. Printed letters serve the purpose, but where possible they should be copied on a cyclostyle, as it is less formal and is more likely to appeal to the readers.

The weighing of the milk and cream should be done by crediting each patron for all full pounds of "up-beam" weight. The practice of taking a few 
pounds of milk from each delivery in order to get a large "overrun" should not be followed, as it is dishonest, and sooner or later causes trouble. As soon as the milk is emptied from the patron's can into the weighing can, a sample should be placed in a pint bottle for testing. Samples should be taken from each and every delivery. The plan of taking a sample occasionally, or once a week, should not be allowed, as this results in an injustice to all parties.

A large quantity of milk in the receiving vat should not be heated to over 50 to 60 degrees, as there is danger of souring in case anything goes wrong with the machinery. In very cold weather a part of the heating may be done in the receiving vat, but a small heater or pasteurizer should be used for bringing milk to the proper separating temperature. Live steam should not be turned into the milk, nor should whole milk be elevated and heated by an ejector, as it tends to deteriorate the quality of the butter, and it is more difficult to get a complete separation of the cream where this method is adopted. The best temperature for separating is from 80 to 95 degrees in summer, and 100 to $\mathrm{r}$ IO degrees in winter, when not pasteurizing. It is necessary to heat the milk to a higher temperature with some separators than with others, in order to get "close skimming." The separator should run at full speed, and from five to ten minutes should be taken to attain full speed. If for any cause speed is decreased, there should be a corresponding decrease in the feed, or supply of milk, to the machine. No convenient form of speed indicator is yet sent out 
with separators. All separators should be provided with a speed indicator, which shows the rate of speed at any time by a glance. Present speed indicators are clumsy, inconvenient pieces of mechanism, and manufacturers ought to remedy this defect at once, because speed is such an important factor in good work with a cream centrifuge. When speed or temperature of the milk, or both, increase there may be a slight increase in the feed. It is not wise, however, to increase the speed beyond 500 revolutions per minute over that recommended by the manufacturer.

We may repeat the law of centrifugal force as applied to centrifugals : double the diameter of the bowl and the centrifugal force is doubled, double the speed of the bowl and centrifugal force is increased four times.

The separator requires constant oil of the best quality, especially when creaming pasteurized milk. The manufacturer's direction should also be closely followed. A separator must run smoothly to do good work. Trembling or vibration causes an added loss of fat in the skim-milk. The cream should be delivered in a smooth condition, and contain from thirty to forty per cent. fat. The cream with a high fat content requires less labor and vat room, is more easily and exhaustively churned, and can be churned at a lower temperature, thus producing a better quality of butter. Many buttermakers make the mistake of having the cream too thin or with too much skim-milk in it. If at any time during the run the feed of the milk to the separator is shut off, the bowl should be 
flushed with warm water to remove the cream and prevent it clogging the outlet. Sometimes the bowl will tend to clog during the run, when a pail of warm water will often overcome the difficulty: In case the outlets become clogged it will be necessary to stop the machine and clean the bowl. The relative amounts of cream and skim-milk which come from the separator are determined by the rate of the inflow of the milk, speed of the bowl, temperature of the milk, and by the adjustment of the cream or skim-milk screws. The larger the volume of milk entering the separator bowl in a given time the thinner the cream; the greater the speed for a given inflow of milk the richer the cream, or the higher the percentage of fat in it ; the higher the temperature of milk at separating the less the volume of cream and the higher its fat content; the smaller the outlet for the cream and the nearer it is to the centre of the bowl the richer is the cream; the larger the opening for skim-milk (in case of a skim-milk screw) the richer is the cream. When the milk is all through, the cream should be flushed from the bowl by using part of a pail of warm water, then flush again by using the remainder of the pail of water. The slime should be removed and burnt and the bowl thoroughly cleaned, ready for the next day's run.

As in the case of hand separators, there is no best power separator, but the Alpha de Laval takes a leading place among the power machines used in Canadian creameries. One authority says: "In all probability there is nearly as much difference in 
efficiency of separation between different machines of the same make as there is between the different makes themselves."

The percentage of fat in the whole milk which is recovered in the form of cream-is known as the creaming co-efficient of a separator. It is important that this should be as high as possible in order to reduce the loss of fat in the skim-milk.

Creams containing different percentages of fat have about the following composition :

\begin{tabular}{|c|c|c|c|}
\hline$\%$ & $\%$ & $\%$ & $\%$ \\
\hline Fat........ I 5.2 & 20.0 & 25.0 & $67 \cdot 5$ \\
\hline Water $\ldots \ldots 76.6$ & 71.7 & 66.3 & 29.0 \\
\hline Casein, etc... 3.I & 3.1 &, 3.2 & 1.2 \\
\hline Milk sugar ... 4.5 & 4.6 & 4.8 & 2.2 \\
\hline Ash ........ .6 & .6 & .7 &. $\mathrm{I}$ \\
\hline
\end{tabular}

\section{CARE AND RIPENING OF THE CREAM.}

In the cream-gathering creamery during the hot weather the cream is often delivered in a ripe condition, in which case it should be cooled at once to churning temperature or below. In some cases it may be advisable to churn the cream soon after it is cooled if there is danger of it being over-ripe by the next morning. Churning at night is not to be recommended unless absolutely necessary. If the cream can be cooled to below 60 degrees very little acid will develop in the cream, and the butter will be firmer if the cream stands at the churning temperature for several hours, as compared with churning it 
soon after cooling. In cool weather it may be necessary to ripen the cream by warming it to about 65 degrees and using five to ten per cent. of a good culture.

Cream from the separator should be cooled to a temperature of about 65 degrees and have from ten to fifteen per cent. of a good-flavored culture added. Where pasteurization is adopted it is very important to have a good culture, as the flavor of the butter depends nearly altogether upon the character of the organisms introduced into the cream by means of the culture. The culture may be added to the cream as soon as it cools to a temperature of about 70 degrees. If added above this temperature there is danger of abnormal fermentations taking place. It is not a good plan to put the culture in the cream vat and then run in the warm cream. If the culture is first put in the vat, then the cream should be cooled before entering.

In order to test the acidity of the cream, and to develop a uniform acidity day after day, an acidimeter should be used. The alkaline solution should be of such strength that each cubic centimeter of the solution required to neutralize the acid will represent one-tenth of a per cent. of acid in the cream or milk, when ten c.c. of cream or milk are used to make a test. Phenol is the indicator needed to show when the acid is all neutralized. To make a test of the acidity of cream, first thoroughly mix the whole vat of cream, then measure ten c.c. of it into a glass or white cup. Add five or six drops of phenol, then 
from a graduated burette slowly add the alkaline solution, stirring the cream all the time with a glass stirring rod. When the cream turns a pink color throughout the whole mass, the acid is neutralized. Now count the number of c.c. of alkali used and this represents the percentage of acid in the milk or cream in tenths ; e.g., ten c.c. cream is used for a test and this requires 5.6 c.c. of alkaline solution to neutralize the acid, then the percentage of acid in the cream is .56. By having the alkaline solution of this strength it saves the trouble of figuring as required with a one-tenth normal solution and there is less danger of error.

When ready to churn the cream should have from .5 to .6 per cent. of acid-the smaller amount for export butter. Very rich cream, or cream containing a high percentage of fat, should not have quite so. much acid as thin cream, or cream containing a low percentage of fat. In creamery practice this is not an important point. The percentage of acid, however, may vary considerably without affecting the quality of the butter very much, so long as the flavor is clean and there are no abnormal fermentations. If the buttermilk contains about 8 per cent. of acid it will be about right for local markets. For export butter the buttermilk should not have more than 6 to .7 per cent of acid, as a milder flavor is liked in such butter.

The ripening of cream consists chiefly in the development of the lactic acid by suitable bacteria, which causes coagulation of the casein when there is about 4 
per cent. of acid. This ripening also causes a pleasant flavor in the cream and butter, aids in the churnability of the fat, and adds to the keeping quality of the butter. Proper ripening of cream is the most important and most scientific part of buttermaking. He who can control this part of the business has mastered the most difficult thing in the art of buttermaking. Cream which becomes over-ripe is apt to produce butter containing specks and strong or undesirable flavors. Too much acid in the cream also tends to cut the color of the butter, making it appear bleached. Lactic acid, however, does not cut or dissolve the fat in the cream. As much or more butter can be made from ripe cream as from similar cream churned sweet. Lots of cream having different degrees of ripeness should not be mixed and churned at once, as this practice causes an excessive loss of fat in the buttermilk, due to the fact that the ripened cream churns more quickly than the sweeter lots. Where cream is to be churned the second day after separating, it should be cooled to and held at a temperature of 50 to 55 degrees after it thickens. Less culture should be used also.

Bulletin 40 from the Iowa experiment Station states:

"I. Butter flavor is produced mostly by the bacterial fermentations which take place in milk or cream.

"2. The superiority of summer butter is mainly due to the lactic acid organisms, which are found in greater number in summer than in winter milk and cream.

" 3. Good flavored cream ready for churning contains about three $\mathrm{m}$. bacteria per c. c. - ninety-one to ninety-eight per cent. lactic acid. 
"4. A good natural skim-milk starter is practically a pure culture of acid-producing bacteria.

" 5. The most common souring organism (Bacterium lactici) gives the best results.

"6. The most important factors in cream ripening are the development of typical acid fermentations and the suppression of injurious types."

\section{CHURNING.}

Churning changes the liquid fat to a solid, in addition to massing the fat globules. This is done by means of a churn, which should be easy to clean, easy to get the cream into it, and easy for getting the butter out; and it should give sufficient concussion to the cream to bring the butter in less than one hour. It is necessary to cool the cream to churning temperature from two to four hours before churning, in order to get a proper body and texture in the butter. If coloring is used, it should be put into the cream when in the vat, or directly after it has been placed in the churn. The basis for coloring may be at a certain rate per thousand pounds of milk (usually about one dram), according to the fat content of the cream, or at so much per pound of butter fat. No coloring is necessary in the summer time, and it is always safer to under-color rather than over-color butter. The amount of color required must be determined by each buttermaker, as it varies according to the natural color of the milk, the demands of the market, the strength of the coloring, whether the cream has been pasteurized or not, and upon the amount of salt which is added. Butter colors are of two general 
classes - vegetable and mineral. The former is usually made from Annatto seed dissolved in vegetable oils. The latter are made from coal-tar, a by-product in the manufacture of gas. There appears to be little or no difference in their effect on the butter.

Before putting the cream into the churn, it should be well prepared by scalding and afterwards cooling, to fill the pores of the wood with water, so that the cream will not stick to it. The cream should then be strained into the churn to remove any particles of curd or clotted cream. The temperature for churning should be between 50 and 60 degrees. The lower the temperature at which the cream will churn in a reasonable time the more exhaustive will be the churning and the less curdy matter there will be in the butter. If the churning comes too quickly, the liquid fat is not all changed to a solid, hence the butter is of a soft, greasy texture.

The churn should turn at the rate of fifty to seventy revolutions per minute. A small churn should revolve more rapidly than a large one. The gases, composed chiefly of carbonic acid and hydrogen, should be allowed to escape three or four times during the first ten minutes, or till the gases cease to accumulate. If the cream thickens in the churn it will be necessary to dilute it with water at the same temperature as the cream. When the granules of butter appear the size of clover seed, a small quantity of water, preferably brine, should be added in warm weather, to firm the butter and cause a more complete separation. In winter the water should be of about the same tempera- 
ture as the cream. The churning should then be continued until the butter is about the size of wheat grains, when the buttermilk may be drawn. It should be somewhat bluish in appearance, and should not have over .2 per cent. of fat. The buttermilk should be strained in order to catch any particles of butter which may leave the churn. The butter may then be washed once with a volume of water equal to that of the cream, and at a temperature of about 45 degrees in hot weather. In winter the temperature of the water should be about 55 degrees, or warmer if working in a cold room. Butter which has a bad flavor may be washed twice, and one of these waters may have some salt dissolved in it. Butter from rich cream may require a larger volume of water than there was of cream. It is a mistake, however, to wash good butter too much, as it removes the fine flavor. After washing, the butter should drain for ten to thirty minutes in order to reduce an excessive loss of salt, as is the case when the salt is added to butter containing a great deal of moisture. About one-half the salt is lost when applied to butter in the ordinary way, at the rate of one ounce per pound of butter.

\section{SALTING CREAMERY BUTTER.}

As salt absorbs flavors very readily it is important that it be kept in a pure, clean place, where no objectionable taint can be imparted from the salt to the butter. A bitter taste in butter is sometimes caused by an excess of magnesium chloride 
in the salt. Good butter salt (moisture free) should contain from ninety-eight to ninety-nine per cent. sodium chloride, be pure, fine, easily soluble in cold water and white in color. The objects of salting butter are to preserve it, to give the salt flavor, to give grain and color to the butter, to cause a more complete separation of the buttermilk, and to expel the surplus moisture from butter. The rate of salting depends upon the market. For home markets from three-quarters to one ounce per pound of butter is sufficient. At no time should more than one ounce of salt per pound of butter be used, Export butter should not contain more than three per cent. salt in the finished butter. For the fresh butter trade not more than one-quarter of one per cent. is needed. Butter salted at the rate of one-quarter of an ounce per pound of butter from the churn will contain about one per cent. salt in the finished butter. One-half ounce salting gives two per cent.; threequarter ounce about three per cent., and one ounce. from 3.5 to 4 per cent. salt in the finished butter. These figures vary according to the accuracy of the salting, amount of moisture in the butter when the salt is applied, etc. The quantity of salt in the finished butter depends upon the amount of salt added, the moisture in the butter at the time of adding the salt, and upon the working which the butter receives. It varies a great deal.

Experiments made in shipping pasteurized fresh creamery butter from the Ontario Agricultural College in solids and pound prints have been quite satis- 
factory. The butter has proved to be equal to the best Danish. An English correspondent writing to a Canadian paper on February 26th, 1903, says :

"The lower price of Canadian creamery butter as compared with the Danish is due to its being stale. Canada can make and ship fancy creamery butter that will compare favorably with any butter in the world. Not long since an Englishman interested in Canadian prosperity was discussing this matter with the Ontario Government Agent in Liverpool, and he opened correspondence with the Dairy Department of the Ontario Agricultural College at Guelph, and as a result a sample of butter was made and shipped here from the O. A. C. that has given every satisfaction. The quality, the flavor, and the texture has been pronounced equal to Danish, or any other butter imported, and it has realized about top price. Of course this was mild, fresh-made butter and shipped as soon as made."

The shipment referred to was made the first week in January, 1903, from pasteurized milk cream, and salted one-quarter of one per cent. Part of it was shipped in "solid" form and part in pound prints. The prints were put in pariffine-lined boxes containing two dozen prints each, and wrapped in parchment paper. There is no doubt a profitable trade for creameries which are in a position to make fresh pasteurized butter and ship it as soon as made, or at least once a week. It is also important that the butter be kept below 32 degrees while at the creamery, and under 40 degrees while on the cars and steamships. Butter made in this way requires no preservative other than salt. The Author does not believe that any form of preservatives other than salt should be used in the manufacture of Canadian butter. 
Salt does not penetrate the fat globules of the butter, but is held in the form of brine between the particles of butter. An excess of salt beyond that which will dissolve readily in the water causes "grittiness" in the butter and is very objectionable. Uneven distribution of the salt through the butter is the chief cause of mottles, waves, streaks, etc., in the butter. Those parts not touched by the salt remain the natural color of the fat, which is paler than the salted portions; hence the uneven color. Sometimes the streaks are due to buttermilk which has not been removed by the washing. White specks are usually caused by particles of curdy matter in overripe cream, or by dried cream. These usually can be removed by straining the cream into the churn.

Having the butter in granular form at the time of adding the salt is favorable to an even distribution of the salt and for removal of the buttermilk, otherwise there is no particular advantage in having the butter in "granular form." It is possible that too much value has been placed on "granular butter."

\section{WORKING BUTTER.}

The temperature of the butter at working should be about 55 degrees. In a very cold room it may be 5 degrees warmer, and in a warm room it may be 5 degrees colder. It is better to work the butter in a closed worker if the temperature of the room is very cold or very warm, as it is not so much affected by the temperature of the air in the room under these circum- 
stances. Such a worker is not so favorable for observing the butter as the open revolving table, but has advantages in saving labor and protecting the butter from the air of the creamery. No rule can be given for working the butter. Once working is sufficient in ordinary practice. The butter should be examined frequently after two or three days to see if the color is even. It is customary to work by time or by a given number of revolutions on or in the worker. About twenty-five revolutions of the Mason worker and twenty-seven to thirty of the Simplex may be taken as a guide. These are to be used as a guide only, and should be varied to suit the condition of the butter. If the butter is over-worked, worked when too hard, or worked when too soft, the grain and texture are spoiled.

\section{PREPARING BUTTER FOR MARKET.}

The package for butter should be light, strong, tight, and suitable for the market to which the butter is sent. For home trade there is no better package than the oblong pound print, wrapped in a good quality of parchment paper, which is stamped with the name of the creamery in indelible ink. Printers which make several prints at once have no advantage so far as the Author has tried them. The butter can be printed more quickly, but when the time required for wrapping is considered there is nogain in time. The prints should be neatly and attractively prepared, and be put into cold-storage for at least twenty-four hours before shipping, so that they may get firm before 
placing them in the shipping box. In cold weather a box without wooden trays may be used, but in warm weather the prints should not rest on each other. A returnable box, holding from 100 to 150 pound prints, is very suitable, although it is difficult to get it returned promptly, and many are lost. Some creameries use a smaller, cheaper and lighter box, which is not returned, or returned but a few times. One print in each layer should have the corners of the paper projecting, or have a small strip of paper put around the print with the ends so that they may be taken hold of to remove the first print. If this is not done, some of the packages are bruised in getting out the first print of each layer. It is important that the prints should weigh from sixteen and a quarter to sixteen and a half ounces, when wrapped in wet paper, that there may be no complaints on account of short weights. The packages should be tested frequently in order to see if they are of proper weight. In hot weather, if shipping over fifty miles, the butter boxes should have broken ice placed in galvanized iron boxes which are in the centre of the prints or above them.

Butter for the export trade is best packed solidly and closely in fifty-six or twenty-eight pound spruce boxes, lined with paraffine wax. Before putting in the butter they should be rinsed with cold water or brine, and then be lined with two thicknesses of heavy parchment paper, which has been previously soaked in brine or a solution of formaiin to destroy germs of mould. The butter should be put into the boxes in small quantities, 
and be well pounded along the sides and in the corners of the box, so that when the package is stripped the butter will present a close uniform appearance, with no openings along the sides where brine or buttermilk is likely to collect, which gives a bad appearance to the package when placed on the counter of the retail merchant in Great Britain. The top of the box of butter should be finished neatly and smoothly with a rolling pin or a straight-edge, notched on the ends, to allow it to cut the butter from the box to the desired depth. Each box should contain at least fiftyseven pounds of butter, so that it may weigh fifty-six pounds net when it reaches the British customer. The latter is very much annoyed at short weights, and it pays to give close attention to this point. After making a smooth and attractive finish, the top of the butter should be covered with two to four thicknesses of the paper; and if it is to be held some time in cold-storage, a light salt paste may be put on top of the paper. The lid should now be fastened and the butter placed in cold-

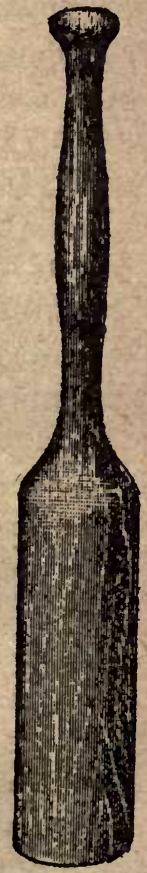
FOR TUBS. 
Unlined wooden tubs should be steamed, then be soaked in brine for twenty-four to thirty-six hours, then be rinsed in cold water and sprinkled with salt before putting in the butter. There is great danger of a woody flavor in the butter placed in unlined wooden packages. This danger is reduced by lining with heavy parchment paper before packing in the butter. The same care should be exercised in packing, as in case of the box, so as to have the butter firm and close.

A few Canadian creameries use the Danish kiel or firkin, holding I I 2 pounds of butter, but it is not so popular as the box.

Butter to be shipped to the Klondike, to the Indies, or to any warm c suntry, should be packed firmly in tins made specially for this purpose, and then soldered and made air tight. Each package of butter sent to a foreign market should have the word Canada in neat, legible letters on the outside of every package. It is also advisable for each creamery to use a registered number, as provided by Dominion Statute. In order to keep the boxes clean during transport, a clean cotton sack should encase each package. This enables the British customer to place an attractive package before the buyer, and this tends to prejudice them in favor of the butter. Too much care cannot be exercised in preparing butter for market in the neatest, most attractive and most convenient packages obtainable. It is a great mistake to neglect this point. 


\section{COMPOSITION, JUDGING, AND CLASSIFICATION OF BUTTER.}

Butter, like other dairy products, varies considerably in its composition or make up. It consists chiefly of fat, which may vary from 80 to 90 per cent. and averages about 84 . The water may vary from 8 to 20 per cent. and averages about 12 in good butter. If it contains over 16 per cent. it is deemed adulterated in Canadian and British markets. The percentage of moisture retained by butter is chiefly affected by the amount of working which it receives. Pasteurized butter tends to be somewhat drier than unpasteurized. The size of the granules, temperature of the wash water, amount of salt added, etc., do not materially affect the percentage of water in the finished butter, so long as it is properly worked. Canadian butter is well within the limit set for moisture content of pure butter.

The curdy matter in butter varies from .5 to 2 per cent. and averages about one. Salt, ash, etc., varies from .5 to 5 per cent. and averages about 3 .

Good butter should be mild, sweet, clean, and pleasant in flavor. It is impossible to describe this delicate aroma, which forms nearly one-half the value of butter. Lack of flavor, bitter, greasy, lardy, fishy, woody, cheesy, dirty, buttermilk, cowy, musty, and cooked flavors are common defects. The grain and texture should be waxy, firm yet pliable, should break like a piece of cast-iron, and not be greasy or salvy in appearance. It should be of such consistency that it readily spreads on bread. The color 
should be uniform, clear and bright, ranging from white to a yellow shade. Export butter should be paler in color than that for local markets. There should be no mottles, waves, streaks, or specks in the butter. The salt must be dissolved and the quantity should suit the taste of the consumer. The package should be neat, attractive and stylish, and suitable for the trade to which the creamery is catering.

Whey butter has not been satisfactory in Canada. The quality is inferior and the labor to produce it is too great.

Process or renovated butter is usually bad butter which has been melted and cleansed and rechurned, so that it is fit for table use. Such butter should not be labelled as "creamery butter," but should be branded properly.

Oleomargarine, butterine, etc., are imitation butters made from melted animal fat containing, in the best grades, a good proportion of creamery butter. In Canada no imitation butter is allowed to be made or sold. The chief injustice of the product arises from the fact that it is sold largely as pure butter, and to this extent is a fraud on the dairy industry.

The following is a classification of butter under the rules of the Boston Chamber of Commerce:

Creamery.-Butter offered under this classification shall be such as is churned, salted, and packed in a creamery, made from the cream obtained either by the system of setting the milk at the creamery, or by the system known as "cream-gathering," by which the farmer sets his milk, raises the cream, and delivers it to the creamery to be then churned into butter, or butter made in a creamery under the system known as the 
Centrifugal Process. "Sweet Cream Creamery" differs from Creamery only in being made from cream before fermentation. Offerings or bids on "Sweet Cream Creamery" must be specially described.

Imitation Creamery.-Butter offered under this classification shall be such as is churned by the dairyman and disposed of by him in its unsalted, unworked condition to the dealer or shipper, and worked, salted, or packed by the dealer or shipper.

Ladle.-Butter offered under this classification shall be such as is collected by the dealer or shipper in the various shapes of rolls, lumps or whole packages, salted and worked, and by the dealer or shipper re-salted, re worked and re-packed.

Dairy.-Butter offered under this classification shall be such as is made, salted, and packed by the dairyman and offered in its original package.

Extras.-Shall be composed of the highest grade of butter made in the season when offered under the different classifications and up to the following standard :

Flavor-Must be fine, sweet, clean, and fresh, if of current make, and fine, sweet and clean, if held.

Body-Must be good and uniform.

Color-Good for the season when made, even and uniform.

Salt-Neither coarse nor slack salted.

Package-Good and uniform.

In extra creamery the delivery must contain at least ninety per cent. of the quality described above (extras), and the balance of the goods may grade as firsts.

Firsts.-Shall be a grade just below extras, and must be fine butter for the season when made and offered under the different classifications and up to the following standard:

Flavor-Must be good, sweet, clean, and fresh, if of current make, and good, sweet, and clean, if held.

Body-Good and uniform.

Color-Good for the season when made, reasonably uniform.

Salt-Neither coarse nor slack salted.

Package-Good and uniform.

In Firsts the delivery must contain at least ninety per cent. of firsts and the balance of the goods may grade as seconds. 
Seconds. - Shall be a grade just below firsts and must be good for the season when offered under the different classifications and up to the following standard :

Flavor - Must be reasonably good and sweet.

Body-If creamery, must be sound. If ladles, must be ninety per cent. solid boring.

Color-Fairly uniform.

Salt-May be high, medium, or slack salted.

Package-Good and uniform.

Thirds. - Shall be a grade below seconds.

Flavor-Must be reasonably good and may be strong on top and sides.

Body-Fair boring, if creamery, and at least fifty per cent. boring a full trier, if ladles.

Color-Fair for the season when made.

Salt-High, low or irregular.

Package-Fairly uniform.

Fourths. - Shall be a grade just below thirds and may consist of straight or promiscuous lots.

Body-May or may not draw a full trier.

Flavor-May be off-flavored and strong on tops and sides.

Salt-High, low or irregular.

Package-Any kind of package mentioned at time of sale.

Extra Dairies.-Shall correspond with the different kinds of dairy butter under which they are offered.

Grease Butter.-Shall consist of all grades below fourths, free from adulteration.

Parties wishing to offer butter not described in the foregoing classifications, can specify the character of butter in making the offer.

\section{REFRIGERATION IN CREAMERIES.}

Good refrigeration is a very important part of creamery work. It is necessary for cooling the cream and hardening the butter, as well as for preserving 
the butter. The two common methods of refrigeration are, by the use of ice or by mechanical means, such as applying pressure 10 gases. The first thing is to have the room properly insulated, as outlined in a previous chapter.

Refrigeration is the production of cold. Cold is produced by transferring heat from a warmer to a colder body, or by extracting heat and rendering it latent. Heat is rendered latent (of no effect) when bodies are changed from a solid to a liquid, or from a liquid to a gas. In the case of ice, cooling is the result of heat being absorbed or rendered latent, as it changes from a solid condition to that of a liquid. This heat is taken from the surrounding bodies, hence they become colder. If the water be evaporated, heat is again rendered latent and cold is produced.

In order to produce cold rapidly the ice should be broken finely, as it will then produce cold more quickly. If ice be mixed with salt, the degree of cold is greater and it is produced more rapidly, because salt has a great affinity for water, and it attacks the ice in order to get water to slake its thirst. In doing this it is dissolved by the water, and we have two solid bodies changing to a liquid, hence more cold produced. To get the best results from ice and salt, the mixture should be placed in galvanized iron cylinders about one foot in diameter and as deep as the cold-storage room. A sufficient number of these should be placed in the cold-storage to give the desired temperature. The liquid should be removed to a drain, having a trap on it to prevent the warm 
air coming into the refrigerator. Use about five or six per cent. of salt with the broken ice.

Where a moderately low temperature of, say, 35 to 40 degrees is aimed at, but which is not low enough to hold butter for any length of time, having the ice so arranged that the cold air will circulate from the ice into the refrigerator and back over the ice again saves the labor of handling the ice. In this method the walls of the ice-house must be well insulated, and no sawdust or other protecting material may be placed on the ice. The body of ice rests on timber, so that there are spaces below from which the cold air may travel into the cooling chamber. There are also strips on the sides so that the ice does not rest against the wall. Ice packed in this way should not be exposed to the air by opening the doors. It would be necessary to have a separate supply for cooling water and cream.

A false ceiling, with an opening the full width of the cooling chamber on the side farthest from the ice, and also on the side next to the ice, tends to produce circulation of the air.

The inside lining of this chamber should be made of spruce lumber, and should not be painted but given a coating of shellac or common whitewash. If pine lumber be used on the inside it will taint the butter for several years. To destroy mould germs, spray the walls with a strong solution of formalin or corrosive sublimate (I to I000 of water) after thoroughly cleaning them with hot water.

The more modern method of producing cold is by 
means of mechanical refrigeration. In this method a gas is put under heavy pressure, which changes it to a liquid and heat is given off. When the pressure is released in the cooling pipes or brine tanks, it returns to a gaseous form and absorbs as much heat as was given off by it when pressure was applied. This heat is taken from the pipes or brine tank, the air of the room, and from the substances in the room, thus cooling them. The two most common gases used are carbon dioxide (carbonic acid gas) and ammonia. Manufacturers of both types of machines claim theirs is the best. Both have advantages and disadvantages.

Three systems are in use for creameries:

I. Direct expansion, where the cold is produced by the expansion of the gas in pipes placed in the room, in water, or in connection with the cream vat. The advantage of this plan is that it saves the cost of a brine tank, and it is less wasteful of the cold gas. The disadvantage is that the compressor has to be run for a longer time each day to produce the results aimed at.

2. In the brine system the expansion coils are placed in a brine tank, and the cold brine is pumped through pipes where required. This method reduces the time required for operating the compressor, but is more expensive to install and requires the operation of a brine pump.

3. A combination of the foregoing is sometimes used where the direct expansion is operated while the creamery machinery is in operation, and the cold brine for that portion of the day when the machinery is not running. 
The machinery required is a compressor, condenser, expansion pipes, and in case of brine circulation, a brine tank, pump, and circulating coils. Machines can now be had suitable for ordinary creamery work at a cost of $\$ 1,000$ to $\$ 1,500$, which may be run from the line shaft in the creamery. They will run on an ordinary foundation or solid floor, and require from four to six horse-power to operate the compressor.

The advantages of mechanical refrigeration are that a lower and more uniform temperature can be maintained than with ice, and the cold may be relied upon except in case of breakage of the machinery, whereas the ice-supply often fails at a time when it is most needed. Further, cooling may be obtained with less labor and less expense in large creameries. Icehouses do not last very long in connection with the average creamery. Where the ice has to be hauled some distance it will cost nearly as much as mechanical refrigeration, which can be obtained at less than one dollar per ton.

If butter is to be held for any length of time at the creamery, it should be at a temperature of from 12 to 20 degrees F., or from 20 to 12 degrees below freezing. Where this temperature cannot be maintained in the creamery refrigerator the butter should be sent weekly to a convenient and safe cold-storage, the use of which can now be had in nearly every town at a moderate cost. The temperature of the room where the butter is stored should not vary more than 2 or 3 degrees from day to day. Some 
authorities recommend freezing the butter quickly after it is made, at a temperature of 5 to 10 degrees $\mathrm{F}$., then holding it at about 20 degrees $\mathrm{F}$. Others say that it should be gradually cooled to about 12 degrees $\mathrm{F}$. and be held at that temperature. If the butter can be cooled to 20 degrees soon after it is made, and be held at that temperature until ready to be placed on a refrigerator car, and then be transported in a refrigerator compartment on board a steamship, Canadian butter would soon improve in its quality and reputation when placed upon the markets of Great Britain. 


\section{CHAPTER IX.}

\section{MARKETING CHEESE AND BUT'TER.}

OUk markets are of two classes - home and foreign. The demand for dairy products of fine quality is growing in our home markets. We are consuming more butter and cheese each year as our population grows. Especially is this true in reference to good butter. We have not yet cultivated a taste for good cheese, probably because it is so difficult to get good cheese at home, as most of our first-class quality is exported and the "culls" are often placed on the market for Canadian consumers.

Our best foreign market is Great Britain, although it is probable that the United States of America will require Canadian dairy products in the near future. The West Indies, Japan, China, and South Africa are promising markets for Canadian dairy produce.

Our chief competitors in the British butter markets are Denmark, Ireland, France, Russia, Australia, New Zealand, and the Argentine Republic of South America. Our competitors in cheese are New Zealand, Continental Europe, and to a limited extent the United States. Canadian cheese has a reputation for being the best imported cheese and about equal to the home product. Over sixty per cent. of Britain's 
imported cheese comes from Canada, but less than ten per cent. of her butter comes from the same source. The chief butter markets of Great Britain are Manchester, London, Liverpool, Bristol, and Glasgow. Manchester is considered the best market, as about thirty million dollars are paid annually for butter, alone, in that city. It is the centre of the Danish butter trade for England.

The Canadian butter producers should study the wants of the consumer, sell as directly as possible to the consumer, make a first-class quality of butter at all times, and have a regular supply all the year. Generally speaking our home markets require butter with a high flavor, yellow color, and moderately high salt. Butter for the British market should be mild, sweet and clean in flavor, light in color, and mildly salted.

Butter may be sold to the commission houses, to exporters, or directly to importers and dealers in Great Britain. The latter plan would seem to be the best, but there are many difficulties in the way, chief of which are getting the returns promptly in order to be able to pay the patrons monthly, and the long distance which makes communication expensive and slow. If a sufficient number of factories would cooperate, it would pay to place an agent in the chief British markets, who would look after the interests of producers. Otherwise the sending of Canadian butter and cheese directly to old country customers is not likely to prove satisfactory. The time will doubtless come when first-class butter and cheese will have a 
uniform value and fixed price, and there will be less "rigging of the market" than at present.

Previous to 1873 , when cheese markets (boards of trade) were established, the cheese were sold at the factory, or on the street of some central town. This "hole and corner" method was very unsatisfactory to salesmen, and it was thought that when cheese boards were established and cheese were sold by auction to the highest bidder, the main difficulty in marketing cheese had been overcome. For various reasons, the cheese latterly have not been sold on the cheese boards, though a few have adhered to the rule. The boards have been used as a "feeler" of the market, and the cheese have been sold afterwards privately. Apparently this is to the advantage of the seller, as buyers pay a higher price than is offered on the markets, but it is really to the advantage of the buyers, who are better posted on the condition of the market. If cheese are sold for the highest price which can be obtained at public auction, and buyers know that they cannot get the cheese except for the highest market price upon the board, the best average prices are likely to be got for the cheese. It is in the interest of the buyer and not of the salesman to do away with the selling of cheese by public auction at convenient centres. Where this is not satisfactory it would probably pay for several factories to co-operate and deal directly with importers of cheese.

The salesmen should be competent, wide-awake, business men, who are in touch with the markets and convenient to the telegraph or telephone. As this 
position is a very important and responsible one, only men of tried ability and keen judgment should be appointed for this work. To facilitate the business and reduce expenses, it would be better for several factories to engage one man to act as salesman for a group. This is done very largely where there are "combinations" of factories, as in Eastern Ontario. The salesman should consult with the cheesemaker before making sales. If there are any cheese not firstclass in quality, the salesman should know this, and these cheese should not be sold as "finest," but for what they are worth. The practice of putting these in as fine goods after they have been rejected by the buyer is to be condemned. It would further reduce the expense to the buyer of inspecting cheese if the cheese were concentrated at a central point. Coldstorages near the railway, where the cheese may be sent weekly, would solve the problem and improve the quality. The cheese would be safe in the cold-storage if the salesman did not consider it wise to sell. If the cheese are left in the factory during the hot weather, it is almost necessary to sell weekly, as they deteriorate rapidly in quality at a high temperature. In any case the cheese should be inspected and paid for before they leave the railway station at the point of shipment. The plan of selling cheese subject to weight and inspection at some distant point has given rise to considerable trouble and is not in the interest of harmony and fair dealing. The placing of an official referce in Montreal, who may be called upon in case of a dispute between buyer and seller, has 


\section{MARKETING CHEESE AND BUTTER. 225}

overcome the difficulty to some extent; but there is room for improvement.

A proper invoice, showing the weight and number of cheese, should be sent to the buyer with each shipment. The net weight of each box of cheese should be plainly marked or stencilled on the side of the box, near the lap, so that it may be readily located. 


\section{CHAPTER X.}

\section{CONDENSED MILK.}

THE condensing of milk is a growing industry in Canada. Those factories which have been well managed are profitable industries. The farmers receive a larger price for the milk, usually ten to twenty-five cents more per hundred pounds than is paid for milk at creameries or cheeseries, and the business is remunerative to all concerned:

So early as 1837 a method of separating milk by warm air in a vacuum was patented. The milk was then pulverized and mixed with sugar. From time to time improvements were made in the methods of condensing. Copper vacuum pans are now used.

Very recently a cheap method of separating the milk solids, by drying milk in shallow pans, has been invented by an Ontario man. It promises good results, whereby all the solids of milk may be preserved for food in a concentrated and palatable form.

According to an American authority, the requisites for a condensed milk factory are: An abundant supply. of good fresh milk, a large supply of water, and good shipping facilities. A large water supply is very necessary, as it is estimated that twelve times as much water is required as there is milk to be condensed.

Regarding the amount of condensed milk which 
can be made from fresh milk, this same authority says, "IOO to 120 pounds of milk and 14 to $I 7$ pounds of cane sugar will make a case ( 48 pounds) of condensed milk." It is usually put upon the market in two forms-plain and sugared. The former is being largely used for confectionery purposes, and is replacing cream. The two kinds have about the following percentage composition :

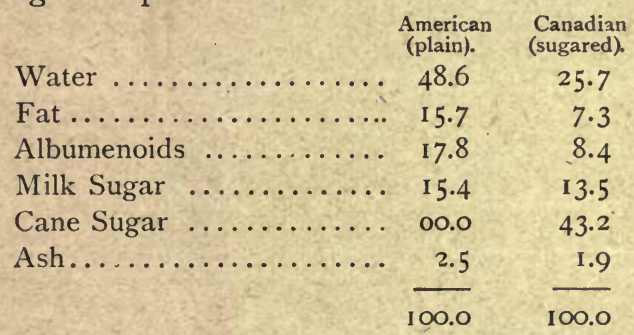

The desirable qualities in a condensed milk are: The absence of unpleasant, cheesy, or fermented flavor; absence of undissolved sugar ; the color nearly white, with a yellowish or creamy tinge ; and such a consistency of body as will dissolve readily and completely in about four parts of cold water, without the presence of any specks or particles of fat.

The milk produced for condensing purposes must be exceptionally good in quality and be wholesome and clean. The cows must be clean and fed on food which will not impart any flavor to the milk. The milk must be cooled and be well cared for, or it will not be accepted at the condensing factories. The factories are kept scrupulously clean, and all the work is done in a cleanly manner. This is very necessary or the result will be failure in the product. 



\section{APPENDIX.}

\section{FERTILIZING INGREDIENTS . IN DAIRY PRODUCTS.}

(WOLL'S HAND-BOOK).

\begin{tabular}{l|c|c|c|c}
\hline & Nitrogen & $\begin{array}{c}\text { Phosphoric } \\
\text { Acid }\end{array}$ & Potash & Value per Ton \\
Whole Milk... & $.53 \%$ & $.19 \%$ & $.175 \%$ & $\$ 2.17$ \\
Skim-milk.... & .56 & .20 & .185 & 2.31 \\
Cream ....... & .40 & .15 & .130 & .66 \\
Buttermilk..... & .48 & .17 & .158 & 1.98 \\
Whey......... & .15 & .14 & .181 & .84 \\
Butter........ & .12 & .04 & .036 & .49 \\
Cheese........ & 3.93 & .60 & .120 & 14.19 \\
\hline
\end{tabular}

COMPARATIVE VALUE OF CATTLE FOODS.

(WOLL's HAND-BOOK).

\begin{tabular}{|c|c|c|c|c|c|}
\hline \multirow{2}{*}{ FEEDING STUFFS. } & \multicolumn{5}{|c|}{$\begin{array}{c}\text { Value Per Ton or Bushel When Wheat } \\
\text { Bran is Worth }\end{array}$} \\
\hline & $\$ 9.00$ & $\$ 10.00$ & $\$ 12.00$ & $\$ 16.00$ & $\$ 20.00$ \\
\hline Barley..... & \$o.16 & \$o. 18 & 0.22 & \$o. 30 & $\$ 0.36$ \\
\hline Indian corn & 0.18 & 0.21 & 0.24 & 0.32 & 0.42 \\
\hline Corn and cob meal. & 0.16 & 0.18 & 0.22 & 0.30 & 0.36 \\
\hline Millet seed......... & 0.20 & 0.22 & 0.26 & 0.34 & 0.44 \\
\hline Oats... & 0.10 & 0.12 & O. I 4 & 0.18 & 0.24 \\
\hline Peas.... & 0.40 & 0.47 & 0.56 & 0.74 & 0.94 \\
\hline Rye.... & 0.22 & 0.24 & 0.28 & 0.38 & 0.48 \\
\hline Wheat shorts... & 7.20 & 8.00 & 9.60 & 12.80 & 16.00 \\
\hline Wheat.. & 0.24 & 0.25 & 0.30 & 0.40 & 0.50 \\
\hline Cotton-seed meal... & 23.14 & 25.60 & 30.72 & 40.96 & 51.20 \\
\hline Linseed meal.... & 19.86 & 22.08 & 26.50 & $35 \cdot 32$ & 44.16 \\
\hline
\end{tabular}


DIGESTIBLE NUTRIENTS IN ONE POUND OF SOME COMMON FEEDING STUFFS.

(Bulietin 154, By J. L. Stone, Cornell, N. Y.)

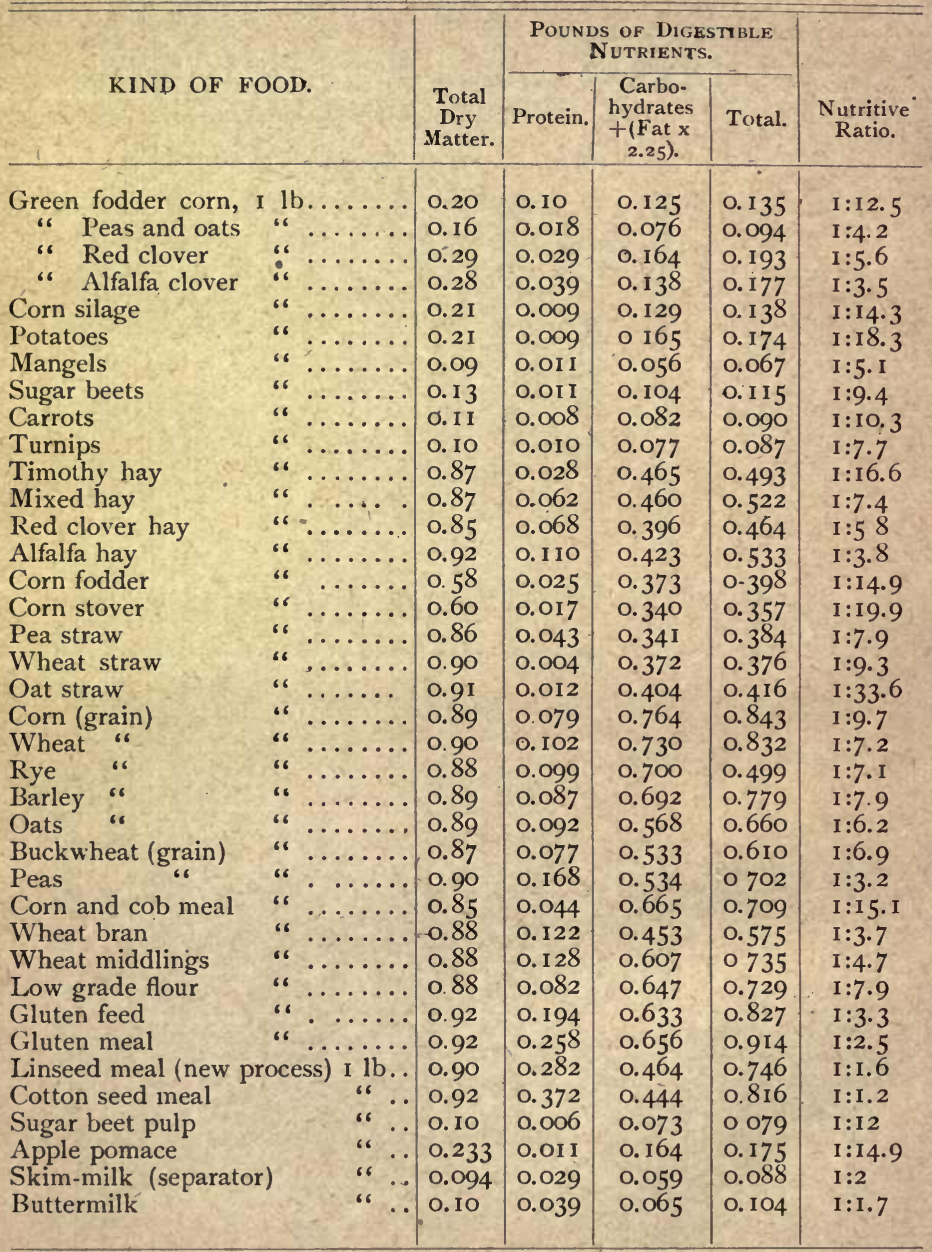

To find the pounds of nutrients in any given number of pounds of any feeding-stuff, multiply the pounds by the anount of nutrients in one pound as yiven in the table. 
COMPARISONS OF FAHRENHEIT AND CENTIGRADE THERMOMETER SCALES (WOLL).

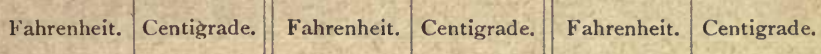

\begin{tabular}{|c|c|c|c|c|c|}
\hline+212 & +100.00 & 170 & 76.67 & I 28 & 53.33 \\
\hline 211 & 99.44 & 169 & 76. I I & 127 & 52.78 \\
\hline 210 & 98.89 & 168 & 75.55 & 126 & 52.22 \\
\hline 209 & 98.33 & I67 & 75.00 & .125 & 51.67 \\
\hline 208 & 97.78 & I 66 & 74.44 & I 24 & 5 I. I I \\
\hline 207 & 97.22 & 165 & 73.89 & 123 & 50.55 \\
\hline 206 & 96.67 & I 64 & 73.33 & 122 & 50.00 \\
\hline 205 & 96. I I & 163 & 72.78 & 121 & $49 \cdot 44$ \\
\hline 204 & 95.55 & 162 & 72.22 & I 20 & 48.89 \\
\hline 203 & 95.00 & 161 & 71.67 & I 19 & 48.33 \\
\hline 202 & 94.44 & 160 & 71.11 & I I 8 & 47.78 \\
\hline 201 & 93.89 & I 59 & 70.55 & 117 & 47.22 \\
\hline 200 & 93.33 & 158 & 70.00 & I 16 & 46.67 \\
\hline 199 & 92.78 & 157 & 69.44 & I I 5 & 46. I I \\
\hline 198 & 92.22 & 156 & 68.89 & I I 4 & 45.55 \\
\hline 197 & 91.67 & 155 & 68.33 & I I 3 & 45.00 \\
\hline 196 & 9I. I I & I 54 & 67.78 & 112 & $44 \cdot 44$ \\
\hline 195 & 90.55 & 153 & 67.22 & I I I & 43.89 \\
\hline I 94 & 90.00 & I 52 & 66.67 & IIO & 43.33 \\
\hline 193 & 89.44 & 151 & 66. I I & IO9 & 42.78 \\
\hline 192 & 88.89 & 150 & 65.55 & 108 & 42.22 \\
\hline 191 & 88.33 & I 49 & 65.00 & 107 & 41.67 \\
\hline 190 & 87.78 & 148 & 64.44 & 106 & 4 I. I I \\
\hline 189 & 87.22 & 147 & 63.89 & 105 & 40.55 \\
\hline 188 & 86.67 & 146 & 63.33 & IO4 & 40.00 \\
\hline I 87 & 86. I I & 145 & 62.78 & 103 & 39.44 \\
\hline I 86 & 85.55 & I 44 & 62.22 & 102 & 38.89 \\
\hline 185 & 85.00 & 143 & 61.67 & IOI & 38.33 \\
\hline 184 & 84.44 & 142 & 61. II & 100 & 37.78 \\
\hline 183 & 83.89 & I 41 & 60.55 & 99 & 37.22 \\
\hline 182 & 83.33 & 140 & 60.00 & 98 & 36.67 \\
\hline I $8 \mathrm{I}$ & 82.78 & 139 & 59.44 & 97 & 36. I I \\
\hline I 80 & 82.22 & 138 & 58.89 & 96 & 35.55 \\
\hline 179 & 81.67 & I 37 & 58.33 & 95 & 35.00 \\
\hline 178 & 8I. I I & 136 & 57.78 & 94 & 34.44 \\
\hline 177 & 80.55 & 135 & 57.22 & 93 & 33.8 , \\
\hline 176 & 80.00 & 134 & 56.67 & 92 & 33.33 \\
\hline 175 & 79.44 & I 33 & 56.11 & 91 & 32.78 \\
\hline I 74 & 78.89 & 132 & 55.55 & 90 & 32.22 \\
\hline 173 & 78.33 & I3I & 55.00 & 89 & 31.67 \\
\hline 172 & 77.78 & 130 & 54.44 & 88 & 3I.I I \\
\hline I 7 I & 77.22 & 129 & 53.89 & 87 & 30.55 \\
\hline
\end{tabular}


THERMOMETER SCALES-Continued.

\begin{tabular}{|c|c|c|c|c|c|}
\hline Fahrenheit. & Centigrade. & Fahrenheit. & Centigrade. & Eahrenheit. & Centigrade. \\
\hline 86 & 30.00 & 43 & 6.11 & 0 & 17.78 \\
\hline 85 & 29.44 & 42 & 5.55 & $-I$ & 18.33 \\
\hline 84 & $28: 89$ & $4 I$ & 5.00 & 2 & I 8.89 \\
\hline 83 & 28.33 & 40 & 4.44 & 3. & 19.44 \\
\hline 82 & 27.78 & 39 & 3.89 & 4 & 20.00 \\
\hline $8 I$ & 27.22 & 38 & 3.33 & 5 & 20.55 \\
\hline 80 & 26.67 & 37 & 2.78 & 6 & 21.11 \\
\hline 79 & 26. I I & 36 & 2.22 & 7 & 21.67 \\
\hline 78 & 25.55 & 35 & 1.67 & 8 & 22.22 \\
\hline 77 & 25.00 & 34 & I. I I & 9 & 22.78 \\
\hline 76 & 24.44 & 33 & 0.55 & 10 & $23 \cdot 33$ \\
\hline 75 & 23.89 & 32 & 0.00 & I I & 23.89 \\
\hline 74 & 23.33 & $3 I$ & -0.55 & 12 & 24.44 \\
\hline 73 & 22.78 & 30 & I. I I & 13 & 25.00 \\
\hline 72 & 22.22 & 29 & 1.67 & 14 & 25.55 \\
\hline 71 & 2I. I I & 28 & 2.22 & I 5 & 26.11 \\
\hline 70 & 21.55 & 27 & 2.78 & 16 & 26.67 \\
\hline 69 & 20.55 & 26 & 3.33 & 17 & 27.22 \\
\hline 68 & 20.00 & 25 & 3.89 & 18 & 27.78 \\
\hline 67 & 19.44 & 24 & 4.44 & 19 & 28.33 \\
\hline 66 & 18.89 & 23 & 5.00 & 20 & 28.89 \\
\hline 65 & I 8.33 & 22 & 5.55 & 2 I & 29.44 \\
\hline 64 & 17.78 & 21 & 6. I I & 22 & 30.00 \\
\hline 63 & 17.22 & 20 & 6.67 & 23 & 30.55 \\
\hline 62 & I6.67 & 19 & 7.22 & 24 & 3 I. I I \\
\hline $6 I$ & I6. I I & I 8 & 7.78 & 25 & 31.67 \\
\hline 60 & 15.55 & 17 & 8.33 & 26 & 32.22 \\
\hline 59 & 15.00 & 16 & 8.89 & 27 & 32.78 \\
\hline 58 & I 4.44 & 15 & 9.44 & 28 & 33.33 \\
\hline 57 & I 3.89 & I 4 & 10.00 & 29 & 33.89 \\
\hline 56 & I 3.33 & 13 & 10.55 & 30 & 34.44 \\
\hline 55 & 12.78 & 12 & I I. I I & $3 I$ & 35.00 \\
\hline 54 & 12.22 & I I & 11.67 & 32 & 35.55 \\
\hline 53 & 11.67 & 10 & 12.22 & 33 & 36. I I \\
\hline 52 & I I. I I & 9 & 12.78 & 34 & 36.67 \\
\hline $5 I$ & 10.55 & 8 & 13.33 & 35 & 37.22 \\
\hline 50 & 10.00 & 7 & 13.89 & 36 & 37.78 \\
\hline 49 & 9.44 & 6 & I 4.44 & 37 & $3^{8} .33$ \\
\hline 48 & 8.89 & 5 & I 5.00 & $3^{8}$ & 38.89 \\
\hline 47 & 8.33 & 4 & 15.55 & 39 & 39.44 \\
\hline 46 & 7.78 & 3 & I6. I I & 40 & 40.00 \\
\hline 45 & 7.22 & 2 & 16.67 & & \\
\hline 44 & 6.67 & I & 17.22 & & \\
\hline
\end{tabular}


TABLE SHOWING THE QUEVENNE LACTOMETER DegReES CORRESPONDING TO THE SCALE OF LACTOMETERS GRADUATED FROM O TO I2O (WOLL).

\begin{tabular}{|c|c|c|c|c|c|}
\hline $\begin{array}{c}\text { Per Cent. } \\
\text { Scale. }\end{array}$ & $\begin{array}{l}\text { Quevenne } \\
\text { Scale. }\end{array}$ & $\begin{array}{l}\text { Per Cent. } \\
\text { Scale. }\end{array}$ & $\begin{array}{l}\text { Quevenne } \\
\text { Scale. }\end{array}$ & $\begin{array}{l}\text { Per Cent. } \\
\text { Scale. }\end{array}$ & $\begin{array}{l}\text { Quevenne } \\
\text { Scale. }\end{array}$ \\
\hline 60 & 17.4 & $8 I$ & 23.5 & IOI & $29 \cdot 3$ \\
\hline $6 I$ & 17.7 & 82 & 23.8 & 102 & 29.6 \\
\hline 62 & 18.0 & 83 & 24.1 & IO3 & 29.9 \\
\hline 63 & 18.3 & 84 & 24.4 & 104 & 30.2 \\
\hline 64 & I 8.6 & 85 & 24.6 & 105 & 30.5 \\
\hline 65 & 18.8 & 86 & 24.9 & 106 & 30.7 \\
\hline 66 & I9. I & 87 & 25.2 & 107 & 31.0 \\
\hline 67 & I9. 4 & 88 & 25.5 & 108 & $31 \cdot 3$ \\
\hline 68 & 19.7 & 89 & 25.8 & 109 & 31.6 \\
\hline 69 & 20.0 & 90 & 26. I & I IO & 31.9 \\
\hline 70 & 20.3 & $9 I$ & 26.4 & I I I & 32.2 \\
\hline 71 & 20.6 & 92 & 26.7 & 112. & 32.5 \\
\hline 72 & 20.9 & 93 & 27.0 & 113 & 32.8 \\
\hline 73 & 21.2 . & 94 & 27.3 & I I 4 & 33.1 \\
\hline 74 & 21.5 & 95 & 27.6 & I I 5 & 33.4 \\
\hline 75 & 21.7 & 96 & 27.8 & 116 & 33.6 \\
\hline 76 & 22.0 & 97 & 28. I & 117 & 33.9 \\
\hline 77 & 22.3 & 98 & 28.4 & 118 & 34.2 \\
\hline 78 & 22.6 & 99 & 28.7 & I 19 & 34.5 \\
\hline 79 & 22.9 & 100 & 29.0 & I 20 & 34.8 \\
\hline 80 & 23.2 & & & & \\
\hline
\end{tabular}


TABLE SHOWING PER CENT. OF SOLIIS NOT FAT, CORRESPONDING TO QUEVENNE LACTOMETER.

Readings and Per Cent. of Fat (Babcock in Wolli's Hand-Book).

\begin{tabular}{|c|c|c|c|c|c|c|c|c|c|c|c|c|}
\hline \multirow{2}{*}{$\begin{array}{c}\text { Per } \\
\text { Cent. } \\
\text { Fat. }\end{array}$} & \multicolumn{11}{|c|}{ LACTOMETE } & \multirow{2}{*}{$\begin{array}{l}\text { Per } \\
\text { Cent. } \\
\text { Fat. }\end{array}$} \\
\hline & 26 & 27 & 28 & 29 & 30 & $3^{I}$ & 32 & 33 & 34 & 35 & 36 & \\
\hline .0 & 6.50 & 6.7 & 7.00 & 7. & 7.50 & 7.75 & Do & 8.25 & 8.50 & 8.75 & 9.00 & .0 \\
\hline I & $6.5^{2}$ & 6 & 7.02 & 7.27 & $7 \cdot 5^{2}$ & 7.77 & 8.02 & 8.27 & 8.52 & 8.77 & 9.02 &.$I$ \\
\hline .2 & 6.54 & 6. & 7.04 & 7.29 & $7 \cdot 54$ & 7.79 & 8.04 & 8.29 & 8.54 & 8.79 & 9.04 & .2 \\
\hline$\cdot 3$ & 6.56 & $6.8 \mathrm{I}$ & 7.06 & $7 \cdot 31$ & $7 \cdot 56$ & $7.8 \mathrm{I}$ & 8.06 & 8.31 & 8.56 & $8.8 \mathrm{I}$ & 9.06 & $\cdot 3$ \\
\hline .4 & $6.5^{8}$ & 6.83 & 7.08 & 7.33 & $7 \cdot 5^{8}$ & 7.83 & 8.08 & 8.33 & 8.58 & 8.83 & 9.08 & .4 \\
\hline .5 & 6. & & 7.10 & $7 \cdot 35$ & 7.60 & 7.85 & 8.10 & $\cdot 35$ & 8.60 & 85 & 9.10 & $\cdot 5$ \\
\hline .6 & 6. & 6. & 7.12 & $7 \cdot 37$ & 7.62 & 7.87 & 8. 12 & 8.37 & 8.62 & 8.87 & 9.12 & .6 \\
\hline .7 & 6.64 & 6.89 & 7.14 & $7 \cdot 39$ & 7.64 & 7.89 & 8. I4 & 8.39 & 8.64 & 8.89 & 9. 14 & .7 \\
\hline .8 & 6.66 & $6.9 I$ & 7.16 & $7 \cdot 41$ & 7.66 & 7.91 & 8.16 & $8.4 \mathrm{I}$ & 8.66 & 8.91 & .16 & .8 \\
\hline$\cdot 9$ & 6.68 & 6.9 & 7.18 & 7.43 & 7.68 & 7.93 & 8. 18 & 8.43 & 8.68 & 3 & 8 & .9 \\
\hline 1.0 & 6.70 & & 7.20 & 7.45 & 7.70 & 7.95 & 8.20 & 8.45 & 8.70 & & .20 & 1.0 \\
\hline I. I & 6.72 & 6 & 7.22 & 7.47 & 7.72 & 7.97 & 8.22 & 8.47 & 8.72 & & 9.22 & I. I \\
\hline I. 2 & 6 & 6 & 7.24 & 7. & 7.74 & 7.99 & 8.24 & 49 & 8.74 & & .24 & 1.2 \\
\hline I. 3 & 6. & 7.01 & 7.26 & $7 \cdot 5^{1}$ & 7.76 & 8.01 & 8.26 & 8.51 & 8.76 & OI & 9.26 & I. 3 \\
\hline I. 4 & 6.78 & 7.0 & 7.28 & 7. & $7 \cdot 7^{8}$ & 8.03 & 8.28 & 8.53 & 8.78 & 3 & 9.28 & I. 4 \\
\hline I. 5 & 6.80 & & 30 & & 7.80 & 8.05 & & & & & 9.30 & I. 5 \\
\hline 1.6 & 6.82 & 7.07 & $7 \cdot 32$ & 7.57 & 7.82 & 8.07 & $8.3^{2}$ & 57 & 82 & 07 & $9 \cdot 3^{2}$ & 1.6 \\
\hline I. 7 & 6.84 & 7.09. & 7.34 & 7.59 & 7.84 & 8.09 & 8.34 & 8.59 & 8.84 & 09 & 9.34 & I.7 \\
\hline I. 8 & 6.86 & 7.11 & $7 \cdot 36$ & & 7.86 & 8. I I & 8.36 & 8.61 & 8.86 & I & 9.37 & 1.8 \\
\hline 1.9 & 6.88 & 7.13 & $7,3^{8}$ & & & 8.13 & $8.3^{8}$ & 8.63 & 8.88 & 9. 14 & 9.39 & I. 9 \\
\hline 2.0 & & 7. & 40 & & 7.90 & & & & & & $.4 \mathrm{I}$ & 2.0 \\
\hline 2. I & 6.92 & 7.17 & 7.42 & 7. & 7.92 & 8. I7 & 8.42 & 68 & 8.93 & 9. I 8 & 9.43 & 2.1 \\
\hline 2.2 & 6.94 & 7.19 & $7 \cdot 44$ & 7.69 & 7.94 & 8.19 & 8.44 & 8.70 & 8.95 & 20 & 9.45 & 2.2 \\
\hline 2.3 & 6.96 & 7.21 & $7 \cdot 46$ & 7.71 & 7.96 & 8.21 & 8.46 & 8.72 & 8.97 & 9.22 & 9.47 & 2.3 \\
\hline 2.4 & 6.98 & 7.2 & $7 \cdot 4^{8}$ & 7 & 7.98 & 8.23 & 8.48 & 8.74 & 8.99 & 9. & 49 & 2.4 \\
\hline 2.5 & 7 & 7.25 & 7 & & 8.00 & 8.25 & & & & 26 & $9 \cdot 5^{1}$ & 2.5 \\
\hline 2.6 & 7.02 & 7.27 & $7 \cdot 5^{2}$ & 7. & 8.02 & 8.27 & $8.5^{2}$ & 8.78 & 3 & 9.28 & 9.53 & 2.6 \\
\hline 2.7 & 7.04 & 7.29 & $7 \cdot 54$ & 7.79 & 8.04 & 8.29 & 8.54 & 8.80 & 9.05 & 9.30 & 9.55 & 2.7 \\
\hline 2.8 & 7.06 & $7 \cdot 31$ & $7 \cdot 5^{6}$ & $7.8 \mathrm{I}$ & 8.06 & $8.3 I$ & 8.57 & 8.82 & 9.07 & $9 \cdot 3^{2}$ & 9.57 & 2.8 \\
\hline 2.9 & 7.08 & $7 \cdot 33$ & $7 \cdot 5^{8}$ & 7.83 & 8.08 & 8.33 & 8.59 & 8.84 & 9.09 & $9 \cdot 34$ & 9.59 & 2.9 \\
\hline 3.0 & & & 7.60 & & 8. I0 & & & & 9. I I & & 9.01 & 3.0 \\
\hline 3. I & 7.12 & $7 \cdot 37$ & 7.62 & 7.87 & 8. I 3 & $8.3^{8}$ & 8.63 & 8.88 & 9.13 & $9 \cdot 3^{8}$ & 9.64 & 3.1 \\
\hline
\end{tabular}


APPENDIX.

TABLE SHOWING PER CENT. OF SOLIDS NOT FAT, CORRESPONDING TO QUEVENNE LACTOMETER.

-Continued.

\begin{tabular}{|c|c|c|c|c|c|c|c|c|c|c|c|c|}
\hline \multirow{2}{*}{$\begin{array}{c}\text { Per } \\
\text { Cent. } \\
\text { Fat. }\end{array}$} & \multicolumn{11}{|c|}{ LACTOMETER READINGS AT $60^{\circ}$} & \multirow{2}{*}{$\begin{array}{l}\text { Per } \\
\text { Cent. } \\
\text { Fat. }\end{array}$} \\
\hline & 26 & 27 & 28 & 29 & 30 & $3 I$ & 32 & 33 & 34 & 35 & 36 & \\
\hline & 4 & 9 & 4 & & & & 8.65 & 8.90 & & $9.4 \mathrm{I}$ & 9.66 & 3.2 \\
\hline & & & 6 & 7.92 & & & 8.67 & 8.92 & & 9.43 & 9.68 & 3.3 \\
\hline 3. & 7.18 & 7.43 & 7 & $7 \cdot 94$ & 8. 19 & 8 & 8.69 & 8.94 & 9.20 & 9.45 & 9.70 & 3.4 \\
\hline 3.5 & 20 & 5 & 7.71 & 6 & 8.21 & 6 & 8.71 & 8 & 9.22 & 9.47 & 9.72 & $3 \cdot 5$ \\
\hline 3. & 7.22 & 8 & 7.73 & & 3 & & 8.73 & 8.98 & 9.24 & 9.49 & 9.74 & 3.6 \\
\hline 3. & .24 & o & 7.75 & 8 & & & 8.75 & 9 & & $9.5^{1}$ & 9.76 & 3.7 \\
\hline 3.8 & 26 & & 7.77 & 8 & 8. & 8. & 8.77 & 2 & 9 & 9.53 & 9.78 & 3.8 \\
\hline 3.9 & 7.28 & $7 \cdot 54$ & 7.79 & $8 . c$ & 8.29 & 4 & 8.79 & 4 & 9.30 & 9 & 9.80 & 3.9 \\
\hline 40 & 30 & 56 & $7.8 \mathrm{I}$ & 6 & I & & $8.8 \mathrm{I}$ & .06 & $9.3^{2}$ & 9.57 & 83 & -4.0 \\
\hline 4 & 2 & 8 & 7.83 & 8 & 8. & 8. & 8.83 & 9 & 9.34 & & 9.85 & 4. I \\
\hline 4.2 & 34 & & 7.85 & & & 8 & 8.85 & 9 & 9 & 9. & 9.87 & 4.2 \\
\hline $4 \cdot 3$ & $7 \cdot 36$ & & 7. & & & & 8 & 9 & & & 9.89 & $4 \cdot 3$ \\
\hline $4 \cdot 4$ & 2. 38 & 7. & 7. & 4 & 18 & 8 & 8.90 & 5 & 9. & 9 & $9 I$ & 4.4 \\
\hline 4 & 40 & & & & & & & & & 9 & 3 & 4.5 \\
\hline 6 & 43 & & & & & & 8. & & 9. & 9. & 9.95 & 4.6 \\
\hline 4.7 & 7.45 & 7.70 & 7.95 & & 8. & & 6 & 9.21 & 9.46 & 9.7 & 9.97 & 4.7 \\
\hline 4.8 & $7 \cdot 47$ & 7 & 7.97 & & & & 8.98 & 9 & $9.4^{8}$ & 9. & .99 & 4.8 \\
\hline 4.9 & 7.49 & & & & & & & & & & OI & 4.9 \\
\hline 50 & $5^{1}$ & & & & & & & & & 9. & & 5.0 \\
\hline 5.1 & $7 \cdot 53$ & 7.78 & 8.03 & & 3 & 9 & 4 & 9 & 9.54 & 9.8 & .05 & 5.1 \\
\hline 5.2 & 7 & 7.80 & 8.05 & & 8. & $3 I$ & 9.06 & & 9.56 & 9. & 07 & 5.2 \\
\hline $5 \cdot 3$ & & 7. & 8.07 & & & 8.83 & 9.08 & 9.33 & $9.5^{8}$ & & O9 & $5 \cdot 3$ \\
\hline $5 \cdot 4$ & 7.59 & 7.8 & 8.09 & 8.34 & 8.60 & 8.85 & 9.10 & 9.36 & $9.6 \mathrm{I}$ & 9. & I I & 5.4 \\
\hline 5. & & & & & & & & & & & & 5.5 \\
\hline 5.6 & 7.63 & 7.88 & & & & & 9.15 & 9.40 & 9.65 & & & 5.6 \\
\hline 5.7 & 65 & 7.90 & 8. & & & & 9.17 & 9.42 & 9.67 & 9.92 & 17 & 5.7 \\
\hline & & & & & & & & 9.44 & 9.69 & 9.94 & 19 & 5.8 \\
\hline 5.9 & 7.69 & 7.94 & 8. & & & & 9.21 & 9.46 & $9.7 \mathrm{I}$ & 9.96 & 22 & 5.9 \\
\hline 6.0 & 7.71 & 7.96 & 8.22 & 8.47 & 8.72 & 8.98 & 9.23 & $9.4^{8}$ & 9.73 & 9.98 & 10.24 & 6.0 \\
\hline
\end{tabular}


OUNCES REDUCED TO DECIMALS OF A POUND (WOLL).

\begin{tabular}{|c|c|c|c|c|c|c|c|c|c|}
\hline I & oz. & $=$ & .06 & lb. & 9 & Oz. & $=$ & .56 & lb. \\
\hline 2 & 11 & $=$ & .13 & 11 & 10 & 11 & $=$ & .63 & 11 \\
\hline 3 & 11 & $=$ & .19 & 11 & I I & 11 & $=$ & .69 & 11 \\
\hline 4 & 11 & $=$ & .25 & 11 & 12 & 11 & $=$ & .75 & 11 \\
\hline 5 & 11 & $=$ & $\cdot 3 I$ & "I & I3 & 11 & $=$ & .81 & 11 \\
\hline 6 & 11 & $=$ & $\cdot 3^{8}$ & 11 & 14 & 11 & $=$ & .88 & 11 \\
\hline 7 & "I & $=$ & .43 & 11 & I 5 & 11 & $=$ & .94 & 11 \\
\hline 8 & H & $=$ & .50 & 11 & 16 & II & $=$ & I & 11 \\
\hline
\end{tabular}

POUNDS OF MILK REQUIRED TO MAKE ONE POUND OF BUTTER (WOLL).

i Lb. Fat in the Milk makes i. if Lbs. Butter.

\begin{tabular}{|c|c|c|c|}
\hline $\begin{array}{l}\text { Per Cent. } \\
\text { Fat in Milk. }\end{array}$ & $\begin{array}{c}\text { Jbs. Milk } \\
\text { per } \mathrm{x} \text { lb. Butter. }\end{array}$ & $\begin{array}{l}\text { Per Cent. } \\
\text { Fat in Milk. }\end{array}$ & $\begin{array}{l}\text { Llbs. Milk } \\
\text { per I lb. Butter. }\end{array}$ \\
\hline 2.8 & 31.1 & 5.0 & 17.4 \\
\hline 3.0 & 29.0 & 5.2 & 16.7 \\
\hline 3.2 & 27.2 & 5.4 & I6. I \\
\hline 3.4 & 25.5 & 5.6 & 15.5 \\
\hline 3.6 & 24.2 & 5.8 & 15.0 \\
\hline 3.8 & 22.9 & 6.0 & 14.5 \\
\hline 4.0 & 21.7 & 6.2 & 14.0 \\
\hline 4.2 & 20.7 & 6.4 & 13.6 \\
\hline 4.4 & I9.8 & 6.6 & I 3.2 \\
\hline 4.6 & 18.9 & 6.8 & I 2.8 \\
\hline 4.8 & I8. I & 7.0 & 12.4 \\
\hline
\end{tabular}




\section{AMOUNT OF SALT FOR BUTTER.}

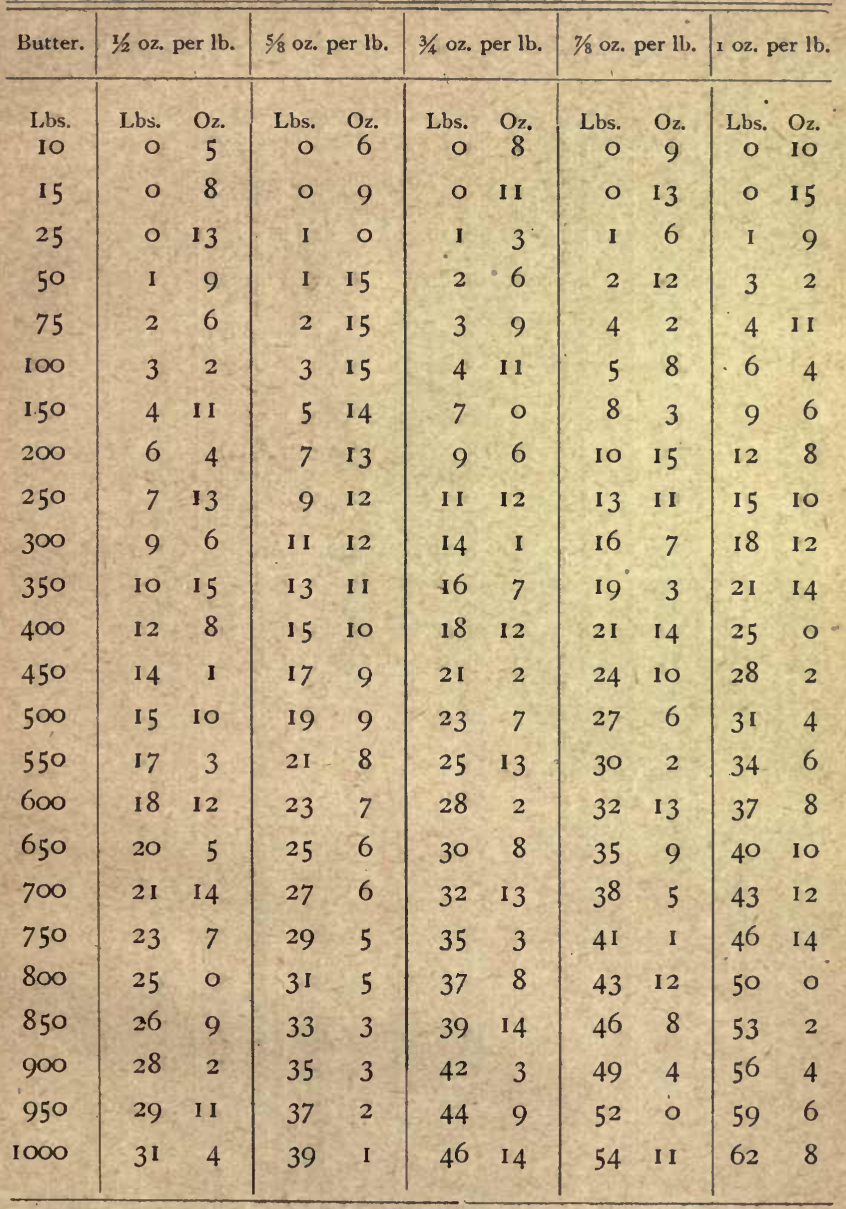


PERCENTAGE SALTING OF BUTTER.

\begin{tabular}{|c|c|c|c|c|c|c|c|}
\hline $\begin{array}{l}\text { Lbs. } \\
\text { Butter. }\end{array}$ & 1/2\% Salt. & $1 \%$ Salt. & $2 \%$ Salt. & 3\% Salt. & $4 \%$ Salt. & $5 \%$ Salt. & $6 \%$ Salt. \\
\hline 100 & $\begin{array}{l}\text { Lbs. } \\
0.50\end{array}$ & $\begin{array}{l}\text { Lbs. } \\
1.00\end{array}$ & $\begin{array}{l}\text { Lbs. } \\
2.00\end{array}$ & $\begin{array}{l}\text { Lbs. } \\
3.00\end{array}$ & $\begin{array}{l}\text { Lbs. } \\
4.00\end{array}$ & $\begin{array}{l}\text { Lbs. } \\
5.00\end{array}$ & $\begin{array}{l}\text { Lbs. } \\
6.00\end{array}$ \\
\hline 125 & 0.62 & 1.25 & 2.50 & 3.75 & 5.00 & 6.25 & 7.50 \\
\hline 150 & 0.75 & I. 50 & 3.00 & $4 \cdot 50$ & 6.00 & 7.50 & 9.00 \\
\hline 175 & 0.87 & 1.75 & $3 \cdot 50$ & 5.25 & 7.00 & 8.75 & $10.5^{0}$ \\
\hline 200 & 1.00 & 2.00 & 4.00 & 6.00 & 8.00 & 10.00 & 12.00 \\
\hline 225 & I. 12 & 2.25 & $4 \cdot 50$ & 6.75 & 9.00 & I I. 25 & I 3.50 \\
\hline 250 & I. 25 & $2.5^{\circ}$ & 5.00 & $7 \cdot 50$ & 10.00 & 12.50 & 15.00 \\
\hline 275 & I. 37 & 2.75 & $5 \cdot 50$ & 8.25 & I 1.00 & 13.75 & 16.50 \\
\hline 300 & 1.50 & 3.00 & 6.00 & 9.00 & 12.00 & 15.00 & 18.00 \\
\hline 325 & 1.62 & 3.25 & 6.50 & 9.75 & 13.00 & 16.25 & 19.50 \\
\hline 350 & 1.75 & 3.50 & 7.00 & 10.50 & 14.00 & 17.50 & 21.00 \\
\hline 375 & I. 87 & 3.75 & $7 \cdot 50$ & 11.25 & 15.00 & 18.75 & 22.50 \\
\hline 400 & 2.00 & 4.00 & 8.00 & 12.00 & 16.00 & 20.00 & 24.00 \\
\hline 425 & 2.12 & 4.25 & $8.5^{\circ}$ & 12.75 & 17.00 & 21.25 & 25.50 \\
\hline $45^{\circ}$ & 2.25 & $4 \cdot 50$ & 9.00 & 13.50 & 18.00 & 22. 50 & 27.00 \\
\hline 475 & 2.37 & 4.75 & 9.50 & 14.25 & 19.00 & 23.75 & 28.50 \\
\hline 500 & 2.50 & 5.00 & 10.00 & 15.00 & $20-00$ & 25.00 & 30.00 \\
\hline 525 & 2.62 & 5.25 & 10.50 & 15.75 & 21.00 & 26.25 & 31.50 \\
\hline $55^{\circ}$ & 2.75 & $5 \cdot 5^{0}$ & 11.00 & 16.50 & 22.00 & 27.50 & 33.00 \\
\hline 575 & 2.87 & $5 \cdot 75$ & $11.5^{\circ}$ & 17.25 & 23.00 & 28.75 & 34.50 \\
\hline 600 & 3.00 & 6.00 & 12.00 & 18.00 & 24.00 & 30.00 & 36.00 \\
\hline 625 & 3.12 & 6.25 & I 2.50 & I 8.75 & 25.00 & 31.25 & 37.50 \\
\hline 650 & 3.25 & 6.50 & 13.00 & 19.50 & 26.00 & 32.50 & 39.00 \\
\hline 675 & 3.37 & 6.75 & 13.50 & 20.25 & 27.00 & 33.75 & 40.50 \\
\hline 700 & $3 \cdot 50$ & 7.00 & 14.00 & 21.00 & 28.00 & 35.00 & 42.00 \\
\hline 725 & 3.62 & 7.25 & 14.50 & 21.75 & 29.00 & 36.25 & 43.50 \\
\hline 750 & 3.75 & $7 \cdot 50$ & I 5.00 & $22.5^{\circ}$ & 30.00 & $37 \cdot 50$ & 45.00 \\
\hline 775 & 3.87 & $7 \cdot 75$ & 1550 & 23.25 & 31.00 & 38.75 & 46.50 \\
\hline 800 & 4.00 & 8.00 & 16.00 & 24.00 & 32.00 & 40.00 & 48.00 \\
\hline 825 & 4.12 & 8.25 & 16.50 & 24.75 & 33.00 & 41.25 & $49 \cdot 5^{0}$ \\
\hline .850 & 4.25 & $8.5^{\circ}$ & 17.00 & 25.50 & 3400 & 42.50 & 51.00 \\
\hline 875 & $4 \cdot 37$ & 8.75 & 17.50 & 26.25 & 35.00 & 43.75 & 52.50 \\
\hline 900 & $4 \cdot 50$ & 9.00 & 18.00 & 27.00 & $36, \infty$ & 45.00 & 54.00 \\
\hline 925 & 4.62 & 9.25 & 18.50 & 27.75 & 37.00 & 46.25 & 55.50 \\
\hline $95^{\circ}$ & 4.75 & 9.50 & 19.00 & 28.50 & 38.00 & $47 \cdot 5^{\circ}$ & 57.00 \\
\hline 975 & 4.87 & 9.75 & 19.50 & 29.25 & 39.00 & 48.75 & $5^{8} \cdot 5^{\circ}$ \\
\hline 1000 & 5.00 & 10.00 & 20.00 & 30.00 & 40.00 & 50.00 & 60.00 \\
\hline
\end{tabular}




\section{CHEESE AND BUTTER MAKERS' READY RECKONER}

for Coloring, Rennet, or Salt per i,ooo lbs. Milk. (Thompson.)

\begin{tabular}{|c|c|c|c|c|c|c|c|c|c|c|c|c|c|}
\hline$\stackrel{n}{0}$ & 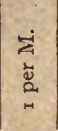 & 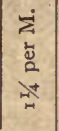 & $\frac{\vec{\Delta}}{2}$ & 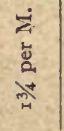 & 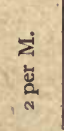 & 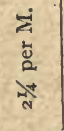 & 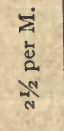 & 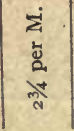 & $\begin{array}{l}\bar{\Sigma} \\
\vdots \\
\\
m\end{array}$ & 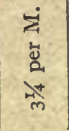 & 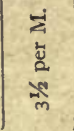 & 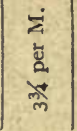 & 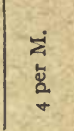 \\
\hline & 2.00 & 2.50 & 3.00 & 3.50 & 4.00 & 4.50 & 5.00 & 5.50 & 6.00 & 6.50 & 7.00 & 7.50 & 8.00 \\
\hline & 2.05 & 2.56 & 3.07 & $3.5^{8}$ & 4. 10 & $4.6 \mathrm{I}$ & 5.12 & 5.63 & 6.15 & 6.66 & 7.17 & 7.68 & 8.20 \\
\hline & 2. 10 & 2.62 & 3.15 & 3.67 & 4.20 & 4.72 & 5.25 & 5.77 & 6.30 & 6.82 & 7.35 & 7.87 & 8.40 \\
\hline 5 & 2. 15 & 2.68 & 3.22 & 3.76 & $4 \cdot 30$ & 4.83 & $5 \cdot 37$ & $5.9 \mathrm{I}$ & 6.45 & 6.98 & 7.52 & 8.06 & 8.60 \\
\hline & 2.20 & 2.75 & $3 \cdot 30$ & 3.85 & 4.40 & 4.95 & $5 \cdot 50$ & 6.05 & 6.60 & 7.15 & 7.70 & 8.25 & 8.80 \\
\hline 50 & 2.25 & $2.8 \mathrm{I}$ & 3.37 & 3.93 & 4.50 & 5.06 & 5.62 & 6.18 & 6.75 & 7.31 & 7.87 & 8.43 & 9.00 \\
\hline 00 & 2.30 & 2.87 & 3.45 & 4.02 & 4.60 & 5.17 & 5.75 & $6.3^{2}$ & 6.90 & $7 \cdot 47$ & 8.05 & 8.62 & 9.20 \\
\hline 50 & 2. 35 & 2.93 & 3.52 & $4 \mathrm{II}$ & 4.70 & 5.28 & 5.87 & 6.46 & 7.05 & 7.63 & 8.22 & $8.8 \mathrm{I}$ & 9.40 \\
\hline 100 & 2.40 & 3.00 & 3.60 & 4.20 & 4.80 & 5.40 & 6.00 & 6.60 & 7.20 & 7.80 & 8.40 & 9.00 & 9.60 \\
\hline 50 & 2.45 & 3.06 & 3.67 & 4. 28 & 4.90 & $5.5 I$ & 6. 12 & 6.73 & $7 \cdot 35$ & 7.96 & 8.57 & 9. 18 & 9.80 \\
\hline 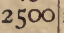 & 2. 50 & 3.12 & 3.75 & $4 \cdot 37$ & 5.00 & 5.62 & 6.25 & 6.87 & 7.50 & 8.12 & 8.75 & 9.37 & 10.00 \\
\hline 50 & 2. 55 & 3. 18 & 3.82 & 4.45 & 5.10 & 5.73 & 6.37 & 7.01 & 7.65 & 8.28 & 8.92 & 9.56 & 10.20 \\
\hline Do & 2.60 & 3.25 & 3.90 & 4.55 & 5.20 & 5.85 & 6.50 & 7.15 & 7.80 & 8.45 & 9.10 & 9.75 & 10.40 \\
\hline 1 & 2.65 & $3 \cdot 3 \mathrm{I}$ & 3.97 & 463 & $5 \cdot 30$ & 5.96 & 6.62 & 7.28 & 7.95 & $8.6 \mathrm{I}$ & 9.27 & 9.93 & 10.60 \\
\hline bo & 2.70 & $3 \cdot 37$ & 4.05 & 4.72 & 5.40 & 6.07 & 6.75 & 7.42 & 8.10 & 8.77 & 9.45 & I0.12 & 10.80 \\
\hline & 2.75 & 3.43 & 4.12 & $4.8 \mathrm{I}$ & 5.50 & 6.18 & 6.87 & $7 \cdot 56$ & 8.25 & 8.93 & 9.62 & 10.31 & 11.00 \\
\hline & 2.80 & 3.50 & 4.20 & 4.90 & 5.60 & 6.30 & 7.00 & 7.69 & 8.40 & 9. IO & 9.80 & 10.50 & I 1.20 \\
\hline & 2.85 & 3.56 & 4.27 & 4.98 & 5.70 & $6.4 \mathrm{I}$ & 7.12 & 7.83 & 8.55 & 9.26 & 9.97 & 10.6 & II. 40 \\
\hline 0 & 2.90 & 3.62 & 4.35 & 5.07 & 5.80 & $6.5^{2}$ & 7.25 & 7.98 & 8.70 & 9.42 & I0. 15 & 10.87 & 11.60 \\
\hline 50 & 2.95 & 3.68 & 4.42 & 5.16 & 5.90 & 6.63 & $7 \cdot 37$ & 8.11 & 8.85 & $9.5^{8}$ & 10.32 & 11.06 & 11.80 \\
\hline & 3.00 & 3.75 & 4.50 & 5.25 & 6.00 & 6.7 & 7.50 & 8.25 & 9.00 & 9.75 & 10.50 & II 1.25 & 12.00 \\
\hline 50 & 3.05 & $38 \mathrm{I}$ & 4.57 & 5.33 & 6.10 & 6.86 & 7.62 & $8.3^{8}$ & 9.15 & $9.9 \mathrm{I}$ & 10.67 & 11.42 & I 2.20 \\
\hline & 3.10 & 3.87 & 4.65 & $54 \mathrm{I}$ & 6.20 & 6.97 & 7.75 & $8.5^{2}$ & 9.30 & 10.07 & 10.85 & I I 62 & I 2.40 \\
\hline & 3.15 & 3.95 & $4.7 \mathrm{I}$ & $5 \cdot 5 \mathrm{I}$ & 6.30 & 7.08 & 7.87 & 8.66 & 9.45 & 10.23 & 11.02 & $11.8 \mathrm{I}$ & 12.60 \\
\hline & 3.20 & 4.00 & 4.80 & 5.60 & 6.40 & 7.20 & 8.00 & 8.80 & 9.60 & 10.40 & I 1.20 & 12.00 & 12.80 \\
\hline & 3.25 & 4.06 & 4.87 & 5.68 & 6.50 & $7 \cdot 3 \mathrm{I}$ & 8.12 & 8.93 & 9.75 & & 11.37 & 1218 & 13.00 \\
\hline 00 & 3.30 & 4.12 & 4.95 & 5.77 & 6.60 & 7.42 & 8.25 & 9.07 & 9.90 & 10.72 & I 1.55 & 12.37 & 13.20 \\
\hline & 3.35 & 4.19 & 5.02 & 5.86 & 6.70 & 7.52 & 8.37 & $9.2 \mathrm{I}$ & 10.05 & 10.87 & 11.72 & 12.56 & 13.40 \\
\hline & 3.4 & 4.25 & 5.10 & 05 & 6.80 & 7.65 & $8.5^{\circ}$ & 9.35 & 10.20 & I 1.05 & I I. 90 & 12.75 & 13.60 \\
\hline & 3.45 & $4.3 \mathrm{I}$ & 5.17 & 6.03 & 6.90 & 7.76 & 8.62 & 9.48 & 10.35 & I I. $2 \mathrm{I}$ & I 2.07 & 12.93 & 13.80 \\
\hline & 3.50 & 4.37 & 5.25 & $6.1 \mathrm{II}$ & 7.00 & 7.87 & 8.75 & 9.62 & 10.50 & II. 37 & 12.25 & 13.12 & 14.00 \\
\hline & 3.55 & 4.43 & $5 \cdot 3^{2}$ & $6.2 \mathrm{I}$ & 7.10 & 7.98 & 8.87 & 9.76 & 10.65 & I 1.53 & 12.42 & I 3.31 & 14.20 \\
\hline & 3.60 & 4.50 & 5.40 & 6.30 & 7.20 & 8. 10 & 9.00 & 9.90 & 10.80 & 11.70 & 12.60 & 13.50 & 14.40 \\
\hline & 365 & 4.56 & $5 \cdot 47$ & $6.3^{8}$ & 7.30 & $8.2 \mathrm{I}$ & 9.12 & I0.03 & 10.95 & I1. 86 & 12.77 & 13.68 & 14.60 \\
\hline & 3.70 & 4.62 & $5 \cdot 55$ & 6.47 & 7.40 & $8.3^{2}$ & 9.25 & 10.17 & II. IO & 12.02 & I 2.95 & 13.87 & 14.80 \\
\hline & 1275 & 4.68 & 5.62 & 6.56 & 7.50 & 8.43 & 9.37 & I0. $3 \mathrm{I}$ & II 1.25 & 12. 18 & I3.12 & 14.06 & 15.00 \\
\hline & & 4.75 & 5.70 & 6.65 & 7.60 & 8.55 & 9.50 & 10.45 & $\begin{array}{ll}1 & 4 \\
\end{array}$ & 12.35 & 13.30 & 14.25 & 15.20 \\
\hline
\end{tabular}




\section{CHEESE AND BUTTER MAKERS' READY RECKONER -Continued.}

\begin{tabular}{|c|c|c|c|c|c|c|c|c|c|c|c|c|c|}
\hline $\begin{array}{l}\bar{\Sigma} \\
\dot{3} \\
\dot{0} \\
\dot{0} \\
z\end{array}$ & 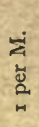 & 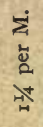 & 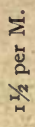 & 离 & 离 & 感 & $\frac{\vec{z}}{a}$ & 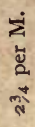 & 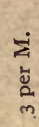 & 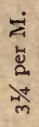 & 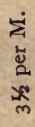 & 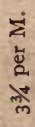 & $\begin{array}{l}\bar{\Delta} \\
\stackrel{\Delta}{\alpha} \\
\sigma\end{array}$ \\
\hline
\end{tabular}

$38503.854 .8 \mathrm{I}$ 39003.904 .87 39503.954 .93 40004.005 .00 40504.055 .06 $41004 \cdot 105,12$ $41504 \cdot 155.18$ 42004.205 .25 $42504 \cdot 25 \quad 5 \cdot 31$ $\begin{array}{llll}4300 & 4.30 & 5.37\end{array}$ $43504.35 \quad 5.43$ $44004.40 \quad 5.50$ 4450 4. 455.56 $4500 \quad 4.50 \quad 5.62$ 45504.555 .68 46004.605 .75 46504.655 .78 47004.705 .87 47504.755 .93 48004.806 .00 48504.856 .06 49004.906 .12 4950 4.95 6:18 50005.006 .25 $50505.056 .3 \mathrm{I}$ 51005.106 .37 51505.156 .43 52005.206 .50 52505.256 .56 $53005 \cdot 306.62$ 53505.356 .68 54005.406 .75 $54505.456 .8 \mathrm{I}$ $55005 \cdot 506.87$ $5550 \quad 5.556 .93$ 56005.607 .00 56505.657 .06
5.77 $\begin{array}{lll}5.85 & 6.82\end{array}$ 5.926 .91 6.007 .00 6.07 7.08 6.157 .17 6.227 .26 $\begin{array}{ll}6.30 & 7.35 \\ 6.37\end{array}$ \begin{tabular}{lll}
$6.37 \quad 7.43$ \\
\hline
\end{tabular} 6.457 .52 6.527 .61 6.607 .70 6.677 .78

6.757 .87

6.827 .96

6.908 .05

6.978 .13

7.058 .22

7.12 7.20 7.27 7.35 7.42 7.50 7.57 7.65 7.72 7.80 7.87 7.95 8.02 8. 10 8. 17 8.25 8.32 8.40 8.47

8.31

8.40

8.48 $\begin{array}{lllllllllllll}8.57 & 9.80 & \text { I I. } 02 & \text { I } 2.25 & \text { I } 3.47 & \text { I } 4.70 & \text { I } 5.92 & \text { I } 7.15 & \text { I } 8.37 & \text { I } 9.60\end{array}$ $\begin{array}{llllllllllllllll}7.70 & 8.66 & 9.62 & 10.58 & 11 & 1.55 & 12.51 & 13.47 & 14.43 & 15.40\end{array}$ \begin{tabular}{lll|l|l|l|llllllll}
7.80 & 8.77 & 9.75 & 10.72 & 1 1.70 & 12.67 & I 3.65 & I 4.62 & I 5.60
\end{tabular} \begin{tabular}{lll|l|l|l|l|l|l|l|l|l}
7.90 & 8.88 & 9.87 & I 0.86 & I I. 85 & I 2.83 & I 3.82 & I 4.8 I & I 5.80
\end{tabular} $\begin{array}{lllllllllllll}8.00 & 9.00 & 10.00 & 1 & 1.00 & 12 & 00 & 13.00 & 14.00 & 15.00 & 16.00\end{array}$ $\begin{array}{lllllllllllll}8.10 & 9.11 & 10.12 & 11.13 & \text { I } & \text { I } 5 & 13.16 & \text { I } 4 & \text { I } & 15.18 & 16.20\end{array}$ \begin{tabular}{llll|l|l|l|l|l|l|l|l|l}
8.20 & 9.22 & 10.25 & I 1.27 & I2.30 & I 3.32 & I 4.35 & I 5.37 & 16.40
\end{tabular} $\begin{array}{lllllllllllll}8.30 & 9.33 & \text { I } 0.37 & \text { I } 1.4 \text { I } & \text { I } 2.45 & \text { I } 3.48 & \text { I } 4.52 & \text { I } 5.56 & \text { I } 6.60\end{array}$

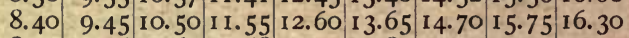
$\begin{array}{lllllllllllll}8.50 & 9.56 & 10.62 & \text { I } .68 & 12.75 & \text { I } 3.8 \text { I } & \text { I } 4.97 & \text { I } 5.93 & \text { 1 } 7.00\end{array}$ $\begin{array}{lllllllllllllll}8.60 & 9.67 & \text { I } 0.75 & \text { I I. } 82 & \text { I } 2.90 & \text { I } 3.97 & \text { I } 5.05 & \text { I } 6.12 & \text { I } 7.20\end{array}$ \begin{tabular}{lll|l|l|l|l|l|l|l|l|l}
8.70 & 9.78 & 10.87 & I 1.96 & I 3.05 & I 4.13 & I 5.22 & I 6.31 & I 7.40
\end{tabular} $8.80 \quad 9.90$ I 1.00 I2. 10 I 3.20 I 4.30 I 5.40 I6. 50 I 7.60 8.90 I0.0I I I. I2 I2.23 I 3.35 I $4.46 \quad 45.57$ I6.68 17.80 $\begin{array}{llllllllllll}9.00 & 10 & 12 & 11.25 & 12.37 & \text { I 3.50 } & \text { I } 4.62 & \text { I } 5.75 & \text { I } 6.87 & \text { I } 8.00\end{array}$ \begin{tabular}{ll|l|l|l|l|l|l|l|l|l}
9.10 & 10.23 & 11.37 & 12.5 & 13.65 & I 4.78 & I 5.92 & I 7.06 & I 8.20
\end{tabular}

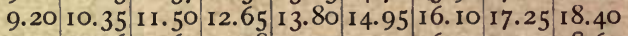

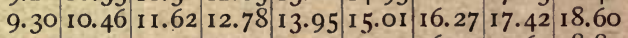

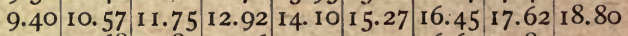
$\begin{array}{lllllllllllll}9.50 & \text { I0.68 } & \text { I } 1.87 & \text { I } 3.06 & \text { I } 4.25 & \text { I } 5.43 & \text { I } 6.62 & \text { I } 7.8 \text { I } & \text { 19.00 }\end{array}$ $9.6010 .8012 .0013 .20 \quad 14.40 \quad 15.60 \quad 16.8018 .0019 .20$ \begin{tabular}{ll|lllllllll}
9.70 & 10.91 & 12.12 & 13.33 & 14.55 & 15.76 & 16.97 & 18.18 & 19.40
\end{tabular} \begin{tabular}{ll|l|l|l|l|l|l|l|l|l|l|l|l|l}
8.66 & 9.90 & I I. I 3 & I 2.37 & I 3.6 I & I 4.85 & I 6.08 & I 7.32 & I 8.56 & I 9.80
\end{tabular}

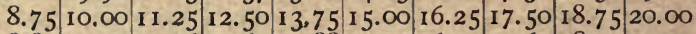

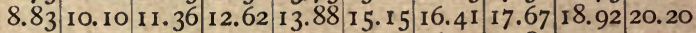

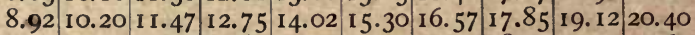

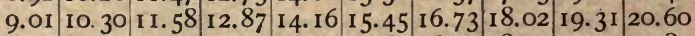

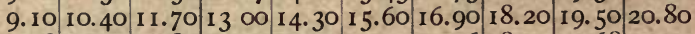
\begin{tabular}{ll|l|l|l|l|l|l|l|l|l|l|l|l|l}
9.18 & 10.50 & 11.8 & 1 & 13.12 & 14.43 & 1 & 5.75 & 17.06 & 18.37 & 19.68 & 21.00
\end{tabular} \begin{tabular}{ll|l|l|l|l|l|l|l|l|l|l|l|l|l}
9.27 & 10.60 & 11.92 & 1 & 13.25 & 14.57 & 15.90 & 17.22 & 18.55 & 19.87 & 21.20
\end{tabular} \begin{tabular}{ll|l|l|l|l|l|l|l|l|l|l|l|l|l}
9.36 & 10.70 & 12.08 & I 3.37 & I 4.7 I & 16.05 & I 7.38 & I 8.72 & 20.06 & 21.40
\end{tabular} $\begin{array}{lllllllllllll}9.45 & 10.80 & 12.15 & 13.50 & 14.85 & 16.20 & \text { I } 7 & 55 & 18.90 & 20.25 & 21.60\end{array}$ \begin{tabular}{ll|l|l|l|l|l|l|l|l|l|l|l|l|l|l}
9.53 & 10.90 & 12.26 & I 3.62 & 14.98 & 16.35 & 17.7 & 19.07 & 20.43 & 21.80
\end{tabular}

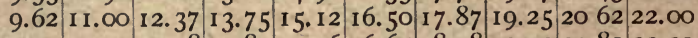

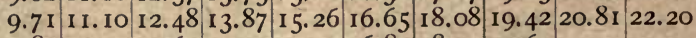
9.80 I I. 20 I 2.60 I 4.00 I 5.40 I 6.80 I 8.20 I 9.60 21.00 22.40

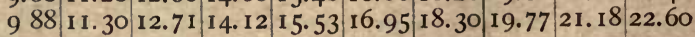


CHEESE AND BUTTER MAKER'S READY RECKONER -Continued.

\begin{tabular}{|c|c|c|c|c|c|c|c|c|c|c|c|c|c|}
\hline $\begin{array}{l}\bar{z} \\
\dot{3} \\
\dot{0} \\
\dot{z}\end{array}$ & ${ }_{2}^{2}$ & 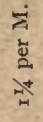 & $\frac{i}{\grave{\Delta}}$ & 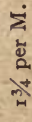 & & $\begin{array}{l}\sum_{j} \\
\vdots \\
\vdots \\
\text { d. }\end{array}$ & 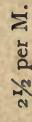 & 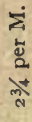 & $\begin{array}{l}\sum_{1} \\
\stackrel{2}{L} \\
m \\
m\end{array}$ & 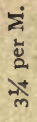 & $\begin{array}{l}\Sigma \\
\overline{\$} \\
\frac{\mathrm{d}}{\mathrm{c}}\end{array}$ & $\begin{array}{l}\dot{\Sigma} \\
\dot{\nu} \\
\text { ले }\end{array}$ & $\begin{array}{l}\sum_{0} \\
\vdots \\
\vdots\end{array}$ \\
\hline
\end{tabular}

57005.707 .12 57505.757 .18 58005.807 .25 58505.857 .31 $59005 \cdot 907 \cdot 37$ 59505.957 .43 60006.007 .50 60506.057 .56 6roo 6. 10 7.62 6 I 506.157 .68 62006.2077 .75 $62506.257 .8 \mathrm{I}$ 63006.307 .87 63506.357 .93 64006.408 .00 64506.458 .06 65006.508 .12 65506.558 .18 66006.608 .25 66506.658 .31 67006.708 .37 67506758.43 68006.808 .50 68506.858 .56

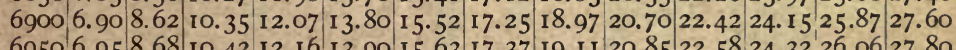

\begin{tabular}{ll|lll|l|l|l|l|l|l|l|l}
8.55 & 9.97 & I I .40 & I 2.82 & I 4.25 & I 5.67 & I 7.10 & I 8.52 & I9 95 & 21.37 & 22.80
\end{tabular}

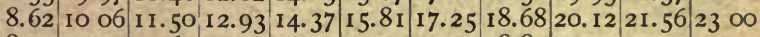

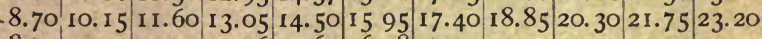

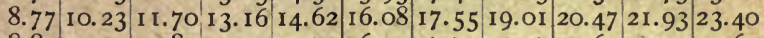

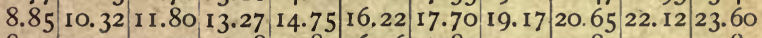

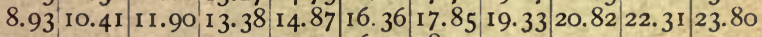
9.00 IO 50 I 2.00 I 3.50 I 5.00 I 6.50 I 8.00 I 9.502 I.00 22. 50 24.00

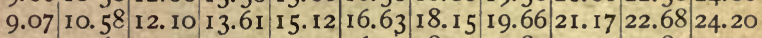

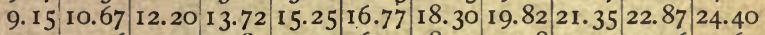

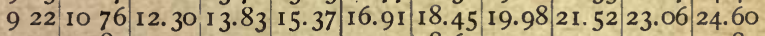

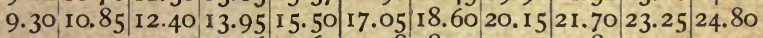

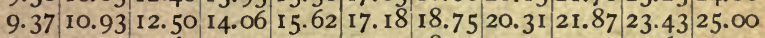

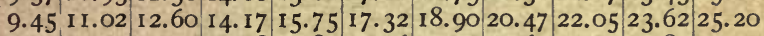
$\begin{array}{llllllllllll}9.52 & \text { I I. I I I } 2.70 & \text { I } 4.28 & \text { I } 5.87 & \text { I } 7.46 & \text { I } 9.05 & 20.63 & 22.22 & 23.81 & 25.40\end{array}$ $\begin{array}{llllllllllll}9.60 & \text { I I. } 20 & \text { I } 2.80 & \text { I } 4.40 & \text { I } 6.00 & \text { I } 7.60 & 19.20 & 20.80 & 22.40 & 24.00 & 25.60\end{array}$

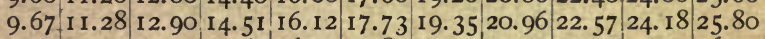

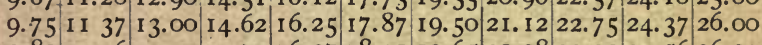

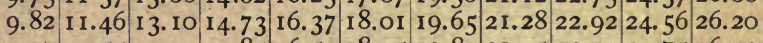
9.9041 .55 I 3.20 I 4.85 I6.50 I8. I 5 I 19.80 21.45 23. I0 24.7526 .40 \begin{tabular}{lll|l|l|l|l|l|l|l|l|l|l|l|l|l|}
9.97 & I I. 63 & I 3.30 & I 4.96 & I 6.62 & I 8.28 & I 9.95 & 2 I.6 I & 23.27 & 24.93 & 26.60
\end{tabular}

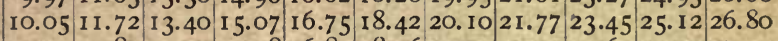

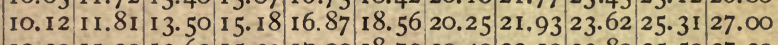

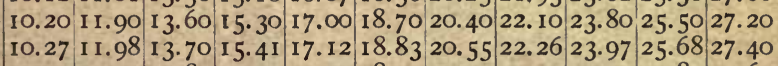
\begin{tabular}{ll|l|l|l|l|l|l|l|l|l|l|l|l}
7000 & 7.00 & 8.75 & 10.50 & 12.25 & 14.00 & I 5.75 & I 7.50 & I 9.25 & 21.00 & 22.75 & 24.50 & 26.25 & 28.00
\end{tabular}

DIRECTIONS : The numb $r$ opposite the quantity of milk and under the rate per M. (1000 lbs.) is the quantity to use. For butter coloring read drams. For cheese coloring and rennet read ounces. For salt read pounds. Example: The weight of milk is $4,550 \mathrm{lbs}$, the rate of coloring is $\mathrm{I} 1 / 4$ per M., rennet $23 / 4$ per M. and salt $2 \frac{1}{4}$ per M. Opposite the weight of milk in the respective columns will be found $-5.68\left(5 \frac{1}{2} \mathrm{dr} \div\right.$. or $\mathrm{oz}$. of coloring); $12.5^{1}$ (12 $1 / 2 \mathrm{oz}$. rennet), and 10.23 (10 $1 / 4$ lbs. salt). 


\section{TABLE SHOWING THE PER CENT. MOISTURE IN THE A'R OF CHEESE RIPENING}

\section{ROOMS.-(KING).}

DIRECTIONS.- Notice that the table is in three column sections. Find air temperature in first column, then find wet bulb temperature in second column, same division. In third column opposite this is per cent. moisture.

Example.-Air temperature is $50^{\circ}$, in the first column; wet bulb is $44^{\circ}$, in the second column, same division. Opposite $44^{\circ}$ is $6 \mathrm{I}$, which is the per cent. of moisture, or the relative humidity in the air.

\begin{tabular}{|c|c|c|c|c|c|c|c|c|c|c|c|c|c|c|}
\hline$\frac{\dot{\xi}}{3}$ & 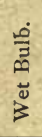 & 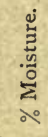 & $\begin{array}{l}0 \\
\overline{3} \\
0 \\
0 \\
0 \\
0\end{array}$ & 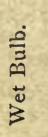 & 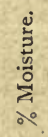 & $\mid \begin{array}{l}0 \\
\tilde{n} \\
2 \\
\hat{n} \\
\hat{A}\end{array}$ & $\begin{array}{l}\stackrel{0}{3} \\
\stackrel{3}{3} \\
3 \\
3\end{array}$ & 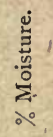 & 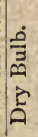 & 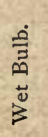 & 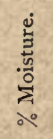 & 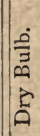 & 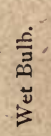 & 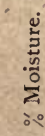 \\
\hline & 32 & 37 & & 33 & 28 & & $4 I$ & 71 & & 37 & 29 & & 43 & 55 \\
\hline & 33 & 44 & & 34 & 34 & & 42 & 78 & & 38 & 35 & & 44 & $6 \mathrm{I}$ \\
\hline & 34 & 52 & & 35 & 41 & 45 & 43 & 85 & & 39 & $4 \bar{I}$ & & 45 & 67 \\
\hline & 35 & 59 & & 36 & 48 & & 44 & 92 & & 40 & 47 & 50 & 46 & 74 \\
\hline & 36 & 68 & & 37 & 55 & $1-$ & & & & 41 & 53 & & 47 & 80 \\
\hline & 37 & 76 & 43 & 38 & 62 & & 35 & 26 & 48 & 42 & 60 & & 48 & 87 \\
\hline & $3^{8}$ & 84 & & 39 & 70 & & 36 & 32 & & 43 & 66 & & 49 & 93 \\
\hline & 39 & 92 & & 40 & 77 & & 37 & 38 & & 44 & 73 & - & & \\
\hline & & tost & & $4 \mathrm{I}$ & 85 & & 38 & 45 & & 45 & 79 & & 40 & 33 \\
\hline & 32 & 31 & & 42 & 92 & & 39 & $5 \mathrm{I}$ & & 46 & 86 & & 41 & 39 \\
\hline & 33 & 38 & - & & & 46 & 40 & 58 & & 47 & 93 & & 42 & 45 \\
\hline & 34 & 46 & & 34 & 29 & & 41 & 65 & - & & & & 43 & 50 \\
\hline & 35 & 53 & & 35 & 36 & & 42 & 72 & & 38 & 30 & & 44 & 56 \\
\hline 41 & 36 & 60 & & 36 & 43 & & 43 & 79 & & 39 & 36 & 51 & 45 & 62 \\
\hline & 37 & 68 & & 37 & 49 & & 44 & 85 & & 40 & 42 & & 46 & 68 \\
\hline & 38 & 76 & & 38 & 56 & & 45 & 93 & & 41 & 48 & & 47 & 74 \\
\hline & 39 & 84 & 44 & 39 & 63 & -1 & & & & 42 & 54 & & 48 & 81 \\
\hline & 40 & 92 & & 40 & 70 & & 36 & 28 & 49 & 43 & 60 & & 49 & 87 \\
\hline & & & & $4 \mathrm{I}$ & 78 & & 37 & 34 & & 44 & 67 & & 50 & 93 \\
\hline & 33 & 33 & & 42 & 85 & & 38 & 40 & & 45 & 73 & - & & \\
\hline & 34 & 40 & & 43 & 92 & & 39 & 46 & & 46 & 80 & & $4 \mathrm{I}$ & 35 \\
\hline & 35 & 47 & - & & 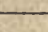 & & 40 & 52 & & 47 & 86 & & 42 & 40 \\
\hline & 36 & 54 & & 35 & 31 & 47 & $4 \mathrm{I}$ & 59 & & 48 & 93 & & 43 & 46 \\
\hline 42 & 37 & 61 & & 36 & 37 & & 42 & 66 & 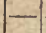 & 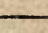 & & & 44 & 51 \\
\hline & 38 & 69 & & 37 & 44 & & 43 & 72 & & 39 & 32 & 152 & 45 & 57 \\
\hline & 39 & 77 & 45 & 38 & 50 & & 44 & 79 & 150 & 40 & 37 & & 46 & 63 \\
\hline & 40 & 84 & & 39 & 57 & & 45 & 86 & & $4 \mathrm{I}$ & 43 & & 47 & 69 \\
\hline & 41 & 92 & & 40 & 64 & & 46 & 93 & & 42 & 49 & & 48 & 75 \\
\hline
\end{tabular}


PER CENT. MOISTURE IN THE AIR.-Continued.

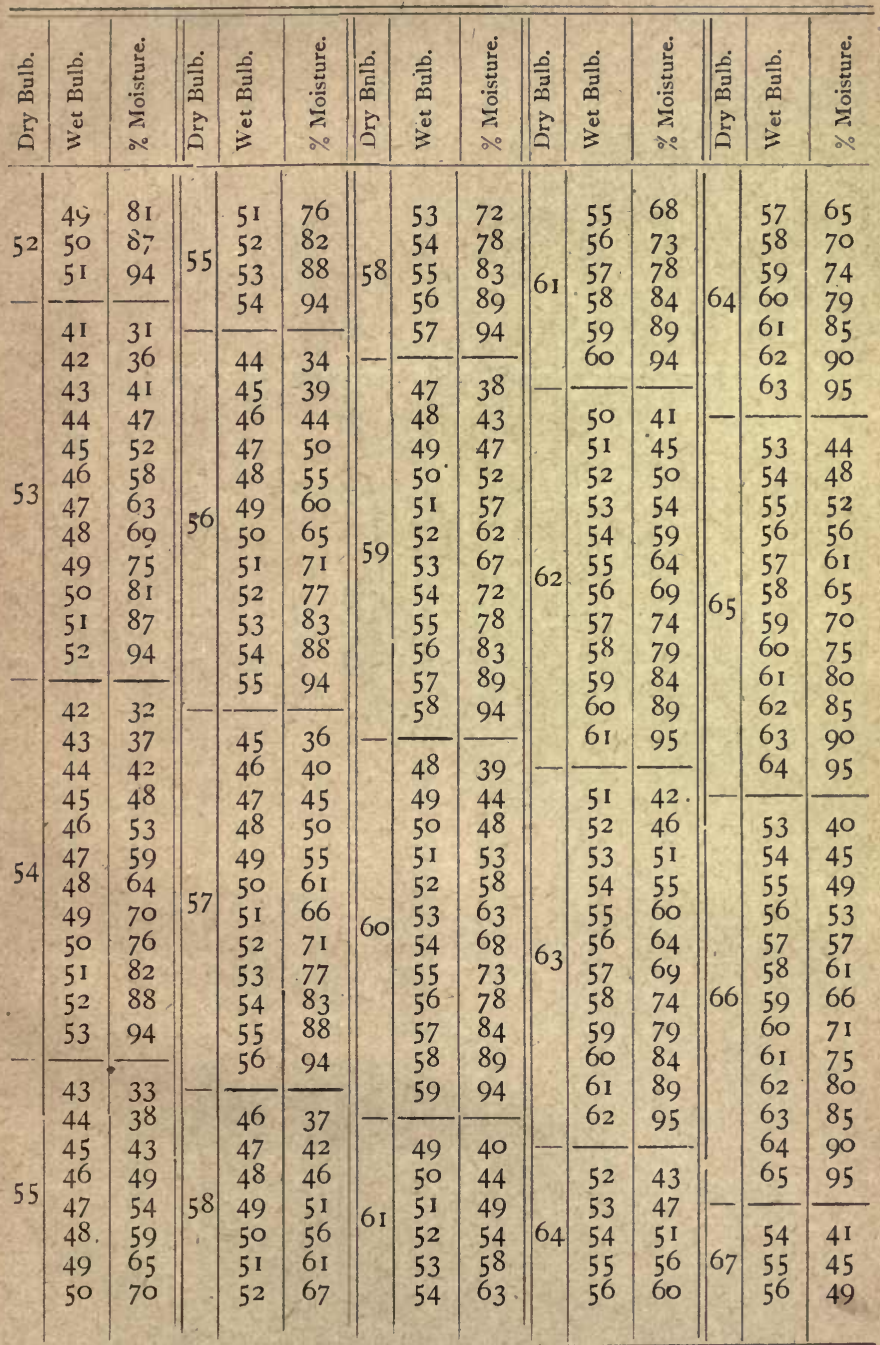


PER CENT. MOISTURE IN THE AIR.-Continued.

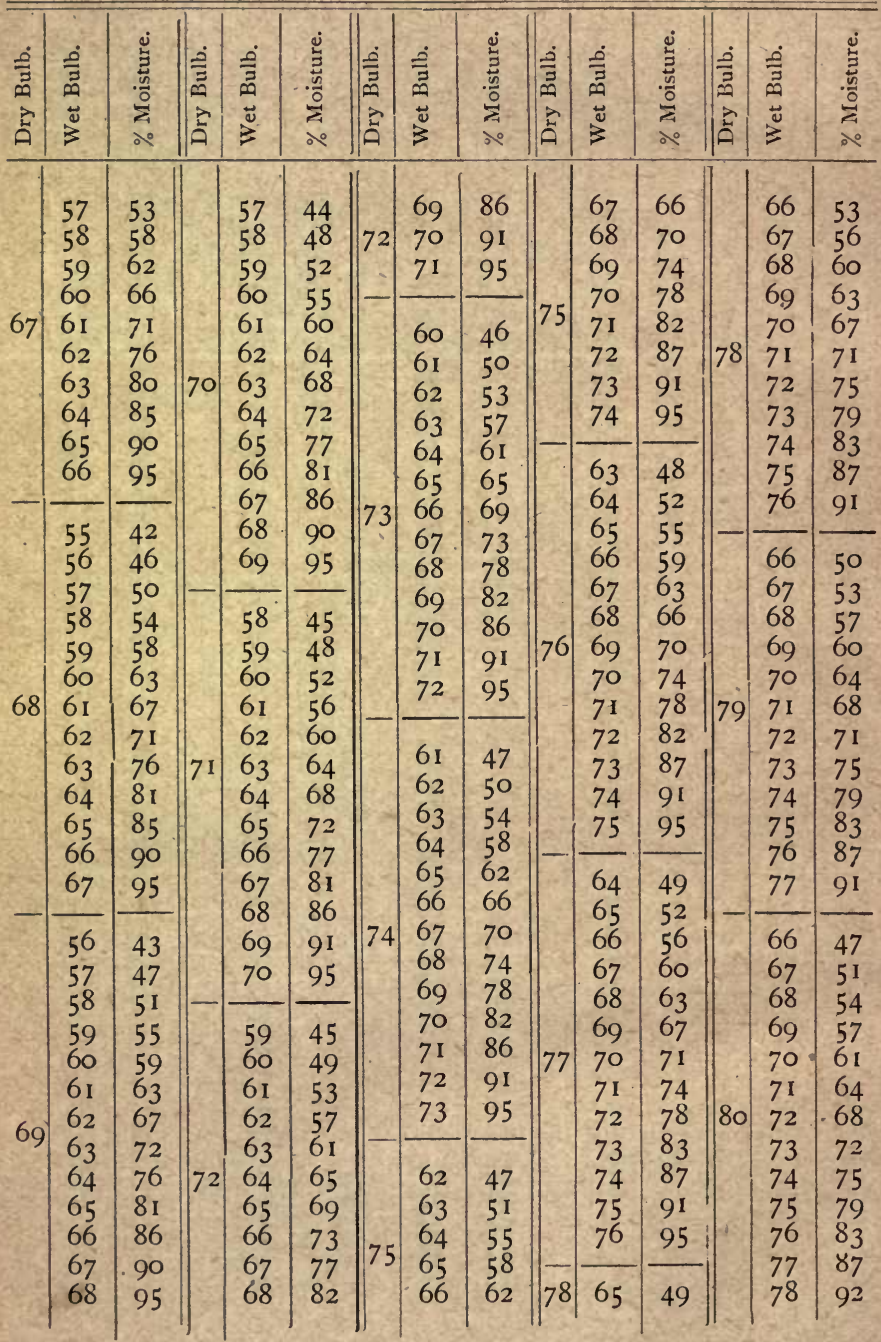



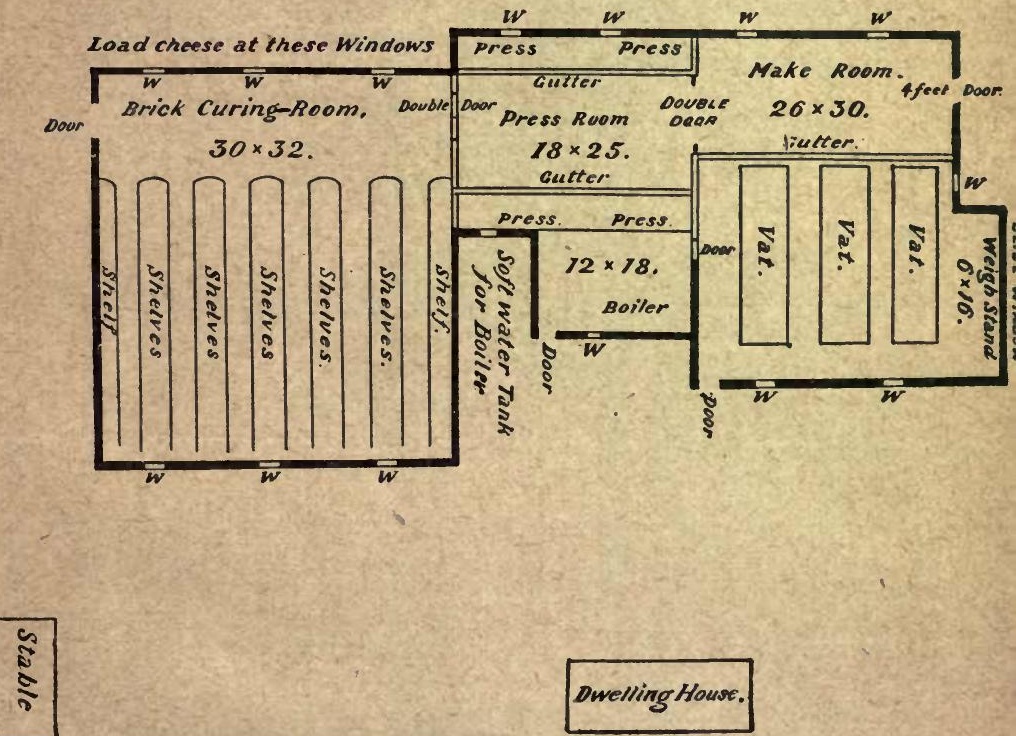

\section{Dwelling House.}

PLAN FOR CHEESERY. 


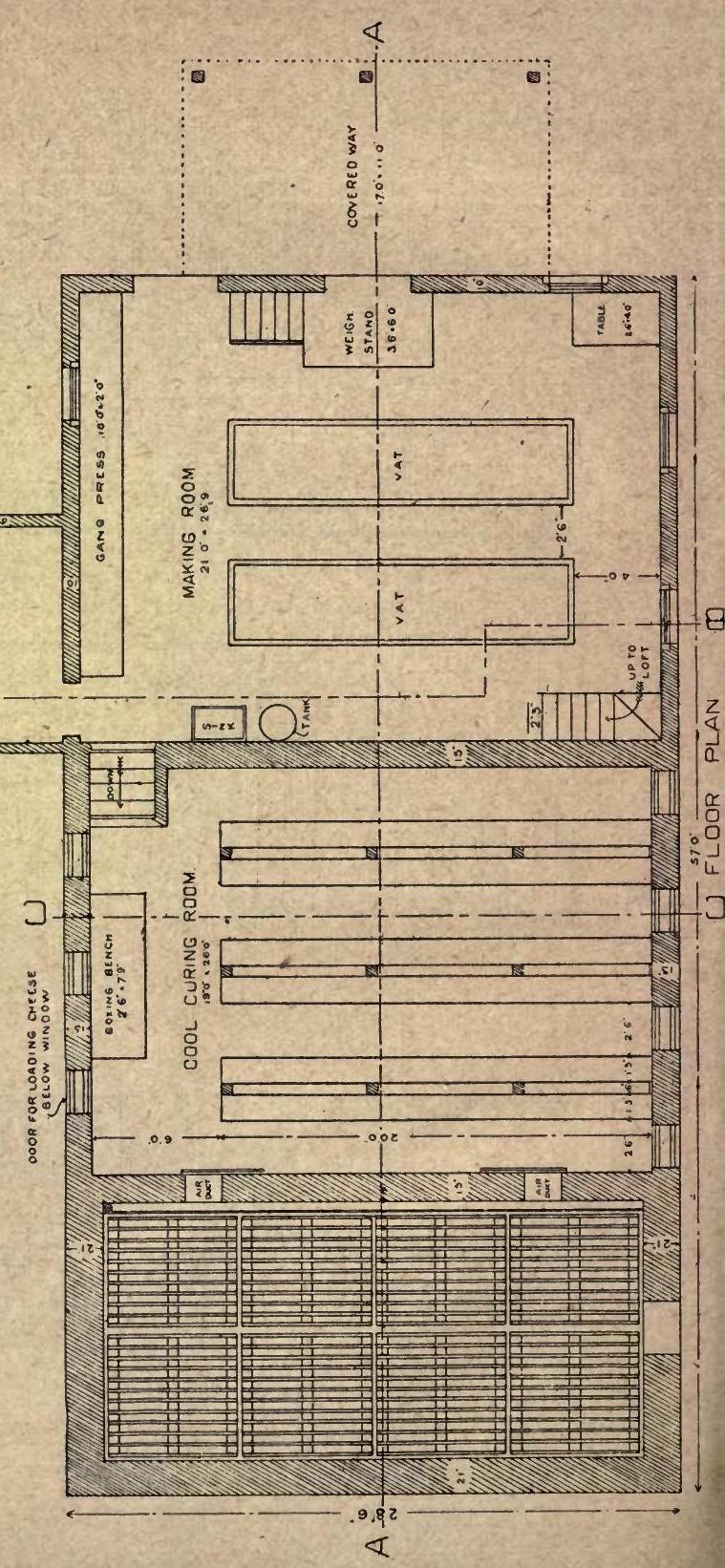




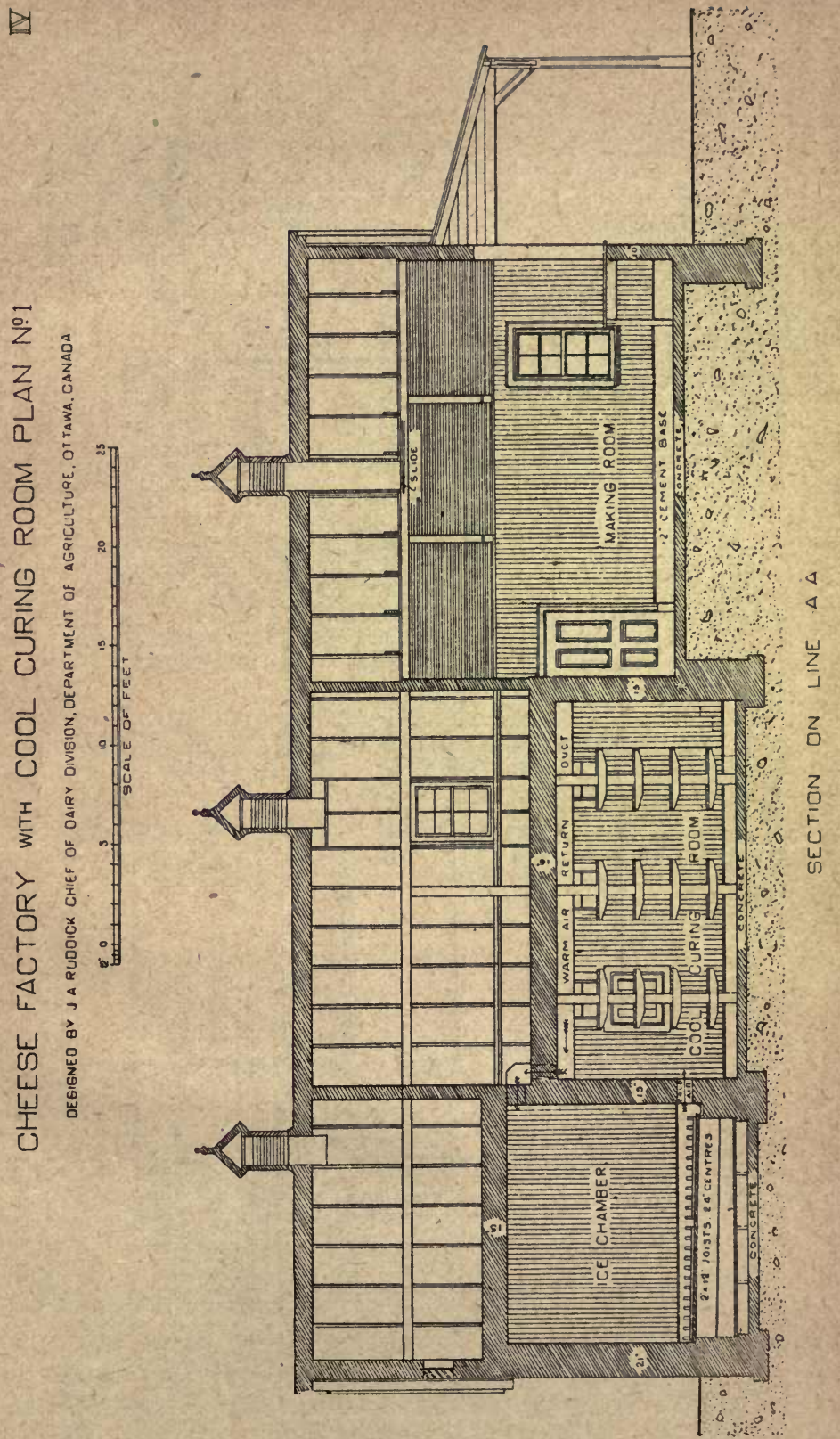




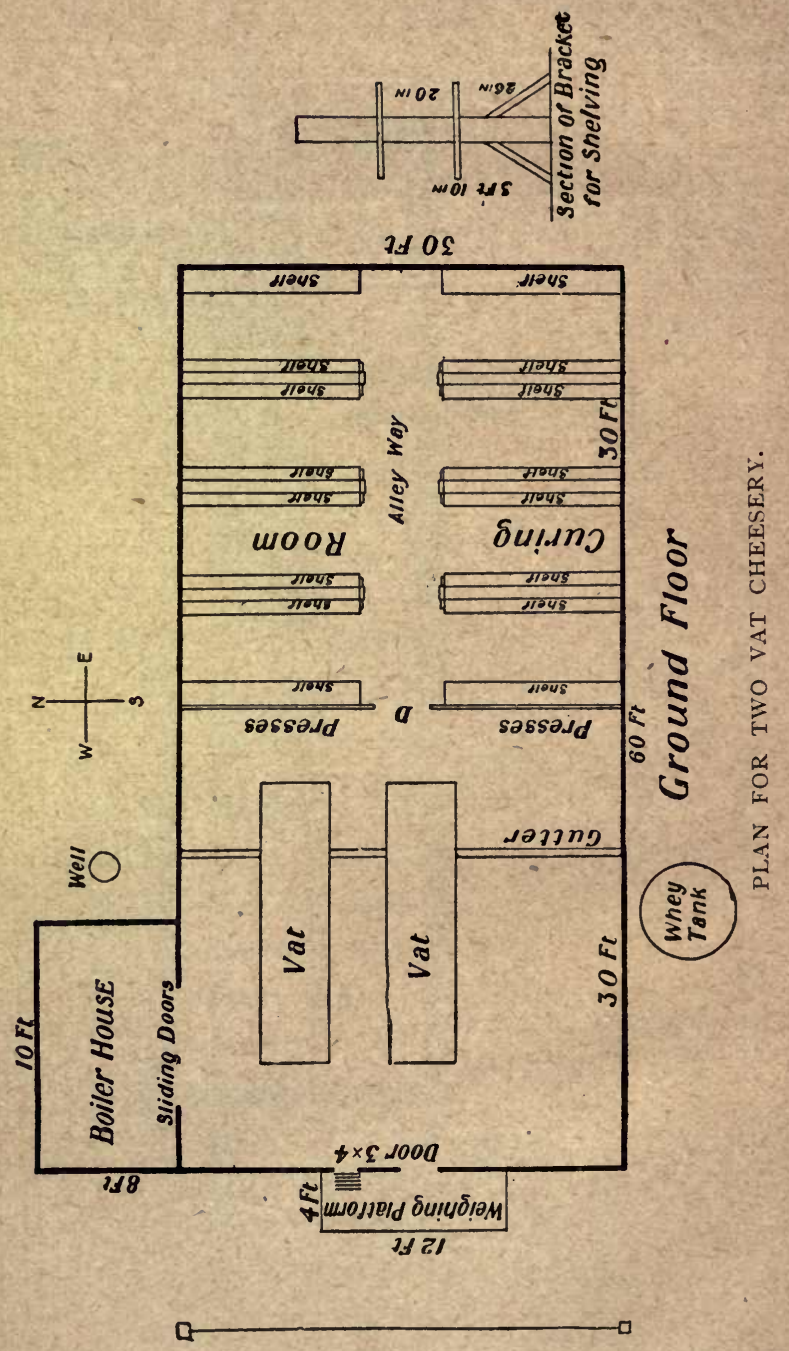




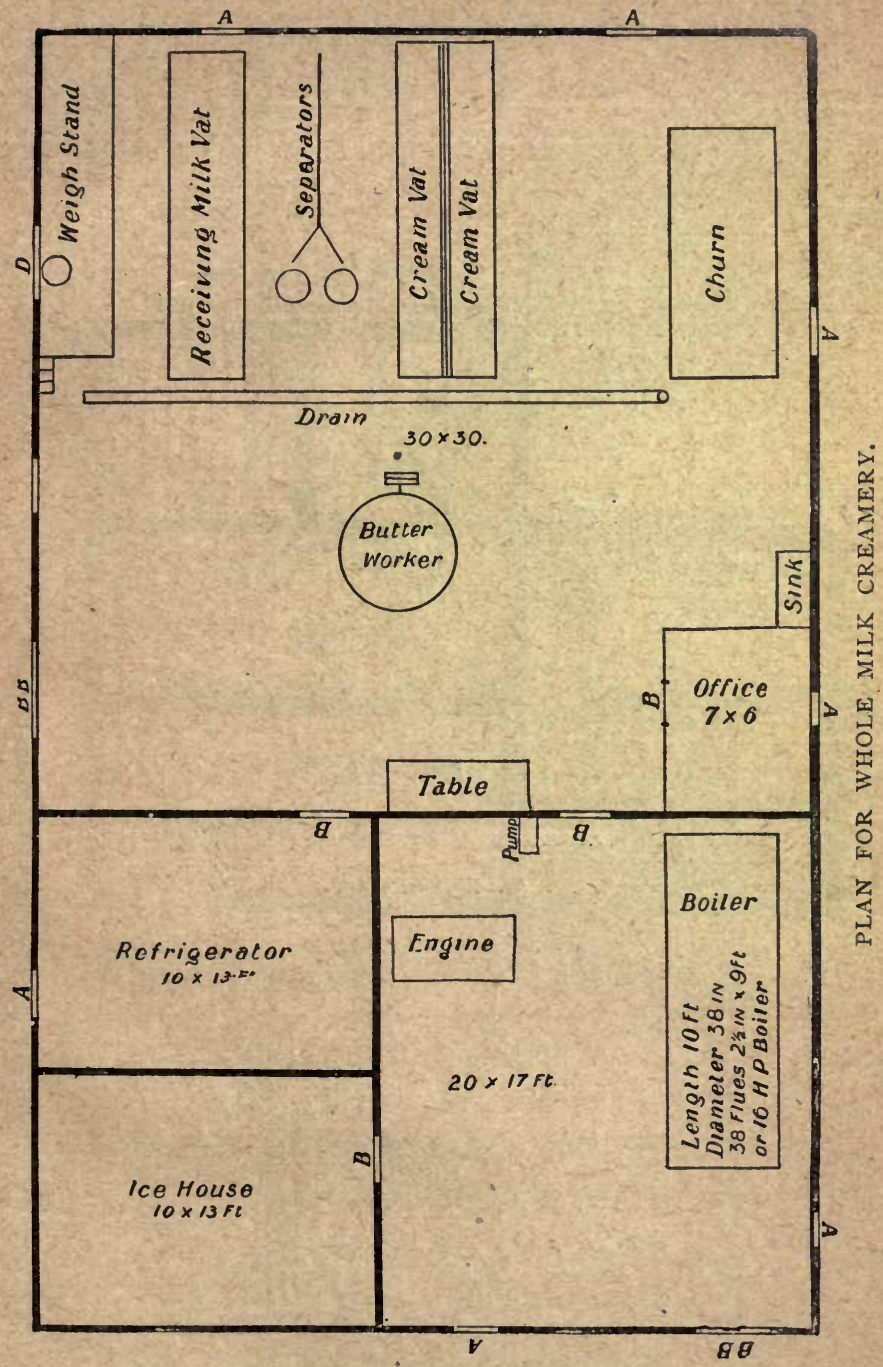




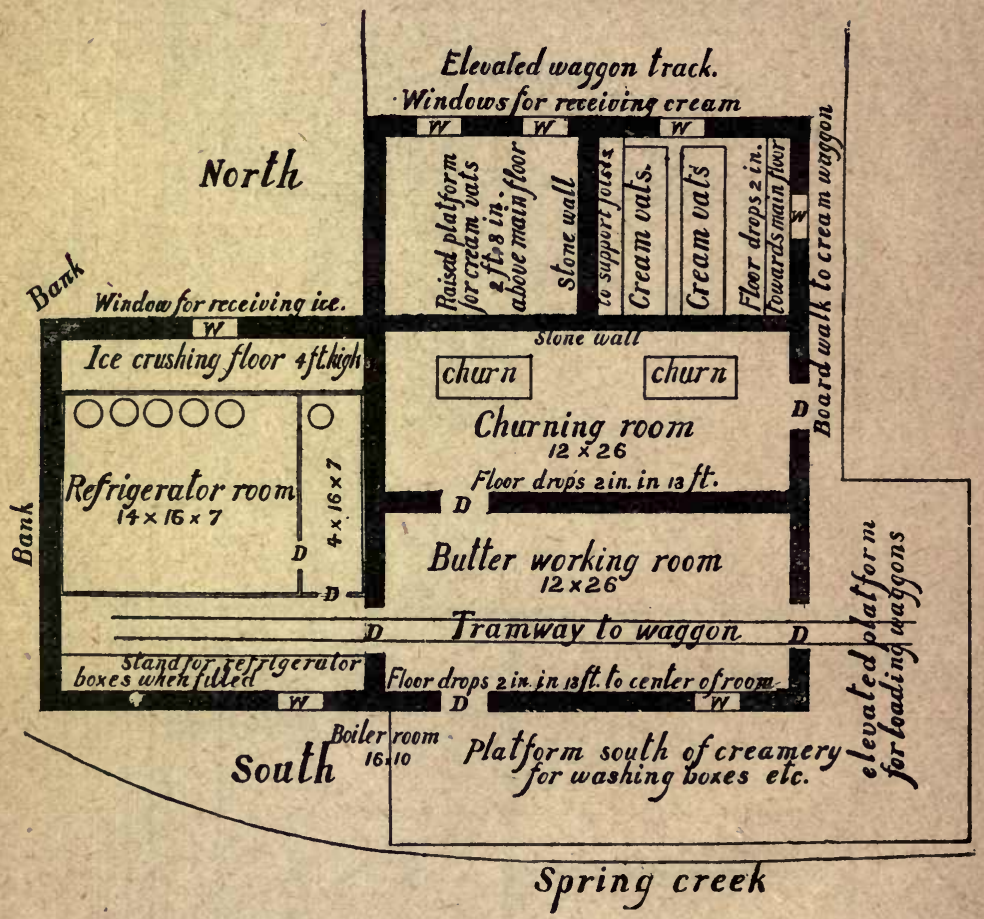

PLAN FOR CREAM-GATHERING CREAMERY. 


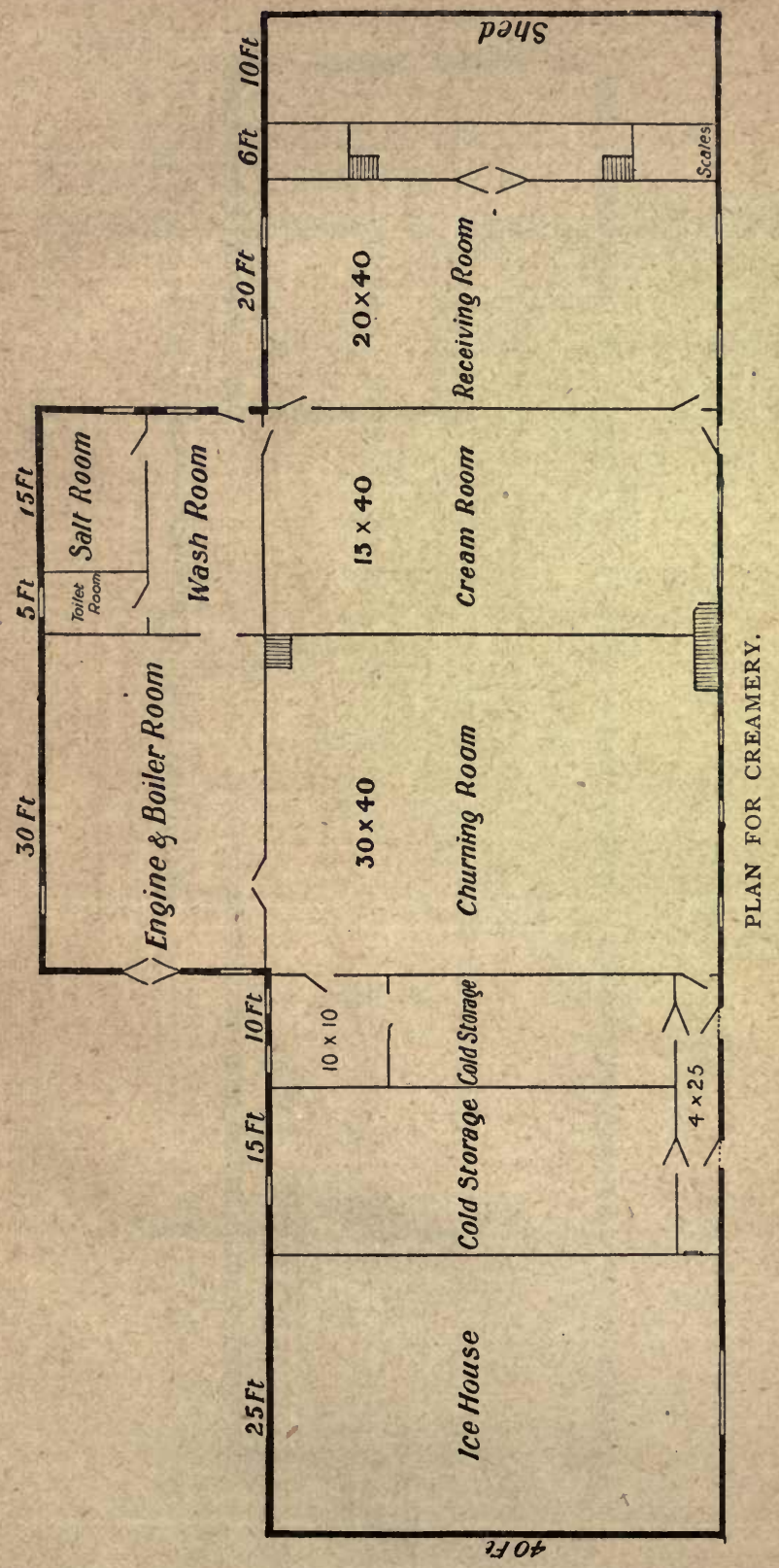




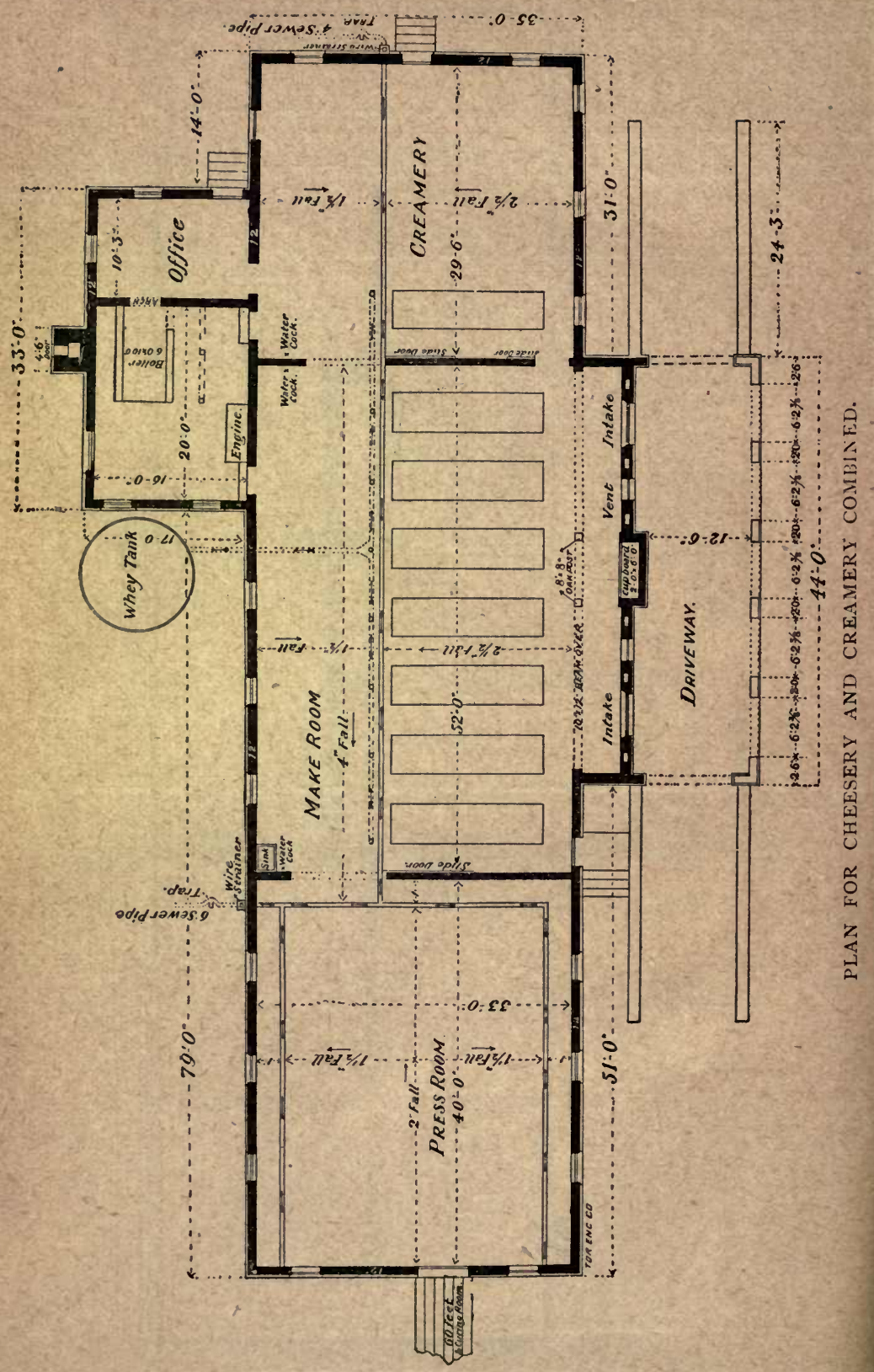




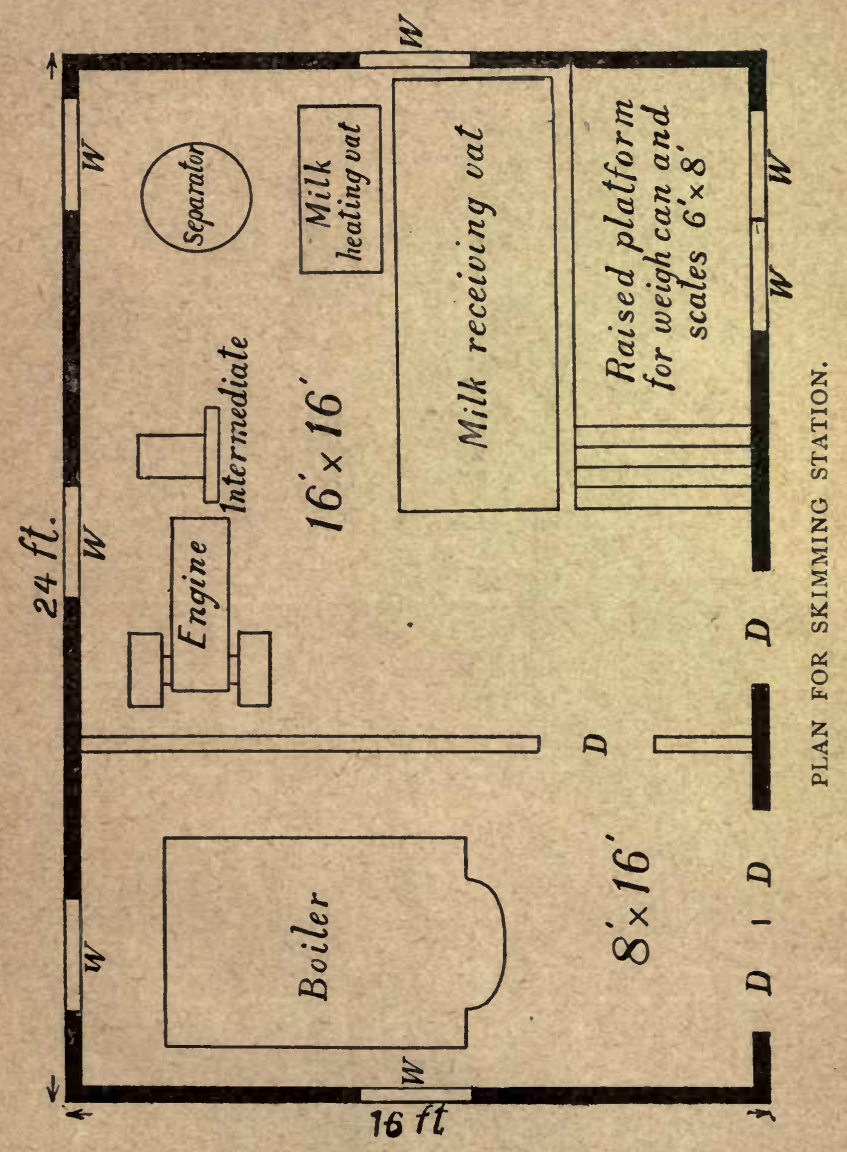





\section{INDEX.}

\section{PART I.-FARM DAIRYING.}

Absorbents for dairy stable PAGE. 'I9 Acid measure for Babcock test 5 I Adulterated milk, testing of 56,57 Agents of dairy farmer, plants and animals

Air should be pure at nilking time

Animal food valuable and easily digested . . . . 10

Ash of milk . . . . 46

Babcock, Dr. S. M. • . 50

Babcock test . . $\quad 50$

Boiling point of milk . $\quad \cdot 47$

Bottles for Babcock test $\quad 5^{I}$

Box stall for sick cows . . 19

Buildings for dairy farm . I I

Buttermaking does not rob soil 13

Buttermilk . I0, 54, 61, 93, 96

Butter, scale of points for judging . . . $\quad 9^{2}$

Calves . $\quad$. $\quad 19,29,31$

Canada well suited for dairying 12

Canadians favor dairying 12

Caring for milk, main points . $6 \mathrm{I}$

Casein . . . 45

Cement floors in stable . . I7

Centrifugal tester . $\quad$. $5 \mathrm{I}$

Centrifugal force, law of . 75

Certified milk . . . I05

Cheese for farm dairy, utensils 97

Cheese for farm dairy, making . . 99, ror

Cheese testing with Babcock 55

Churned samples, testing $\quad 55$

Churning . 86,88

City dairy companies . . IO2

City dairy companies-advant-

ages . . . 102

City dairy companies-disad-

vantages . . . IO3

Cleaning stable . . . 19

Cloudy or burnt readings $\quad 53$

Colostrum . $\quad . \quad \cdot 42$

Color of milk . . . . 46

Coloring cream . . . 87

Cooling milk . . . . 60

Composition of butter $\quad \cdot \quad 92$

Composition of milk . . 43

Co $n$ silage . . . • 35

Cow :

Size . . . . 21

Training . $\quad . \quad \cdot 2 \mathrm{I}$

Selecion . . 21,23

Constitution . $\quad$. 22

Digestion $\quad . \quad$. 22

Milking capacity . $\quad 22$

Beauty • . 23

Record-6,000 lbs. milk, 250 lbs. butter . . 23

Ayrshire . . . 24

Canadian . . . 25

Guernsey . . . 26

Holstein . . . . 26

Jersey ․ . . 27

Short-Horn • • • 28

Sick, isolate . . . $3 \mathrm{I}$

Chewing bones . 3 I

Shade or stable in hot weather . 31,32

Not exposed to cold or storm . . . 32 
Cow-Sunny yard in winter Cream, commercial Cream, churning sweet Creamometer. Cream testing

Dairy :

Crops more certain

Farms not large

Farms-location

Fa:ms-well drained

Farms-water supply

Farms-standard of production

Farming-advantages

Stable requisites

Stable temperature.

Stable ventilation

Stable width .

Dairy sire

Density of milk

Devonshire cream .

Deep setting creaming

Deep setting creaming, advantages.

Dilution separators

Drop behind cows .

Dusty feed and bedding

Electric currents little effect on milk

Factors influencing creaming .

Farm dairy plan

Farm inspection for city milk . IO3

Feeding calves

Feeding, principles .. - 33

Feeding cows twice a day $\quad 34$

Ferment theory . . $\quad 39$

Filtration of milk . $\quad$. $\quad$ ro4

Fly mixture for cows . . $3 \mathrm{I}$

Floor coating . . . 63

Foods cheap. . . . 33

Foods, meal . . . . 34

Food cost of milk, butter and cheese

Forces for creaming milk Frozen m:lk, testing

I

II

2,14

- 16

17

19

47

74

70

73 . 66

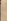

\section{9}

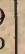

1

3

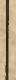

(

$\begin{array}{ll}\text { Mangers for cows } \quad: \quad \text { I } 8 \\ \text { Metamorphic theory } & \text { : } 39\end{array}$

Milk :

Necessary article of food I3 Secreted in mammal gland 37 $\begin{array}{lll}\text { Cisterns in udder } . \quad & 38\end{array}$ Composition . . . 43 Fats . . . 44 Constituents, sources of : 44 Constituents, variation of 45 Varies in composition .48 Stands covered . 60 Milking cow's once, twice or thrice a day . . 40 - 55 Milking, points to observe $4^{\circ}$ 
Milling mage. Milking machines not successful 4I Modified milk 200

Odor of milk . . . 46

Specific gravity of milk

Square cheese . . . . IOI

Stalls for cows $\quad . \quad$ I 8

Opacity of milk . $\quad .46$

Pasteurizing cream . $\quad$. 84

Strippings . $\quad . \quad 39$

Sugar of milk . . 46

Sulphuric acid 'or testing milk 5 I

Pasteurizing milk . . . . IO4

Pioskop. . . . 49

Pipette for Babcock test. $\quad 51$

Profit in manufacturing . . 9

P'rime materials for food-soil, sunlight, air and water $\quad 10$

Private dairying, advantages . 64

Private dairying, disadvantages 64

Printing butter . . 990

Pure milk important for towns 102

Raw materials of dairy farmer 9

Ripening cream . $\quad 84,85$

Salt for cows .

Scale of points for judging

butter
Skim-milk $\quad$ ro, $54,93,95,96$

Successful dairying

Theory of Babcock test . . 56

Thermometer. . . $\quad 48$

Ties for dairy cows . . 18

Training cows . $\quad .21$

Transudation theory . $\quad 39$

Triple servants-breed, feed,

weed . . . 30

Udder: . • . $\quad .37$

Hard to milk . $\quad 38$

Leaks milk • • . 38

Different kinds : . 39

Ideal . . . $\quad 40$

Uses of Babcock test $\quad . \quad 57$

Shallow pan creaming . 68

Slime from centrifuge $\quad . \quad 78$

Shipping butter . . . 9 I

Size of cows. . . . 21

Souring of milk . • . 46

Sour milk, testing . . . 56

Special points in Babcock testing

$\begin{array}{lr}\text { Viscogen } & \text { I05 } \\ \text { Water trough for stable } & 20 \\ \text { Washing dairy utensils } & 64 \\ \text { Whey } & 10,54,61,95 \\ \text { Whey tank } & 6 \mathrm{I}, 94 \\ \text { Whitewash } & \text {. } \\ \text { Whipping cream } & \text { 10 } \\ \text { Wooden floors in stable. } & \text { I8 } \\ \text { Working butter } & 89\end{array}$

\section{PART II.-CO-OPERATIVE DAIRIING.}

Accumulator

PAGE.

Acidimeter

Acidity of milk for renneting . I63

Acidity of cream . . 199, 200

Acid and rennet act differently on milk

Bandager

Bandage for cheese

Best separator

Boards of Trade

Brushes
Buildings for co-operative dairying

\section{Butter :}

- Granules

For market

203,204

Shiper.208.211

Shipping boxes . . 209

Tubs . . . 2II

Tins . . $\quad 21 \mathrm{I}$

Composition of $\quad: 212$

Not contain over 16 per cent. water .212

Qualities described: 212-2I 3 
Butter-Classification PAGE.

Camembert cheese $\quad . \quad 182$

Cap cloths . . . 170

Cement floors for making-room I25, I26, 174

Cheddar cheese - origin . I $51,{ }_{52}$

Cheese and butter markets I 1 2, 223 Cheese:

Factories in Canada

Constituents of milk

Salt . . . . 169

Hoops made of steel $\quad$ I 170

Presses . . . . I7I

Qualities described . 178, 179

Cheesemaking pays best . - I5I

Cheesemaking - main features 152

Cheshire cheese . . . I8I

Churning . 202.204

Churn-rate of turning . $\quad .203$

Closeness in cheese . . I79

Coloring milk for cheesemaking 157

Color of cheese . . . I79

Combined churn and worker - 133

Composition of cheese . . 178

Composition of cream . . 198

Composite samples ․ I44, I45

Composite samples thickened. I45

Composite samples cooled to

65 degrees before testing . 145

Condensed milk :

Composition of $\quad . \quad 227$

Factory . . . . 226

Desirable qualities in $\quad .227$

Co-operative dairying :

Advantages . . 107, I09

Weakness of . . . I IO

Origin of . . I IO, III

Co-operative dairies :

Methods of establishing

- . II3-116

Cost of building and plant II 4

Site for .

Private and joint stock companies . I I 5, I16

Charges for making . $\quad 118$

Co-operation not perfect $\quad$ I08

Cold-storage for cheese . $\quad 224$
Corks for composite samples

Cream gathering vs. whole milk creameries . . 120, I23

Creaming co-efficient . $\quad 198$

Cream separator . 133, 196, 197

Cream cheese . . 180

Culture for ripening milk and

cream . . . I90, I9I

Curd :

Agitators . . . I34

Knives . . . 134, I64

Cutting and cooking $\quad$ I64

Rough handling causes loss 164

Membrane @ . . I65

Heat slowly . . . $\quad$. 165

Contracted by heat . . 165

Fast working may be heated to I Io degrees $\quad 165$

Remove whey to control

acid . . . I65

Washing. $\quad 165,166,168$

P'roperly cooked . . I66

Dipping, matting, milling

•. $\quad$ I66-168

Moisture at dipping $\quad .167$

Advantage of matting . 168

Mills . . . . I68

If matured too much before milling causes loss of fat . . . I68

Ready to salt . . . 169

Amount of salt $\quad$. 169

Ready for hoops . . 170

Temperature at pressing . I7 I

Danish butter pasteurized . 185

Dairymen's associations . . III

Iairy schools . . . . II2

Dressing cheese . . I7 I, I72

Dunlop cheese . . . I8I

Edam cheese . . . . 182

Extractor . . . . 133

Factor to convert inches of cream into pounds . . 144

Fancy and soft cheese can be made in Canada . . . $\quad 184$ 
Fat determines value of milk PAGE. and crean for buttermaking 145

Fat plus 2

Finish of cheese.

\section{Floors}

Flavor of cheese

Flat cheese

Gang press for cheese

Gouda cheese

Gorgonzola cheese .

Granular butter

Gruyere cheese

Ileating rooms with steam

Ice-boxes

Ice for creamery

Imperial cheese

Invoice for cheese

Iowa experiments in cream ripening . . . $20 \mathrm{I}$

Light, effect on ripening cheese 176

Limburg cheese . $\quad{ }^{183}$

Machinery-cost of : I30-133

Markets for cheese and butter 22 I

Nechanical refrigeration 218,219

Milk constituents lost in whey 163

Milk for buttermaking . $\quad 194$

Milk not heated over 50 to 60 degrees in large vat . . 195

Moisture in air of ripeningroom .

Monthly statements . 148-150

Mottled butier

Mould

. 207

. 217

Official referee $\quad . \quad .224$

Oil-test churn $\quad$. I42, I43

Oil for separator . . $\quad$. 196

Open cheese . . . . 179

Overrun in buttermaking 118,119

Paragon cheese

. 180

Pasteur Louis . . . . 185

Pasteurization-meaning $\quad$. 186
Pasteurizers . $\quad 133,186,187$

Pasteurized milk cheese . $\quad$ I 83

Pasteurization :

Advantages $\quad . \quad . \mathbf{I} 87, \mathbf{I} 88$

Disadvantages . . . 189

Essential points . . . 189

Of cream vs. whole milk . I9I

Result of experiments . 192, 193

Pasteurized fresh butter for

England : . $\quad 206$

Paying patrons . . 140, I41

Preservative for composite

samples . . . . 144

Preservative for butter . $\quad 206$

l'ress cheese slowly . 171

Pulleys . . . $\quad 130$

Pumps for milk and cream . 128

Radiator . $\quad . \quad 133$

Rennet :
Tests $\quad$ I 53, I 54, I62

And renneting milk for cheesemaking . 158

Action . . I59, 160, 161

Amount to use . 162

Digests curdy matter $\quad .162$

Dilule with cold water . I63

Refrigeration . . 215

Ripening cheddar cheese 172,178

Ripening cheddar cheese, factors influencing . $\quad . \quad 173$

Ripening cheddar cheese at cool temperature . I74, 175

Ripening cheddar cheese, changes which occur . $\quad 177$

Ripening cream . 198, 202

Ripening milk for cheesemaking 153

Rocquefort cheese ... ISI

Salesman for cheese and butter a 223, 224

Sage cheese . $\quad . \quad 180$

Salt, effect on curd . I70

Salt for butter . . . 204

Scale of points for judging cheese 178

Screens . . . . 129

Sewage . . . . 135, 139

Separator, full speed $\quad$. 195 
Separator speed indicators not satislactory .

. 196

Separator vibration causes loss

of fat .

Separator bowl clogging

Size of rooms

Slime burned . . . . 197

Snyder, Prot. . . . 163

Square cheese .. . . 180

Steam boiler . . . I29

Stock book headings . I1 5, I16

Storch, Prof. . $\quad . \quad$ J 85

Stilton cheese $\quad . \quad 180,181$

Sub-earth duct $\quad . \quad$ I74

Swiss cheese . . . 183

Systems of paying patrons I45-148

Table of experiments in methods of paying patrons . $\quad$ I 47

Temperature :

Eflect on ripening cheese . 176

For separating milk . . 195

For working butter . $\quad 207$

For storing butter . 219, 220
Texture of cheese

Thermometer, $\max$. and $\min .174$

Truckle cheese . . . 180

Value of milk or cream for buttermaking depends on fat I 45

Ventilation in ripening-room . 176

Walls of co-operative dairies $\quad . \quad 126,127$

Washing butter . . 204

$\mathrm{W}$ ate $\mathrm{r}$ for cooling ripening-

room . . . . 174

Weight of cheese marked on

box • . . . 225

Whey :

Acidity at dipping $\quad 166,167$ Acidity at milling . . 168 Acidity less than milk, at dipping $\cdot .167$

Too much acid cuts color 167 Working butter . . 207, 208

Young Canadian cheese $\quad$ I 80 




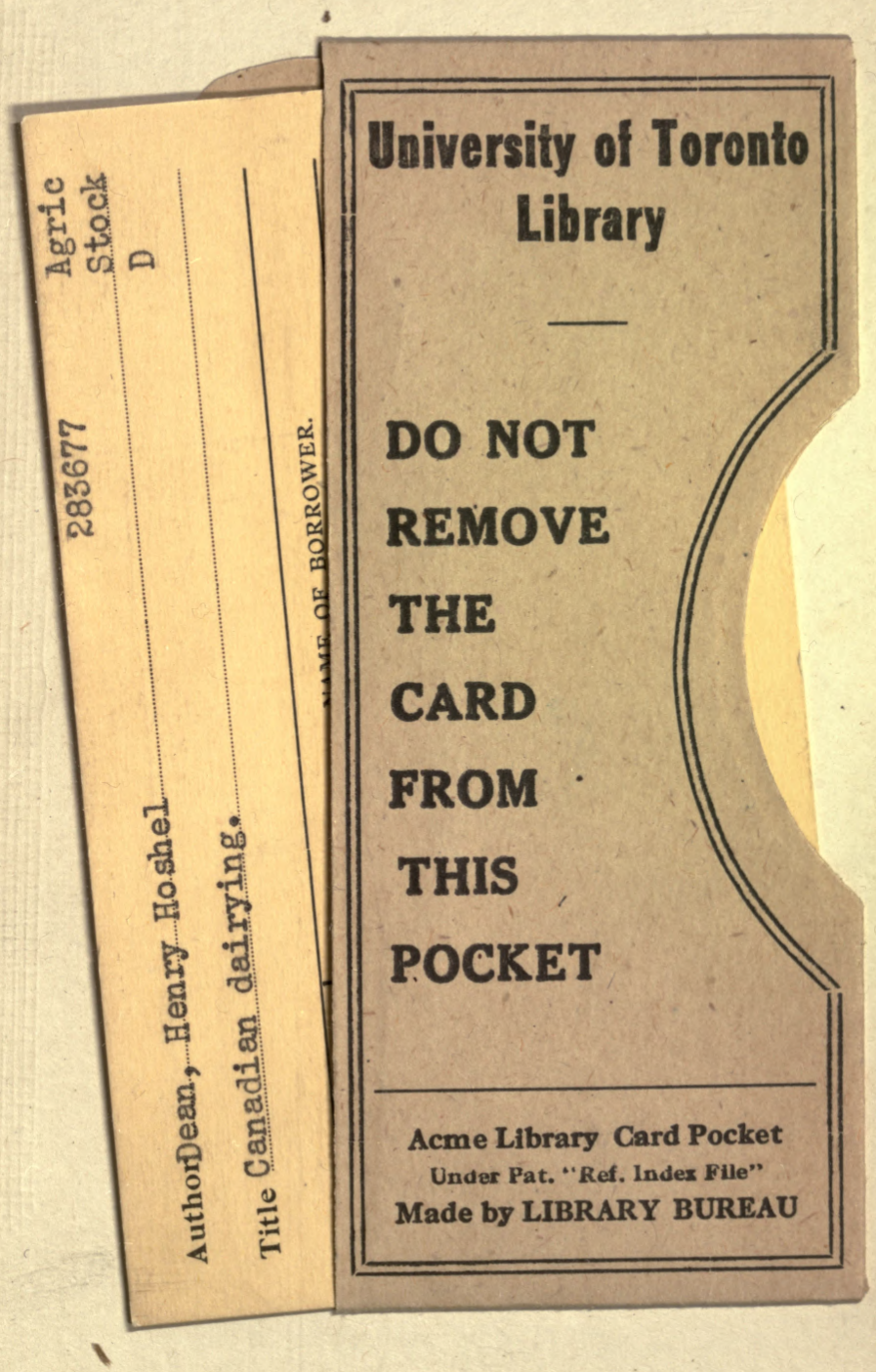


